\title{
NEXT GENERATION POWDER COMPACTION PROCESS
}

By

\author{
Md. Aminul Haque \\ B. Tech in Aerospace Engineering \\ Indian Institute of Technology, Bombay (IITB), Mumbai, India, 1997
}

A thesis

Presented to Ryerson University

In partial fulfillment of the

Requirements for the degree of

Master of Applied Sciences

In the program of

Aerospace Engineering

Toronto, Ontario, Canada, 2009

(C) (Md. Aminul Haque) 2009 


\section{Declaration}

I hereby declare that I am the sole author of this thesis.

I authorize Ryerson University to lend this thesis to other institutions or individuals for the purpose of scholarly research.

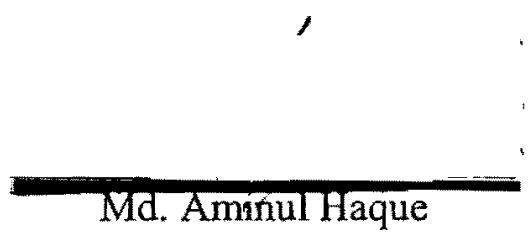

I further authorize Ryerson University to reproduce this thesis by photocopying or by other means, in total or in part, at the request of other institutions or individuals for the purpose of scholarly research.

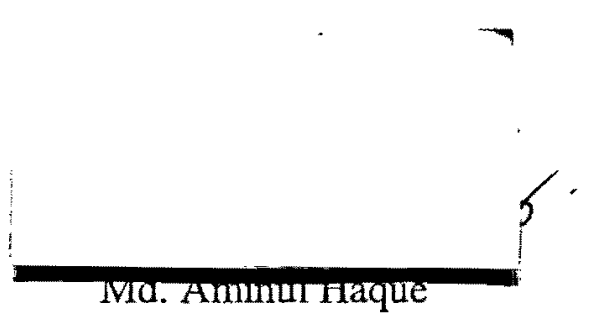




\section{Abstract}

\section{Next Generation Powder Compaction Process}

Md. Aminul Haque

MASc 2009

Department of Aerospace Engineering, Ryerson University

Powder Compaction Process (PCP) is a production method commonly used in the manufacturing industry today. Several analysis methods for powder compaction process are developed and being used in order to minimize costly experiments, to produce complicated near-net shape and to optimize serial production of details. This thesis has dealt with Finite Element (FE) simulation of the cold compaction process. The reason for simulating cold compaction is to predict relative density distribution in the compact for various powder fill and punch motion options. An evaluation of a number of commercial FE codes has been carried out. The MSC_Marc program, which incorporates the Shima Model, has been used for compaction of Fe-based metal powders. The relative density distributions of the pressure models and the displacement models of the cylindrical and the stepped cylindrical geometries obtained via $\mathrm{FE}$ simulation in this research are encouraging that agree well with observations made in practice. 


\section{Acknowledgements}

I would like to thank Professor Kamran Behdinan for his invaluable guidance and unwavering support throughout the course of my studies. I would also like to thank my wife for being a continuous support and Dr. Hamid Ghaemi for his precious help in handling the MSC_Marc software. 


\section{Table of Contents}

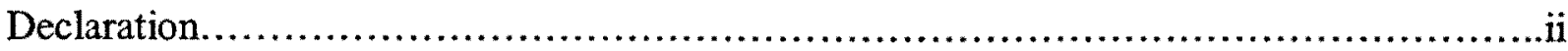

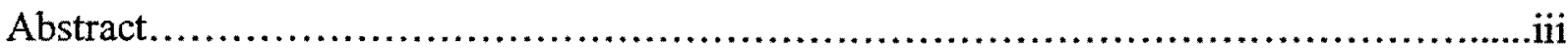

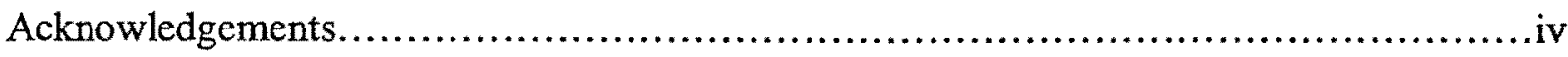

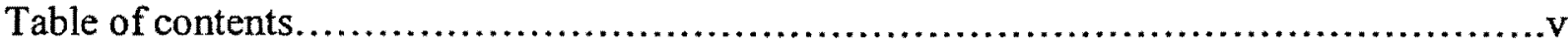

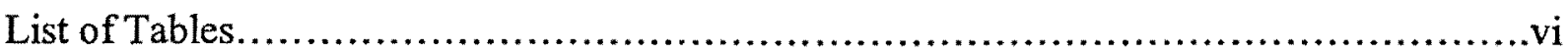

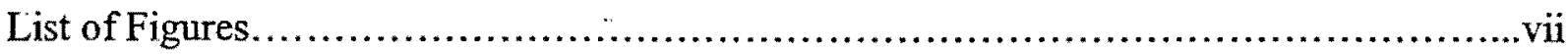

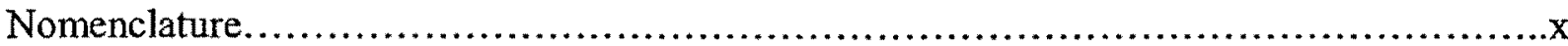

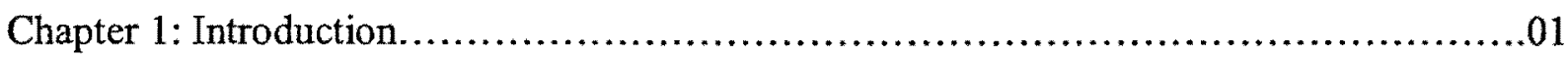

1.1 PM Applications and Markets/Industries........................02

1.2 Fundamental Requirement of Powder Compaction Process (PCP) .....03

$1.3 \quad$ Powder Material Properties..........................................04

1.4 Motivations and/or Objective of the Research........................09

1.5 Thesis Organization.............................................. 10

Chapter 2: Literature Review........................................................11

2.1 Empirical Relationships for Cold Compaction.......................11

2.2 The role of Constitutive Equations................................13

2.3 Analytical Powder Models.......................................16

Chapter 3: Design and Methodology: Simulation of Cold Compaction Process...............27

3.1 Different Finite Element (FE) Models...............................28

3.2 Selection of a Material Model and FE Program.......................29

3.3 Solution Schemes for Non-linear Analysis...........................30

3.4 FE Simulation with MSC_Marc....................................36

Chapter 4: FE Simulation Results.......................................................43

4.1 Cylindrical Pressure Models......................................43

4.2 Cylindrical Displacement Models....................................54

4.3 Stepped Cylindrical Displacement Models...........................61

4.4 Comparison of Results...........................................69

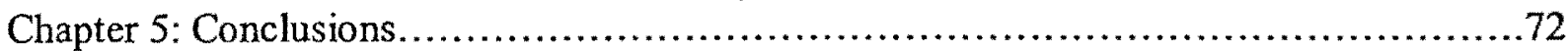

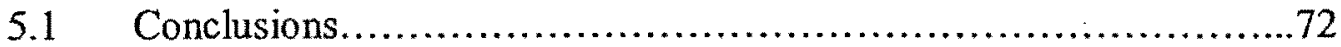

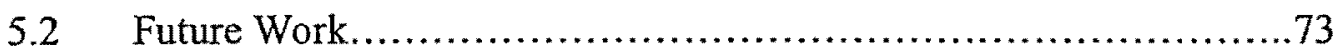

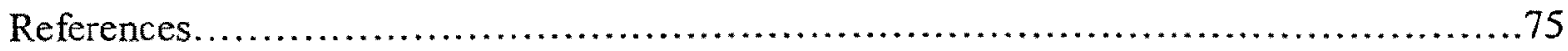




\section{List of Tables}

Table 3.1: Fe-based material properties............................................. 39

Table 3.2: The other parameters used in FE simulation....................................39

Table 4.1: Timing Information for Pressure Model 1....................................44

Table 4.2: Timing Information for Pressure Model 2 ..................................46

Table 4.3: Timing Information for Pressure Model 3....................................48

Table 4.4: Timing Information for Pressure Model 4 ................................52

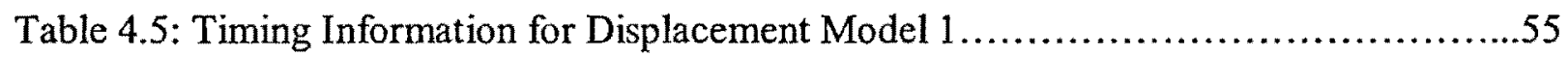

Table 4.6: Timing Information for Displacement Model 2 .............................59

Table 4.7: Timing Information for Stepped Cylindrical Model 1 ..........................64

Table 4.8: Timing Information for Stepped Cylindrical Model 2 .........................65

Table 4.9: Timing Information for Stepped Cylindrical Model 3.........................66 


\section{List of Figures}

Figure 1.1: Experimental set-up for powder compaction..............................02

Figure 1.2: Applications of PM Parts by Market Sector (Courtesy of MPIF)...............03

Figure 1.3: The Hall Flow-meter and standard cup to determine flow rate and apparent

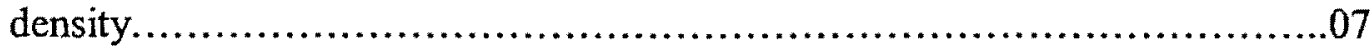

Figure 1.4: Three-point transverse rupture test to determine green strength................09

Figure 2.1: Plasticity model attributes................................................... 15

Figure 2.2: The Cap Model............................................................ 17

Figure 2.3: The Cam-Clay Model....................................................... 19

Figure 2.4: Hydrostatic test results by Hehen-berger et. al ..............................22

Figure 2.5: Yield Surface- Krieg Material Model......................................23

Figure 2.6: Yield Surface - Shima Material Model.....................................25

Figure 3.1: The Pressure Model ......................................................28

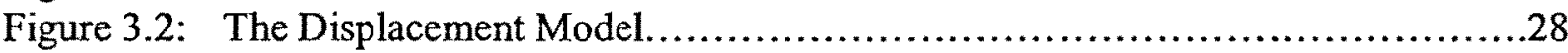

Figure 3.3: The Pressure-Punch Model .................................................29

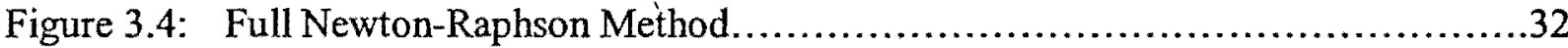

Figure 3.5: Modified Newton-Raphson Method........................................33

Figure 3.6: Cylindrical Geometry (50 axis-symmetric elements) .........................36

Figure 3.7: Stepped Cylindrical Geometry (40 axis-symmetric elements) ..................36

Figure 3.8: Pressure load 1 - Edge Load of $8000 \mathrm{~N} / \mathrm{mm}^{2}$ applied on RH WALL in 200 seconds at an increment of $800 \mathrm{~N} / \mathrm{mm}^{2}$ in 10 steps...........................40

Figure 3.9: Pressure load 2 - Edge Load of $8000 \mathrm{~N} / \mathrm{mm}^{2}$ applied on RH WALL in 4400 seconds and then released in 4320 seconds.................................40

Figure 3.10: Displacement load 1 - an incremental displacement of $2.4 \mathrm{~mm}$ applied in the -ve $x$ direction with a single-punch in 20 seconds and then released to $0.87 \mathrm{~mm}$ in another 20 seconds...........................................................41

Figure 3.11: Displacement load 2-an incremental displacement of $1.2 \mathrm{~mm}$ applied in the -ve $x$ direction with a single-punch in 20 seconds and then released to $0.44 \mathrm{~mm}$ in another 20 seconds........................................................42

Figure 4.1: Pressure Model 1- Edge Load of $8000 \mathrm{~N} / \mathrm{mm}^{2}$ applied on RH WALL in 200 seconds at an increment of $800 \mathrm{~N} / \mathrm{mm}^{2}$ in 10 steps...........................43

Figure 4.2: Relative Density Distribution of the Pressure Model 1 (at increment 10) as

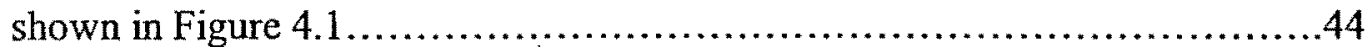

Figure 4.3: Pressure Model 2- Edge Load of $8000 \mathrm{~N} / \mathrm{mm}^{2}$ applied on RH WALL in 4400 seconds and then released in 4320 seconds................................45

Figure 4.4: Relative Density Distribution of the Pressure Model 2 (at increment 10) as shown in Figure 4.3.......................................................46

Figure 4.5: Relative Density Distribution of the Pressure Model 2 (at increment 20) as shown in Figure 4.3 ................................................ 47

Figure 4.6: Relative Density Distribution of the Pressure Model 2 (at increment 30) as shown in Figure 4.3 .....................................................47

Figure 4.7: Relative Density Distribution of the Pressure Model 2 (at increment 40) as

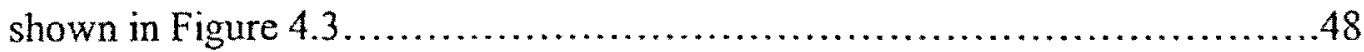


Figure 4.8: Pressure Model 3- Edge Load of $8000 \mathrm{~N} / \mathrm{mm}^{2}$ applied on RH WALL in 4400 seconds and then released in 4320 seconds with added Die-walls...............49

Figure 4.9: Relative Density Distribution of the Pressure Model 3 (at increment 10) as

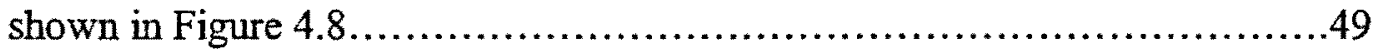

Figure 4.10: Relative Density Distribution of the Pressure Model 3 (at increment 20) as shown in Figure 4.8..................................................50

Figure 4.11: Relative Density Distribution of the Pressure Model 3 (at increment 30) as

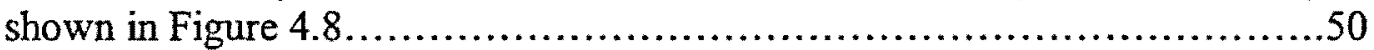

Figure 4.12: Relative Density Distribution of the Pressure Model 3 (at increment 40) as shown in Figure 4.8....................................................51

Figure 4.13: Pressure Model 4- Relative Density Distribution of the Pressure Model 3 (at increment 10 ) as shown in Figure 4.8 with Friction on the Die-walls...........52

Figure 4.14: Relative Density Distribution of the Pressure Model 4 (at increment 20) as shown in Figure 4.13 with Friction on the Die-walls..........................53

Figure 4.15: Relative Density Distribution of the Pressure Model 4 (at increment 30) as shown in Figure 4.13 with Friction on the Die-walls..........................53

Figure 4.16: Relative Density Distribution of the Pressure Model 4 (at increment 40) as shown in Figure 4.13 with Friction on the Die-walls..........................54

Figure 4.17: Displacement Model 1- Incremental Displacement of $2.4 \mathrm{~mm}$ applied in -ve $\mathrm{x}$ direction with a Single-Punch in 20 seconds and then released to $0.87 \mathrm{~mm}$ in another 20 seconds....................................................55

Figure 4.18: Relative Density Distribution of the Displacement Model 1 (at increment 10) as shown in Figure 4.17 with friction on the Die-walls and also at powder-punch interface..................................................................56

Figure 4.19: Relative Density Distribution of the Displacement Model 1 (at increment 20) as shown in Figure 4.17 with friction on the Die-walls and also at powder-punch

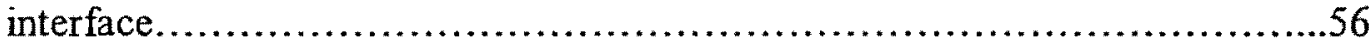

Figure 4.20: Relative Density Distribution of the Displacement Model 1 (at increment 30) as shown in Figure 4.17 with friction on the Die-walls and also at powder-punch interface..............................................................5. 57

Figure 4.21: Relative Density Distribution of the Displacement Model 1 (at increment 40) as shown in Figure 4.17 with friction on the Die-walls and also at powder-punch interface ................................................................5

Figure 4.22: Displacement Model 2- Relative Density Distribution of the Displacement Model 1 (at increment 10) as shown in Figure 4.17 with Friction on the Diewalls only. .58

Figure 4.23: Relative Density Distribution of the Displacement Model 2 (at increment 20) as shown in Figure 4.22 with Friction on the Die-walls only .....................59

Figure 4.24: Relative Density Distribution of the Displacement Model 2 (at increment 30) as shown in Figure 4.22 with Friction on the Die-walls only.....................60

Figure 4.25: Relative Density Distribution of the Displacement Model 2 (at increment 40) as shown in Figure 4.22 with Friction on the Die-walls only.

Figure 4.26: Stepped Cylindrical Model 1- Incremental Displacement of $1.2 \mathrm{~mm}$ applied in ve $x$ direction with a Single-Punch in 20 seconds and then released to $0.44 \mathrm{~mm}$ in another 20 seconds. 
Figure 4.27: Relative Density Distribution of the Stepped Cylindrical Model 1 (at increment 10 ) as shown in Figure 4.26 with Friction on the Die-walls and also at PowderPunch interface. 62

Figure 4.28: Relative Density Distribution of the Stepped Cylindrical Model 1 (at increment 20 ) as shown in Figure 4.26 with Friction on the Die-walls and also at PowderPunch interface. 62

Figure 4.29: Relative Density Distribution of the Stepped Cylindrical Model 1 (at increment 30 ) as shown in Figure 4.26 with Friction on the Die-walls and also at PowderPunch interface.

Figure 4.30: Relative Density Distribution of the Stepped Cylindrical Model 1 (at increment 40 ) as shown in Figure 4.26 with Friction on the Die-walls and also at PowderPunch interface.

Figure 4.31: Stepped Cylindrical Model 2- Relative Density Distribution of the Stepped Cylindrical Model 1 (increment 20) as shown in Figure 4.26 without Friction anywhere. 64

Figure 4.32: Relative Density Distribution of the Stepped Cylindrical Model 2 (at increment 30 ) as shown in Figure 4.31 without Friction anywhere .65

Figure 4.33: Relative Density Distribution of the Stepped Cylindrical Model 2 (at increment 40 ) as shown in Figure 4.31 without Friction anywhere. .66

Figure 4.34: Stepped Cylindrical Model 3- Incremental Displacement of $1.2 \mathrm{~mm}$ applied in both directions with a Double-Punch in 20 seconds and then released to 0.44 $\mathrm{mm}$ in another 20 seconds.

Figure 4.35: Relative Density Distribution of the Stepped Cylindrical Model 3 (at increment 10 ) as shown in Figure 4.34 with Friction on the Die-walls and also at PowderPunch interface.

Figure 4.36: Relative Density Distribution of the Stepped Cylindrical Model 3 (at increment 20 ) as shown in Figure 4.34 with Friction on the Die-walls and also at PowderPunch interface.

Figure 4.37: Relative Density Distribution of the Stepped Cylindrical Model 3 (at increment 30 ) as shown in Figure 4.34 with Friction on the Die-walls and also at PowderPunch interface. 68

Figure 4.38: Relative Density Distribution of the Stepped Cylindrical Model 3 (at increment 40 ) as shown in Figure 4.34 with Friction on the Die-walls and also at PowderPunch interface. 69

Figure 4.39: Comparison of Relative Density Distribution of the pressure model and the displacement model.

Figure 4.40: Comparison of Relative Density Distribution of the stepped cylindrical model using a single-punch and a double-punch. .71 


\section{Nomenclature}

$P \quad$ applied pressure

$\rho \quad$ theoretical density of material

$\rho_{G} \quad$ green density of material

$\rho_{T} \quad$ tap density of powder

$E$ theoretical modulus of porus-free compact

$\mu$ dimensionless static friction coefficient

$D$ diameter of cylindrical compact

$\mathrm{H}$ height of cylindrical compact

$\sigma \quad$ average compaction stress

oy uniaxial yield stress

$\mathrm{S}_{0} \quad$ specific surface $\left(\mathrm{cm}^{2} / \mathrm{cm}^{3}\right)$

g gravitational constant $\left(\mathrm{cm} / \mathrm{sec}^{2}\right)$

$\mathrm{K}$ permeability constant $(\mathrm{cm} / \mathrm{sec})$

$J_{2}^{\prime} \quad$ second deviatoric stress invariant

$J_{l} \quad$ first stress invariant

$P \quad$ hydrostatic pressure (i.e. negative mean stress)

$Q \quad$ von Mises equivalent stress

$\varepsilon_{v o l}^{P} \quad$ volumetric plastic strain

$S_{i j} \quad$ deviatoric stresses

$\sigma_{m} \quad$ hydrostatic stress $1 / 3 \sigma_{\mathrm{kk}}$

$\beta, \gamma \quad$ experimentally obtained material parameters (functions of relative density $\hat{\rho}$ )

$\hat{\rho} \quad$ relative density

$\nu \quad$ the Poisson's Ratio

$\vartheta \quad$ the kinematic viscosity 


\section{Chapter 1}

\section{Introduction}

Powder Metallurgy (PM) is a manufacturing method that has gained interest over the past decades as an economic and fast method to produce near-net shape mechanical parts, as for instance, structural components, self-lubricating bearings and cutting tools. The process in itself is not a new process. The ancient Egyptians (around 3000 B.C.) used this method to compress ferrous metal powder to tools [1]. The Inca Indians produced jewelry and other artifacts by powder compaction. The PM manufacturing process has become a great industrial potential for companies to gain market advantages over other companies using conventional manufacturing methods. One main reason for this is that the details are pressed into near-net shape with little or no machining. This leads to cost savings and a rapid method that is also suitable for mass production.

Many materials are produced by powder metallurgical processes [2]. Materials with a very high melting point, so called refractory metals, such as tungsten, molybdenum and tantalum are manufactured in powder compaction, whereas casting would be a very expensive production process for them. Composite materials, such as copper/tungsten, silver/cadmium and different types of cemented carbides, which may not be easily mixed in other manufacturing methods or handled in post-operation due to its constituents, are used in powder compaction. An experimental set-up for powder compaction [3] is shown in Figure 1.1. It shows different components required to press the powder in a cylindrical die.

Another reason for using powder technology may be that it is economically attractive to make complex shaped structural parts by powder compaction and sintering [2]; this is the case for sintered steel parts, which are used in large quantities, for example, in combustion engines and gear boxes. For other products, such as magnets and multiplayer electronic devices, there is no practical alternative to powder technological production processes. 


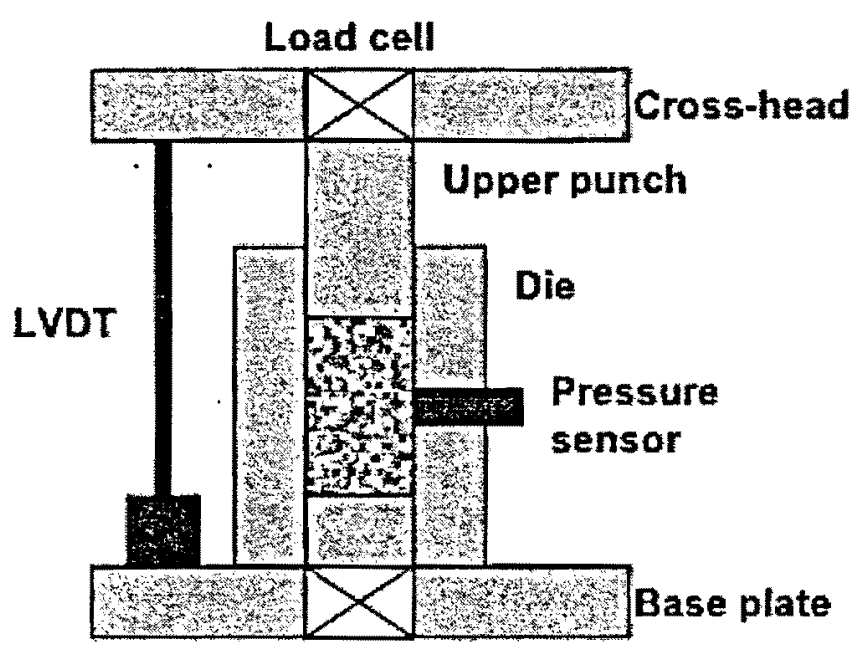

Figure 1.1: Experimental set-up for powder compaction.

\subsection{PM applications and Markets/Industries}

PM parts are used in many end products. The largest buyer of PM parts is the automotive industry. Automotive applications make up approximately $70 \%$ of the North American PM Parts market. In 2001 the typical family vehicle contained about $17 \mathrm{~kg}$ (37.5 lb.) of PM parts, an increase from $10.9 \mathrm{~kg}$ (24lb.) in 1990. Some SUV models utilized $27.2 \mathrm{~kg}(60 \mathrm{lb}$.) of PM parts [38].

Growth for PM applications in automobiles include powder forged low alloy steel connecting rods (a typical connecting rod weighs about $1 \mathrm{Kg}$ ), stainless steel exhaust system flanges, variable value timing systems, and automatic transmission planetary gear carriers. In the latter application, PM offers cost savings and performance improvements over cast iron such as weight reductions, increased durability, close to net shapes, and precision.

Markets for PM parts include: lock hardware, garden tractors, snowmobiles, automobile engines and transmissions, automobile brake and steering systems, washing machines, power tools and hardware, sporting arms, copiers and postage meters, off-road equipment, hunting knives, hydraulic assemblies, $x$-ray shielding, oil and gas drilling wellhead components, fishing rods and wrist watches. A break down of these applications by market sector is given in Figure 1.2. 


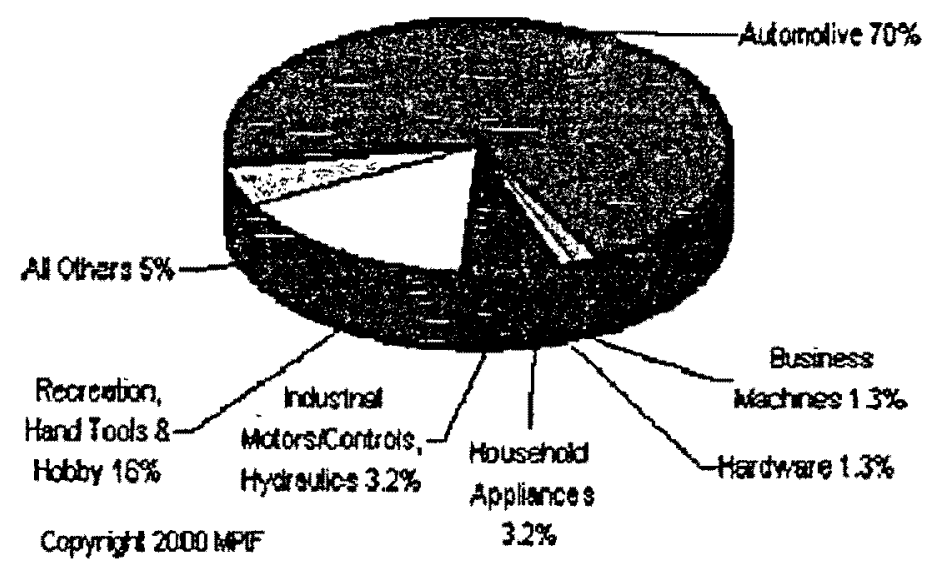

Figure 1.2: Applications of PM Parts by Market Sector (Courtesy of MPIF).

New commercial aircraft engines contain PM extruded super-alloy forgings. Americans consume almost one million $\mathrm{kg}$ of iron powder annually in iron-enriched cereals and bread. Copper powder is used in anti-fouling paints for boat hulls and in metallic pigmented inks for packaging and printing. Aluminum powder is used in solid fuels for booster rockets in the space shuttle program.

The techniques of powder metallurgy (PM) are constantly being used to solve new problems. This is particularly true in the aircraft, space and nuclear fields where there is a virtually insatiable demand for new materials with special properties.

\subsection{Fundamental Requirement of Powder Compaction Process (PCP)}

In engineering applications, the generation of a defect-free green compact is a fundamental requirement for the production of a quality, high strength finished part. A particular goal is the achievement of near uniform powder density with no internal crack propagation due to gross powder movement during compaction. Density variations arise from two mechanisms, firstly friction at the tool surface and secondly powder yielding. Therefore, in the modeling of powder compaction process, consideration of friction between the powder and the die and the yielding characteristics of the powder are both of fundamental importance.

The process of manufacturing parts with PCP [4] can be summarized in three simple steps: 1) mixing the metal powders with/without a suitable lubricant, 2) pressing the mixture in a die to 
obtain a so called green compact; the compression should be sufficient enough to keep the green compact together for safe handling and 3) sintering i.e. heating the green compact in a protective atmosphere up to $60-90 \%$ of the melting point of the main constituent; during sintering the particles will weld together and gain interparticle strength.

Powder compaction in a die usually does not yield a homogeneous density distribution [2] in the pressed part (the so-called green body). Rather, the green density is more or less inhomogeneous depending on the part geometry, the tool design and the friction between powders and die-walls. Non-uniform density distribution is a serious problem in the reliability and performance of PM part and the net-shape forming, since the heterogeneities can generate cracks during die compaction and contribute to non-uniform shrinkage during sintering. The proper selection of the process parameters such as die shape, upper and lower punch displacements, and sequential tool motions helps eliminate the heterogeneities. However, since the requirements for close geometrical tolerances increase continuously, an extra processing step, such as hard machining or sizing may become necessary, if the distortions are too large.

\subsection{Powder Material Properties}

Before discussing on various powder models, it is necessary to highlight some metal powder properties such as composition, particle size, particle shape, particle structure (which includes micro-structure, porosity, inclusions etc.) etc. These primary properties determine other important characteristics of a powder, such as its specific surface (the surface area per unit weight of powder), apparent densities and flow properties, as well as its compacting and sintering characteristics [5].

Composition: Chemical composition influences the properties of the final product and also affects the processing of the powder to that final form. The compacting operation is vitally dependent upon the plasticity and the rate of strain hardening of the metal, and these in turn are related to the chemical composition. Alloy content and impurities also affect the sintering process by their influence on diffusion rates and, in some cases, the formation of liquid phases at the sintering temperature [5]. The techniques of chemical analysis are often simpler 
because of their particulate nature. For example, metal powders usually bave a relatively high oxygen content for their high surface area and this may be determined by wet analysis (M.P.I.F. Standard 7-61) or, more usually, by weight loss after reduction in a stream of hydrogen.

Particle Size, Particle Shape and Specific Surface: These three factors are interrelated since a decrease in particle size or a departure of particle shape from the spherical will lead to an increase in specific surface [5]. These parameters are important due to their influence on the basic operations of compacting and sintering. Very fine particles with an irregular shape (having a high specific surface) are desirable for sintering because of the excess energy (the driving force for bonding during the sintering operation) due to a high surface area. However, very fine powders have poor flow properties and give low apparent densities, the two important factors when compacting on automatic presses. Particle shape also affects the flow properties and apparent density, spherical particles having the best properties in both cases. Spherical particles, however, also have the poorest compacting properties since they provide no mechanical interlocking and have the smallest number of point contacts.

Particle Size - The particle size is determined by direct measurement on the optical microscope, or by the use of electron microscope for very fine powder [5]. Particle size is always expressed as a diameter, although only spherical particles have a true diameter, it is usual to report an 'average diameter'. The optical microscope measures particles down to about $0.3 \mu$, while the electron microscope does it in the range 10 to $0.001 \mu$. All other methods rely on some physical property of the particle, such as its ability to pass through an aperture of known dimension (sieving) or its settling rate in a fluid of known viscosity (elutriation and sedimentation methods).

Particle Shape - The particle shape of most metal powders cannot be accurately described. It significantly affects compacting properties and, together with particle size, it determines the surface area and hence influences sintering activity [5]. The general forms e.g. spherical, angular, irregular etc. are of most importance in compacting, while surface area is related to the amount of fine surface detail as well as the general form. Particle shape is sometimes characterized by means of a 'shape factor', which is the ratio of surface area to particle size. 
Specific Surface - The total surface area of a mass of powder can give us an indication of the average particle size, provided certain assumptions are made as to the particle shape, although it doesn't give any indication of the particle-size distribution. Sorption method and Permeametry method are used for determination of surface area [5].

Sorption methods rely on the calculation of the number of molecules required to form monomolecular or sometimes multi-molecular layers. And then from knowledge of the area covered by a single molecule, the total surface area may be obtained.

-Permeametry methods rely on the calculation of the surface area from the resistance offered to a flowing fluid by a column of packed particles. A fairly simple apparatus is required, consisting of a chamber to contain the powder bed, a pump to force the fluid through the powder and gauges to indicate the fluid flow and pressure drop across the powder bed. Carman's equation gives the surface area as follows:

$$
S_{0}=\sqrt{\frac{(g / k)\left(K \gamma \varepsilon^{3}\right)}{(1-\varepsilon)^{2}}}
$$

Where

$S_{0}$ is the specific surface $\left(\mathrm{cm}^{2} / \mathrm{cm}^{3}\right)$

$g$ is the gravitational constant $\left(\mathrm{cm} / \mathrm{sec}^{2}\right)$

$k$ is the proportionality constant with a value of 5

$K$ is the permeability constant $(\mathrm{cm} / \mathrm{sec})$

$\gamma$ is the kinematic viscosity of the fluid (stokes)

$\varepsilon$ is fractional free volume (ratio of volume of voids to the total volume of the bed)

Particle Microstructure: Knowledge of particle microstructure is important in many instances and may indicate the powder's pressing and sintering behaviors [5]. The numbers and amounts of the various phases, inclusions, etc. present in the particle microstructure are largely dependent upon the chemical composition, which is determined mainly by the method of powder production. Internal closed porosity is often present in particles and such porosity can have severe effects on the behavior of the powder during pressing, particularly if it contains gases or liquids entrapped during the powder production process.

Flow Rate: It is technically important to know the rate at which a powder flows under gravity through an orifice. To achieve rapid production rates and consistent compacts, the powder 
must flow under gravity quickly and evenly into the die. Good flow properties are also required of powders for continuous feeding into the metal-spraying guns and, since pressing properties are not important in this case, these powder are often made as spherical as possible. However, powders that are not spherical are mostly required because of their better compacting properties. Flow properties are greatly affected by particle shape and particle size and also by the presence of lubricants, moisture, etc. Hall Flow-meter (shown in Figure 1.3) is the standard test (M.P.I.F. Standard 3-45) for the determination of flow rate, which consists of an accurately machined conical funnel of $60^{\circ}$ included angle [5]. The orifice at the base may be of $0.100 \mathrm{in}$. or $0.125 \mathrm{in}$. depending on the powder being tested. The funnel is usually made of brass and is supported upon a right stand. The time taken for a weighed sample of powder (usually $50 \mathrm{~g}$ ) to flow from the funnel into a cup below is determined and the flow rate is then expressed in seconds.

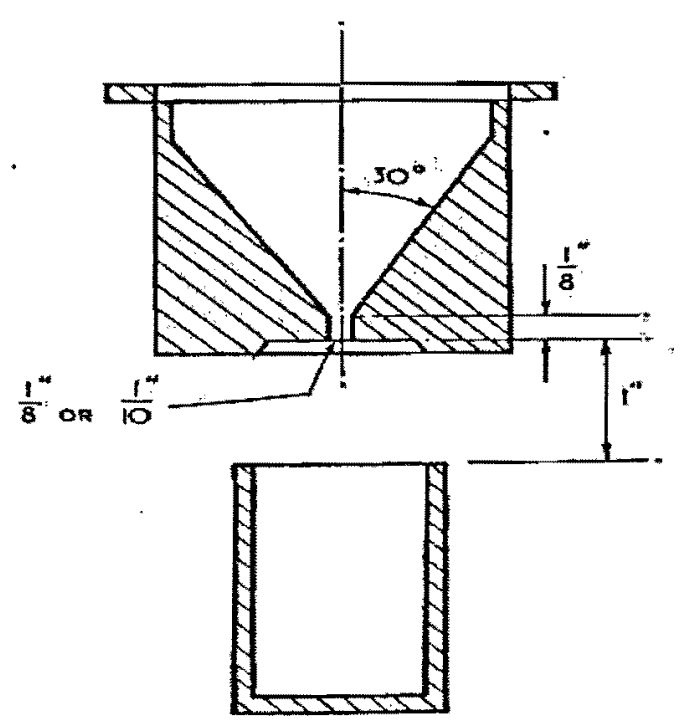

Figure 1.3: The Hall Flow-meter and standard cup to determine flow rate and apparent density.

Apparent Density: The apparent density of a powder is the weight of a unit volume, including all voids between particles, internal porosity etc. The value is obtained by pouring the powder into a container of known volume under standard conditions; thus, in the standard test (M.P.I.F. Standard 4-45), a sample of powder is poured through a Hall Flow-meter funnel into a $25-\mathrm{cm}^{3}$ brass cup [5]. While with the non-standard test, a known weight of powder is 
poured into a graduated cylinder, the cylinder is tapped gently until no further settling is observed and then the volume is read off. This is generally referred to as the 'tap density' and is higher than the 'apparent density' as obtained with the Hall Flow-meter and standard cup.

Green Density: The green density of regular bars and cylinders may be determined simply by calculating their weights and dimensions or, for more complex shapes, by weighing in air and water. In the latter case it is necessary to seal to part by coating with lacquer or to impregnate with oil (M.P.I.F. Standard 8-50). Occasionally the volume of a complex part is determined by displacement in mercury.

Green Strength: The strength of a green (i.e. un-sintered) compact may be determined in a variety of ways depending on the type of damage the part is likely to be exposed to during handling and transportation. There are two types of standard test [5]. The Rattler test determines the abrasion resistance of the green part by tumbling five standard specimens, $1 / 2$ in. diam. X $1 / 4 \mathrm{in}$. long, in a cylindrical barrel of 14 mesh bronze gauze ( $33 / 4 \mathrm{in}$. diam. X 4 in. long, and incorporating a steel baffle) at $87 \mathrm{rpm}$ for 1000 revolutions. The loss in weight of the specimens, as a percentage of their original weight, is thus a measure of their abrasion resistance. This gives a good indication of the way sharp edges withstand handling. The second standard test (M.P.I.F. Standard 15-62) determines the transverse-rupture strength of the green part (Figure 1.4). In this test the specimen fails due to surface tensile stresses, $S$, which may be calculated from the simple formula:

$$
S=\frac{3 W L}{2 b d^{2}}
$$

Where $W$ is the applied load, $L$ is the distance between the outer supports, $b$ is the width of the specimen and $d$ is the thickness of the specimen. 

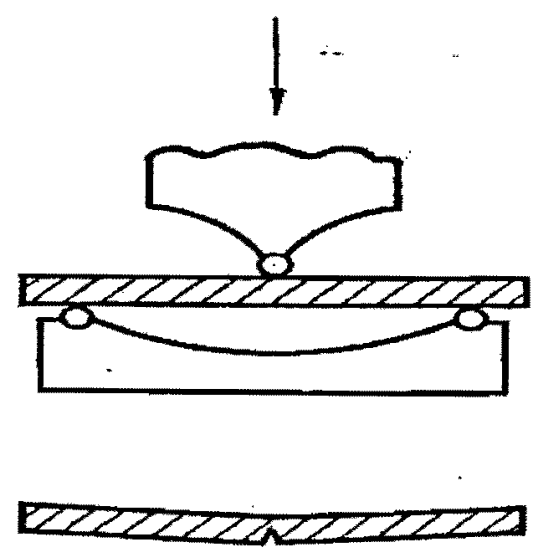

Figure 1.4: Three-point transverse rupture test to determine green strength.

\subsection{Motivations and/or Objective of the Research}

Now that the fundamental requirement of the powder compaction process is defined and various powder material properties are discussed, it has now become the prime objective to generate a defect-free green compact for the production of a quality and high strength finished part. As discussed earlier in this chapter, the uniaxial compaction in a die usually yields an inhomogeneous green density distribution depending on the part geometry, the tool design and the friction between the powder and the die-walls. However, this problem can be eliminated by the proper selection of process parameters such as die shape, upper and lower punch displacements, and sequential tool motions etc.

Several researchers have attempted various powder models to illustrate the behavior of powders during cold closed-die compaction. The non-linear finite element (FE) programs NIKE and DYNA are incorporated with Krieg material model (various material models are discussed in chapter 2). Bandstra, Otto and Massa [30] have used this model of NIKE2D to simulate cold compaction. After comparing their simulation results with the experimental results, they noted that Krieg material model does not represent the powder behavior with sufficient accuracy and they recommended it to be modified.

Krauss et. al. (1991) [31] have used Cap material model offered by FE code DYNA3D and more recently NIKE2D. It is noted that the Cap model suffers from limited ability to 
incorporate the material property changes that accompany densification and deformation of the powder. Therefore, they proposed to update the elastic properties of the powder and also to improve the mathematical description of hardening due to densification and work hardening of the powder.

Armstrong et. al. (1993) [33] have used the Cam-Clay material model, which is provided in the ABAQUS non-linear finite element program for analyzing soil mechanics problems. Here also the material parameters have been modified in order to model 'powder deformation to a limited extend'.

The literature review presented in chapter 2 indicates that from the material models used for modeling of cold compaction process, the Shima material model, developed by Shima and Oyane (1976) [21], Shima and Saleh (1992) [34], Nakagawa (1992) [35] and Zhao (1992) [22], is the one that has been specifically developed for modeling the behavior of metal powders. This model is presently available in the MSC_Marc non-linear finite element (FE) program. The major reasons for simulating cold compaction are: 1) to predict relative density distribution in the compact of various powder fill and punch motion options, 2) to calculate the punch loads needed to achieve a certain overall density level, 3) to calculate tooling stresses and deflections etc.

\subsection{Thesis Organization}

So started with the Powder Metallurgy (PM) concept, the fundamental requirement of powder compaction process $\&$ the powder material properties and the motivations $\&$ objective are clearly depicted in this chapter 1 . The next chapter i.e. chapter 2 deals with the literature review of empirical relationships for cold compaction, the role of constitutive equations and description of available analytical powder models. Design and the methodology of the FE simulation are presented in chapter 3 whereas different FE powder models for cold compaction process are described. The simulation results i.e. the relative density distributions for various green geometries considering different boundary conditions are depicted in Chapter 4. The research is concluded in Chapter 5. 


\section{Chapter 2}

\section{Literature Review}

An extensive literature survey has evolved various approaches used for modeling of compaction problems. Such problems arise in a variety of industries and applications ranging from soil mechanics to metal powder, powders used in pharmaceutical industries and plastic powders. The developments in compaction modeling have diversified in various directions: amongst these are the development of empirical relationships relating the pressure to density distribution in the powder compacts, specialization of continuum models, and the development of discrete models at the scale of powder particles.

\subsection{Empirical Relationships for Cold Compaction}

There has been much activity, in the past few years, in the development of statistical bases for empirical relationships between pressure and density in cold closed-die compaction. Li et. al. (1994) gives a representative model [6] that contains elements of statistical, experimental and empirical origins:

$$
\log P=\alpha \log \left(\log \left(\frac{\rho_{G}}{\rho_{T}}\right)\right)-\beta\left(\frac{\rho-\rho_{G}}{\rho}\right)+\log \left(\frac{E}{\mu}\right)
$$

Where

$P \quad$ applied pressure

$\rho \quad$ theoretical density of material

$\rho_{G} \quad$ green density of material

$\rho_{T} \quad$ tap density of powder

$\alpha$ dimensionless empirical constant (includes effect of particle rearrangement, fragmentation, local plastic deformation, work hardening)

$\beta$ dimensionless empirical constant (a measure of the sensitivity of compact modulus on porosity)

$E \quad$ theoretical modulus of porus-free compact

$\mu \quad$ dimensionless static friction coefficient

The above model has been shown to be appropriate for metallized ceramic powders, mixed ceramic/metallic powders and pure metallic powders. However, it should be noted that the 
experimental setup for the determination of the three empirical constants $(\alpha, \beta, \log (\mathrm{E} / \mu))$ requires the application of a large range of compaction pressures (from $25 \mathrm{MPa}$ to $1000 \mathrm{MPa}$ ).

German (1994) applied a simple analytical method commonly known as the slab method, to analyze friction and geometry effects during compaction [7, 8, and 9]. This method subdivides a cylindrical compact into a stack of disks or slabs, and a force balance is executed for each slab. These are then summed over the whole body to relate local forces to the externally applied forces. The basic assumption of this method is the homogenous behavior of the slab.

Where

$$
P x=P e^{-\left(\frac{4 \mu z x}{D}\right)}
$$

$$
\begin{array}{ll}
P x & \text { pressure at a distance } \mathrm{x} \text { from the nearest } \text { punch }^{1} \\
P & \text { applied pressure } \\
\mu & \text { coefficient of friction between powder and die-wall } \\
z & \text { ratio of lateral stress to axial stress (a measure of inter-particle friction) } \\
x & \text { distance from the nearest punch } \\
D & \text { diameter of cylindrical compact }
\end{array}
$$

Although the basic assumption of homogeneity within a slab is strictly not true, this method is useful in calculating average compaction pressures in cylindrical dies and approximate diewall pressures. The average compaction stress for single-ended pressing is estimated as

$$
\sigma=P\left(1-2 \mu z\left(\frac{H}{D}\right)\right)
$$

and for double-ended pressing as

$$
\sigma=P\left(1-\mu z\left(\frac{H}{D}\right)\right)
$$

where

$\sigma \quad$ average compaction stress

$H$ height of cylindrical compact

\footnotetext{
'The term nearest punch is only relevant for double-ended pressing.
} 
Following reveals from the comparison of the above equations:

1. For a constant $H / D$ ratio, the applied pressure $P$ for a single-ended pressing must be greater than the applied pressure for double-ended pressing.

2. The average compaction stress decreases as the aspect ratio of the compact increases and the friction coefficient increases.

Since the reduction of porosity during consolidation is not homogeneous due to die-wall friction, inter-particle friction, and non-uniformity in local initial density, the above models have their limitations. Therefore, these models cannot be applied with any accuracy to parts having complex geometries. However, they may be used to estimate compaction loads and punch pressures, check quality control on batch-to-batch variation for a particular powder etc.

\subsection{The role of Constitutive Equations}

Constitutive equations describe the physical behavior of the material in mathematical terms. They may be as straightforward as Hooke's law, which in the isotropic case requires only two material constants; or they can be as complicated as the semi-empirical constitutive theories of viscoplasticity in which equations describing flow surfaces, rate and temperature dependence, and hardening are employed, and require scores of variables and constants to operate [4]. Plasticity theory is empirical in that basic assumptions are made in its development, but it is also strongly related to the rigorous theories of continuous media and thermodynamics. Moreover, plasticity theory, having being developed primarily for application to metals, is too restrictive and not appropriate for modeling metallic powders.

The role of constitutive equations may be viewed from three different aspects: 1 . Theoretical development, 2. Fitting to experimental data and 3. Integration with computational tools such as FE method.

In regard to modeling metallic powders, the following assumptions from the theory of plasticity may be used: 
1. The strain rate in the powder can be decomposed into an elastic ( $d \varepsilon^{e}$ recoverable) and a plastic ( $d \varepsilon^{p}$ non-recoverable) part.

$$
d \varepsilon=d \varepsilon^{e}+d \varepsilon^{p}
$$

2. A yield hyper surface, defining the maximum permissible state of stress exists. Moreover, this surface may move, expand, or change shape as a function of hardening parameter, $\kappa$,

$$
\Phi\left(\sigma_{i j}, d \varepsilon_{i j}^{p}, \kappa\right)=0
$$

where $\sigma_{i j}$ is the stress tensor.

3. A plastic potential and a flow rule exists from which a plastic strain increment normal to the plastic potential surface is calculated.

$$
\begin{gathered}
g\left(\sigma_{i j}, d \varepsilon_{i j}^{p}, \kappa\right)=0 \\
d \varepsilon_{i j}^{p}=d \lambda \frac{\partial g}{\partial \sigma_{i j}}
\end{gathered}
$$

where $d \lambda$ is a scalar function.

4. Furthermore, an associated flow rule is often adopted for simplicity, i.e., the yield surface and the plastic potential surface are coincident $(g=\Phi)$. As a consequence the flow rule becomes:

$$
d \varepsilon^{p}=d \lambda \frac{\partial \Phi}{\partial \sigma_{i j}}
$$

and the plastic strain increment is normal to the yield surface.

This theory ultimately leads to the following constitutive equation:

$$
d \sigma_{i j}=C_{i j k l} d \varepsilon_{k l}
$$

where $C_{i j k l}$ is the material properties matrix. To illustrate these points, consider the diagram in Figure 2.1. The surface identified as the envelope defines the maximum shear strength 
(defined in terms of the second deviatoric stress invariant $J_{2}^{\prime}$ ) that can occur for a given pressure (defined in terms of the first stress invariant $J_{l}$ ). The envelope indicates the often observed phenomenon of increasing shear strength with increasing pressure for granular materials. The constitutive equation associated with the surface embodies a mathematical mechanism that ensures any stress state remains bounded by the yield surface. That is, elastic states are within the domain covered by the surface and yielding stress states are tangential to the surface and no stress state can penetrate the surface. The envelope in this example is a generalized form of the Drucker-Prager failure surface and is defined by the following expression:

$$
\sqrt{J_{2}^{\prime}}-A+B e^{-C J_{1}}=0
$$

The constants $A, B, C$ are defined such that this surface approximates the measured values of shear strength versus pressure.

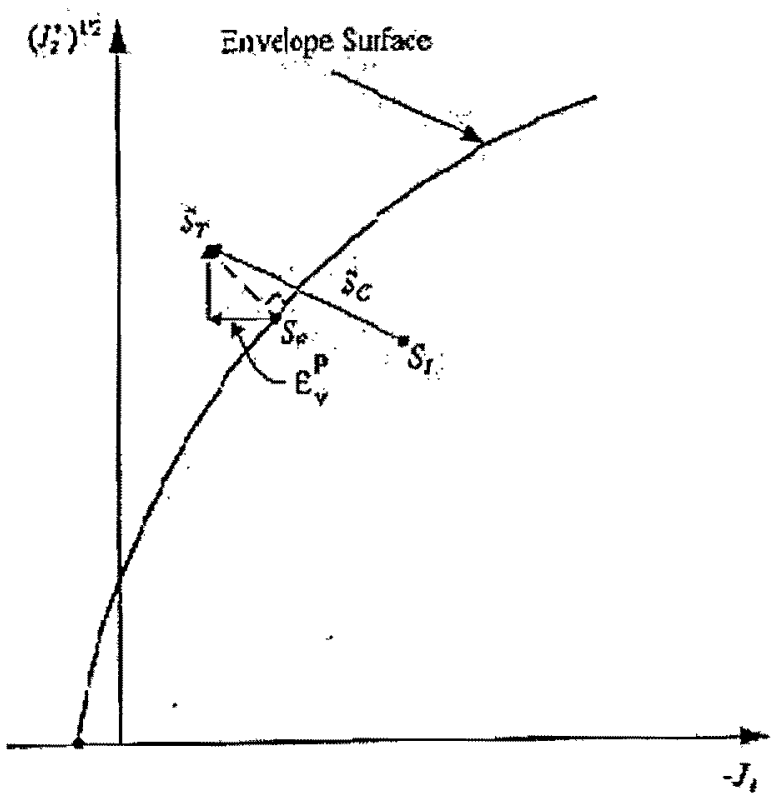

Figure 2.1: Plasticity model attributes.

For an infinitesimal change in the stress state, the graphic representation of this equation is also shown in Figure 2.1. In this presentation, the process commences by computing the final stress based on the elastic properties of the material, denoted as the trial state, $S_{T}$. In other words, $S_{T}$ would be the stress state if plasticity had not occurred. If $S_{T}$ is found to occur 
outside the surface, i.e., a non-permissible stress state, the equation of plasticity as represented below:

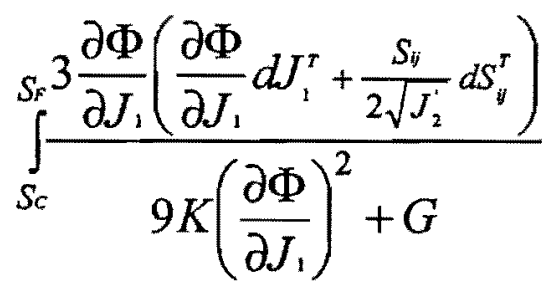

would provide a correction in the form of a plastic stress and strain increment as shown by the dashed line. Because of the assumption of the associativity, the correction is normal to the surface which results in an expansion of the material.

\subsection{Analytical Powder Models}

The use of an analytical model such as Finite Element (FE) method overcomes many of the limitations of empirical models in that all the materials and components of a process may be described at the local level. This facilitates the prediction of the inhomogeneous behavior of the powder through detailed computational models. However, these techniques require a mathematical definition of the yield criteria to describe the mechanical behavior of the materials involved in the process [4].

To simulate cold closed-die compaction analytically, it is essential to capture the behavior of the powders, its deformations that are composed both of large strain and rotation, its flow along the boundaries taking the effect of friction into account. There are different analytical material models available for powder compaction [4]. Among these are the Cap model, the Cam-Clay model, the Krieg model, the Shima model etc.

\section{The Cap Model:}

One of the most often used types of constitutive model in recent finite-element simulations is the so-called cap model [10]. The various cap models developed differ by the functional form of the yield surface but they all have some kind of cap describing the hardening behavior. Described here is the Drucker-Prager-Cap (DPC) model. 
The yield surface of this model consists of the Drucker-Prager failure line or surface $F \mathbf{s}$ [11] and the elliptic cap surface $F c$ [12], which provide a combined convex yield surface in the plane of the first and second stress invariants ( $p-q$ plane) as shown in Figure 2.2 and characterized by the following Equations:

$$
\begin{gathered}
F_{C}=\sqrt{\left(p-p_{a}\right)^{2}+(R q)^{2}}-R\left(d+p_{a} \tan \beta\right)=0 \\
F_{S}=q-p \tan \beta-d=0
\end{gathered}
$$

Where $p=$ hydrostatic pressure (i.e. negative mean stress), $q=$ von Mises equivalent stress. The parameters $R=$ cap eccentricity, $d=$ cohesive strength, $\beta=$ cohesion angle are constant in the original version of the model, and $p_{a}$ is a hardening function depending on the density.

In Figure 2.2 two extensions of the original model are also included: the tension cutoff $T$, which characterizes the tension strength of the powder compact, and the von Mises yield strength $\sigma_{y}$ of the dense material. Inside the yield surface the powder behaves elastically. If the stress state reaches the yield surface, the powder deforms plastically. The density increases, if the stress state is on the cap, whereas it decreases (dilatation), when the stress state reaches the failure line. Dilatation implies softening, so that strain localization and cracking may occur.

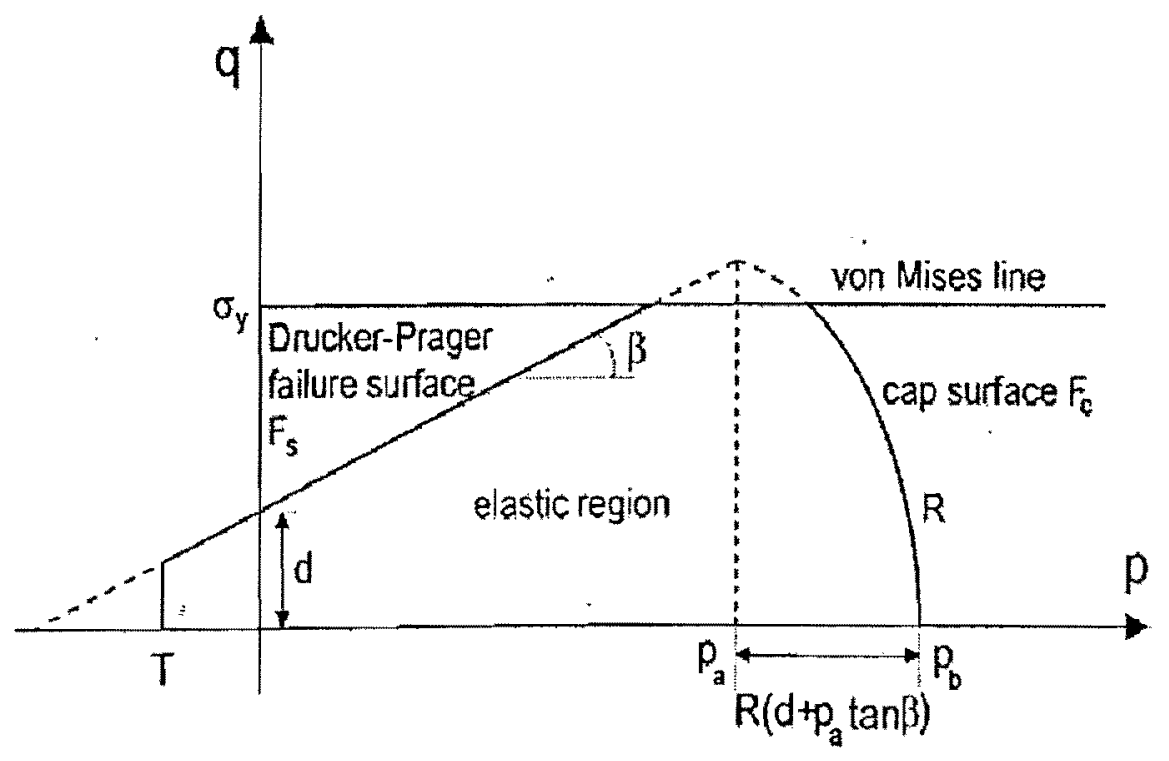

Figure 2.2: The Cap Model. 
To describe the powder behavior more realistically - especially with respect to crack formation during pressing, unloading or ejection - the Drucker-Prager-Cap model was modified by Coube and Riedel [13]. It is plausible that not only the hardening function $p_{a}$, but also the cohesion parameters $d, \beta$ and $T$ as well as the shape of the cap $R$ should depend on the density. In the following relations, the density $\rho$ and the volumetric plastic strain $\varepsilon_{v o l}^{P}$ are alternatively used. They are related by

$$
\varepsilon_{v o l}^{P}=\ln \left(\frac{\rho}{\rho_{0}}\right)
$$

where $\rho_{0}$ is the fill density. It is common in soil mechanics that the volumetric strain is defined positive during compaction. The hardening relation, the cap eccentricity and the cohesion parameters are initially described by the following empirical expressions [13, 14]:

$$
\begin{gathered}
\varepsilon_{v o l}^{P}=W\left(1-\exp \left(-C_{1} P_{a}^{C_{2}}\right)\right) \\
R=R_{1}+R_{2} \exp \left(R_{3} \rho\right) \\
d=d_{1} \exp \left(d_{2} \varepsilon_{v o l}^{P}\right) \\
\tan \beta=b_{1}-b_{2} \varepsilon_{v o l}^{P}
\end{gathered}
$$

The parameters $W, C_{l}, C_{2}, R_{1}, R_{2}, R_{3}, d_{l}, d_{2}, b_{1}$ and $b_{2}$ are determined by experiments. Numerical values for an iron-based powder were given by Coube and Riedel [13] and for an alumina powder by Riedel and Kraft [15]. Instead of the given Equations 2.16 - 2.19, alternative functional forms have also been proposed to describe the observed dependencies $[14,16]$.

\section{The Cam-Clay Model:}

The purpose of this section is to provide information concerning the application of a modified Cam-Clay material model to describe the yielding behavior of powder as it is compacted in a 
die. The basic Cam-Clay model has the major and minor axes coincident with the origin of the hydrostatic and deviatoric stress plane. The modified form has the ellipse major axis offset such that all elliptical surfaces pass through the origin of deviatoric and hydrostatic stress as shown in Figure 2.3.

It represents a "single surface" yield model that has the advantage of making use of a simpler material characterization procedure based on the use of an instrumented-die measurement equipment $[17,18]$. The yield surface of a powder needs to capture the mechanism of densification that makes the powder more difficult to compact. The modified Cam-Clay model describes the yield surface by means of an ellipse function and a typical form is shown in Figure 2.3.

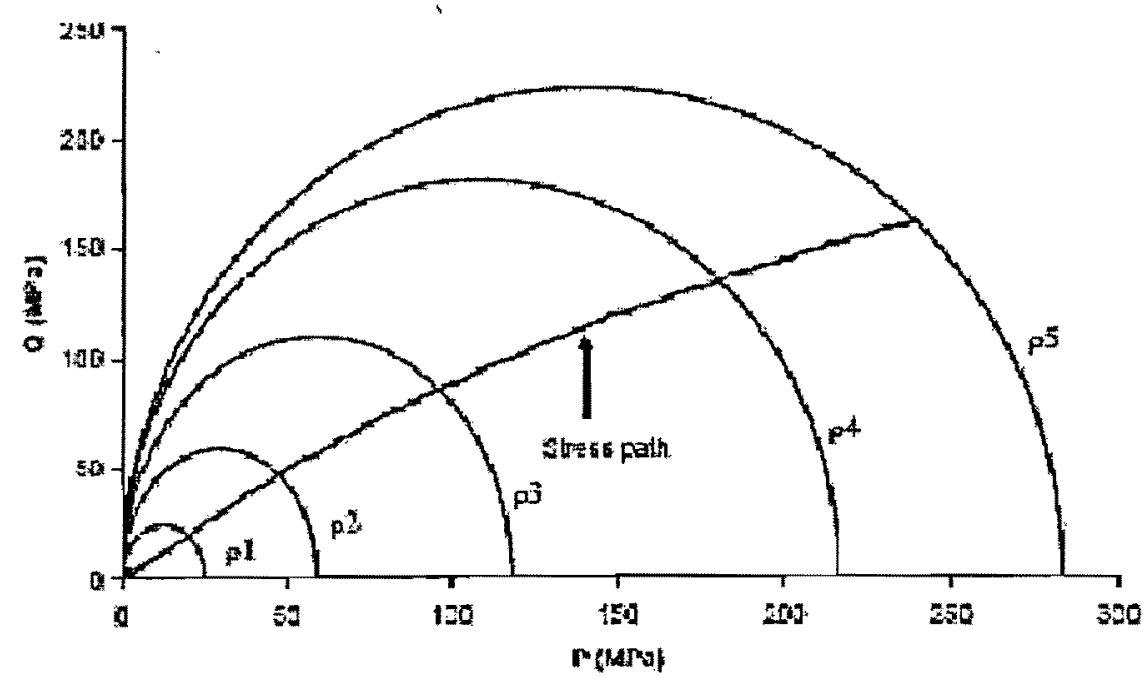

Figure 2.3: The Cam-Clay Model.

The yield surface is expressed in terms of hydrostatic stress $(P)$ and deviatoric stress $(Q)$. For a plain cylindrical part that is typically used in an instrumented-die test, these are given by

$$
\begin{aligned}
& P=\frac{\sigma_{z}+2 \sigma_{r}}{3} \\
& Q=\sigma_{z}-\sigma_{r}
\end{aligned}
$$

Figure 2.3 also includes the stress path that is mapped in an instrumented-die experiment and the properties of this path can be used to establish the yield model that is used within the 
simulation. The surfaces shown in Figure 2.3 are all ellipses and they are presented at different densification levels, thus capturing the increased resistance to compaction. Because the yield surfaces shown in the figure pass through the origin, they exclude cohesive behavior since the powder will not sustain any shear (deviatoric) stress at zero hydrostatic stress. The surfaces can also be offset along the hydrostatic stress axis to account for this mechanism.

Using the basic Equation to represent an ellipse, the yield Equation in its general form is written as:

$$
f=\frac{\left(P\left(\sigma_{i j}\right)-P_{0}\right)^{2}}{P_{0}^{2}}+\frac{Q^{2}\left(\sigma_{i j}\right)}{Q_{0}{ }^{2}}=1
$$

$P_{0}$ and $Q_{0}$ are, respectively, the half-lengths of the major and minor axes of the ellipse. $P_{0}$ also represents the extent to which the ellipse is offset along the hydrostatic stress axis. These material parameters are assumed, as shown above, to vary with density to capture the hardening behavior of the powder and this variation needs to be captured through appropriate Equation fits. Two Equations are required to determine the parameters $P_{0}$ and $Q_{0}$.

The first Equation is derived by inserting Equation 2.20 and Equation 2.21 into Equation 2.22

$$
f=\frac{\left(\frac{\sigma_{z}^{d}+2 \sigma_{r}^{d}}{3}-P_{0}\right)^{2}}{P_{0}^{2}}+\frac{\left(\sigma_{z}^{d}-\sigma_{r}^{d}\right)^{2}}{Q_{0}^{2}}-1=0
$$

where $\sigma_{z}^{d}$ and $\sigma_{r}^{d}$ are, respectively, the axial and radial stresses that are generated within a compact, obtained typically from an instrumented-die test in which a cylindrical sample is formed.

In the absence of further information it is common to assume that the model is associated. This is appropriate in the case of powder forming since the particles are generally small and are approximately uniform in size. This provides the second Equation that may be used to determine $P_{0}$ and $Q_{0}$. In this instance, the plastic strain-rate tensor is expressed as : 


$$
\dot{\varepsilon}_{i j}^{p}=\dot{\lambda} \frac{\partial f}{\partial \sigma_{i j}}
$$

If the die is perfectly rigid, there is no radial displacement during die pressing and hence the plastic radial strain is zero, which implies

$$
\left(\frac{\partial f}{\partial \sigma_{i j}}\right)_{i=j=r}=0
$$

Application to Equation 2.23 gives

$$
\frac{\partial f}{\partial \sigma_{i j}}=\frac{2}{3} \frac{\left(\frac{\sigma_{z}^{d}+2 \sigma_{r}^{d}}{3}-P_{0}\right)}{P_{0}^{2}}+\frac{\left(\sigma_{z}^{d}-\sigma_{r}^{d}\right)}{Q_{0}^{2}}=0
$$

From Equations 2.23 and 2.26, the functions $P_{0}$ and $Q_{0}$ are obtained as

$$
\begin{gathered}
P_{0}=\frac{3\left(P^{d}\right)^{2}+2 P^{d} Q^{d}}{6 P^{d}+2 Q^{d}} \\
Q_{0}=\sqrt{\left(Q^{d}\right)^{2}+\frac{\frac{3}{2}\left(P^{d}\right)^{2} Q^{d}}{2 P^{d}+\frac{2}{3} Q^{d}}}
\end{gathered}
$$

The material yield model as defined by the variation of $P_{0}$ and $Q_{0}$ with density and appropriate functional choices need to be made.

To do this, appropriate Equations must be defined and the following relationships have been utilized. These Equations are not prescriptive and alternatives may be used.

$$
P_{0}=K_{1}\left(\ln \left(1-\frac{\rho-\rho_{0}}{\rho-\rho_{\max }}\right)\right)^{K_{z}}
$$




$$
Q_{0}=Q_{\max } \tanh \left(\frac{K_{3} P_{0}}{Q_{\max }}\right)
$$

The terms $K_{1}$ to $K_{3}$ are curve-fit constants, $\rho_{0}$ and $\rho_{\max }$ are the fill and maximum theoretical density for the powder respectively and $Q_{\max }$ is the maximum deviatoric stress that the fully dense powder can sustain. The functional form of Equations 2.29 and 2.30 has been chosen to obtain the best fit with experimental data and, further, Equation 2.30 ensures that the material behavior is asymptotic to that of the fully dense powder. The parameters are determined by experiments.

\section{The Krieg Model:}

The Krieg model (Krieg 1972) provides a very simple, yet useful model for foam and soils whose material properties are not well characterized [19]. It allows for the specification of a non-linear pressure vs. volumetric strain relationship (by Hehen-berger et. al. (1982) [20]) as depicted below in Figure 2.4:

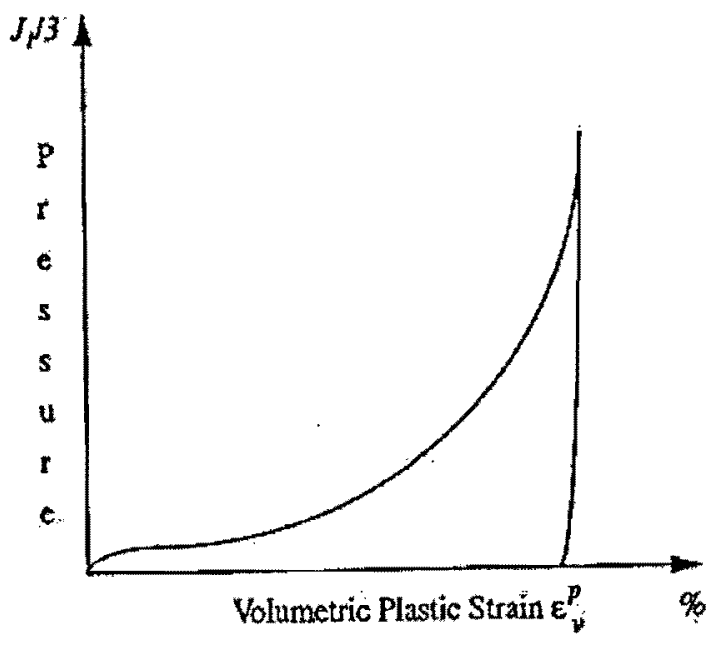

Figure 2.4: Hydrostatic test results by Hehen-berger et. al.

Here the pressure is positive in compression, and the volumetric strain is negative in compression. The deviatoric behavior is elastic-perfectly plastic, with a pressure (p) dependent yield function $\Phi$ given by 


$$
\Phi=J_{2}^{\prime}-F_{e}(P)
$$

where

$$
\begin{gathered}
J_{2}^{\prime}=\frac{1}{2} S_{i j} S_{i j} \\
F_{e}(p)=a_{0}+a_{1} p+a_{2} p^{2}
\end{gathered}
$$

For non-zero $a_{1}$ and $a_{2}$, the flow is non-associative. The yield surface of the Krieg material model, shown in Figure 2.5, is a surface of revolution with a planar end cap. This planar end cap is normal to the hydrostat and moves with work hardening.

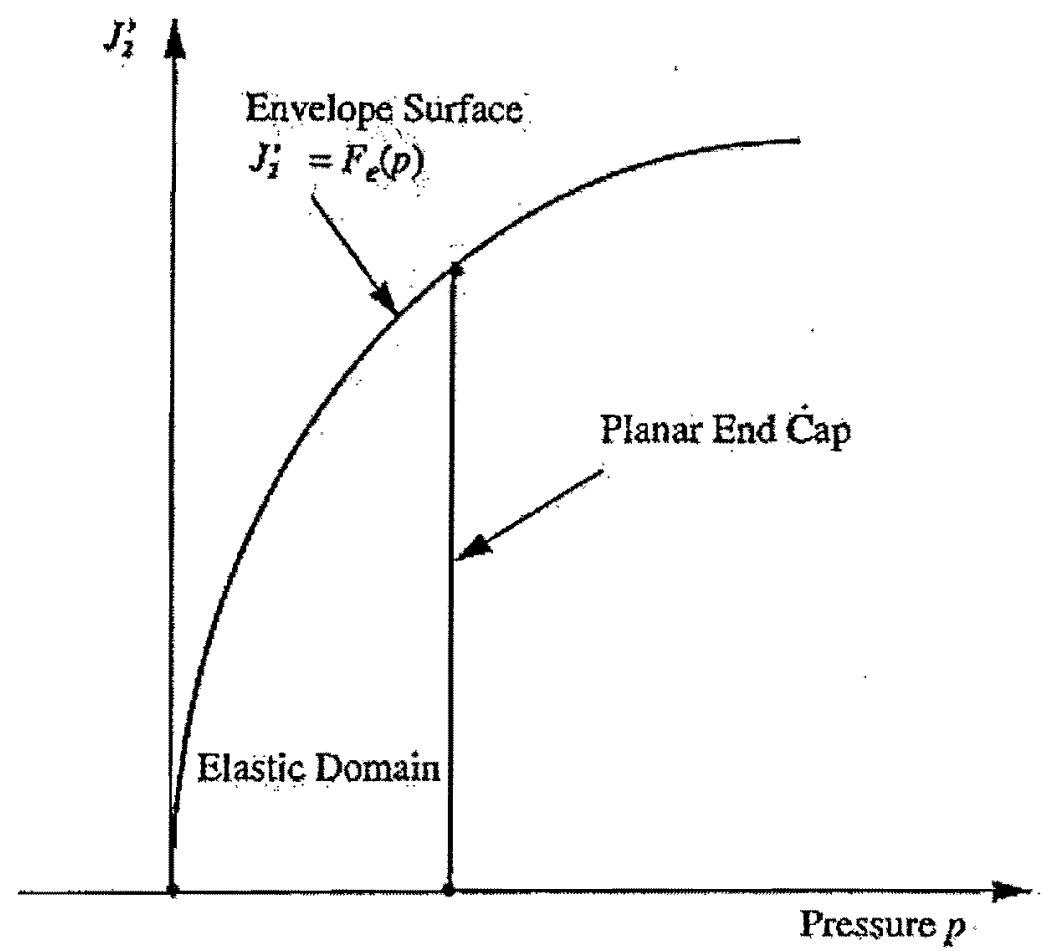

Figure 2.5: Yield Surface- Krieg Material Model.

On the yield surface the following relation holds

$$
J_{2}^{\prime}=\frac{1}{3} \sigma_{y}^{2}
$$

where $\sigma_{y}$ is the uniaxial yield stress. Therefore, constants $a_{i}$ may be determined from a simple uniaxial test data and the equation 


$$
\sigma_{y}=\left(3\left[a_{0}+a_{1} p+a_{2} p^{2}\right]\right)^{1 / 2}
$$

For elastic-perfectly plastic behavior, $a_{l}, a_{2}$ are equal to zero and $\left(3 a_{0}\right)^{1 / 2}$ defines the yield stress. The attractiveness of the Krieg model is its simplicity and the ease by which the material constants $a_{i}$ may be obtained.

\section{The Shima Model:}

Several yield criteria have been developed to describe the behavior of porous materials. Shima et. al. (1976) gives a rigid-plastic model for porous metals [21]. The yield function of the Shima model is given by:

where

$$
\Phi=\frac{1}{\gamma} \sqrt{\left(\frac{3}{2} S_{i j} S_{i j}+\frac{\sigma_{m}^{2}}{\beta^{2}}\right)}-\sigma_{y}
$$

$S_{i j:} \quad$ deviatoric stresses

$\sigma_{m}: \quad$ hydrostatic stress $\frac{1}{3} \sigma_{k k}$

$\sigma y: \quad$ uniaxial yield stress

$\beta, \gamma: \quad$ experimentally obtained material parameters (functions of relative density $\hat{\rho}$ ), which may be expressed as Zhao (1992) [22]:

$$
\begin{aligned}
& \beta=\left(b_{1}+b_{2} \hat{\rho}^{b_{3}}\right)^{b_{4}} \\
& \gamma=\left(q_{1}+q_{2} \hat{\rho}^{q_{3}}\right)^{q_{4}}
\end{aligned}
$$

where

$$
\begin{array}{ll}
\hat{\rho}: & \text { relative density } \\
b_{i} \& q_{i}: & \text { obtained from curve fitting process }
\end{array}
$$

The shima model adopts an associated flow rule and a hardening rule based on volumetric strain. It should be noted that as the material becomes denser the parameters $\beta$ and $\gamma$ 
increase with $\gamma$ approaching unity and $\beta$ approaching infinity as the material becomes fully dense and the Shima model is reduced to the well-known von Mises yield criterion.

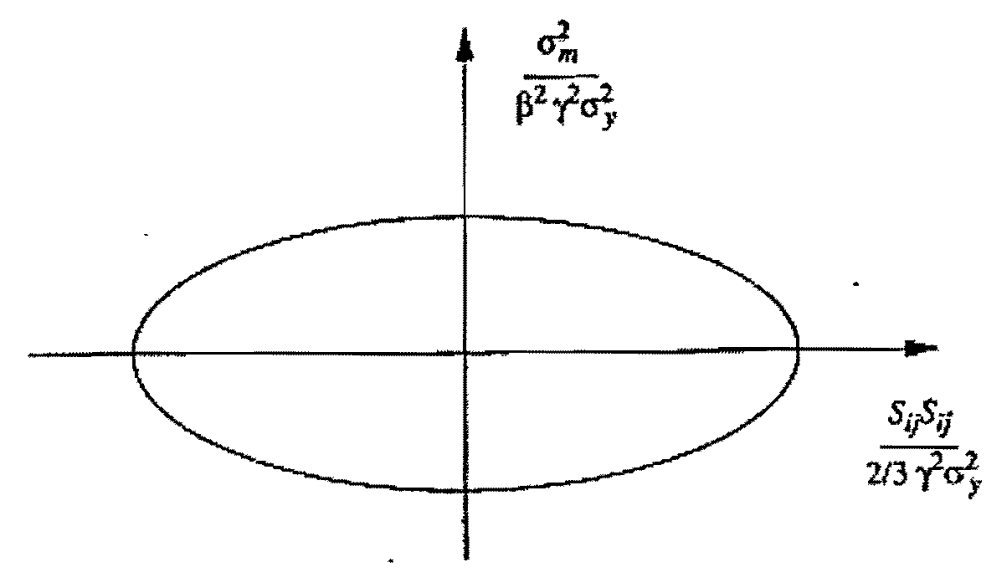

Figure 2.6: Yield Surface - Shima Material Model.

Therefore, in this model, bulk plastic flow results in densification and as full density is achieved, the material behaves as a von Mises material (i.e. as an incompressible material). In powder compaction applications, the yield function given by Equation 2.36 is only valid for the case where the hydrostatic stress satisfies the following condition

$$
\sigma_{m} \leqslant 0
$$

since the powder compact has very little strength in tension. The yield surface for the Shima model is shown in Figure 2.6. In general it is an ellipse, which reduces to circle as the relative density approaches unity.

However, these models have some common defects. The relationship between the mechanical properties of the powder and the compact metal has been totally neglected. The parameters of these models often need complex experiments for them to be determined, and the relationship between these models and the models for the metal compact lack a solid theoretical basis. As discussed in chapter 3: the Krieg material model does not represent the powder behavior with sufficient accuracy, the Cap material model suffers from limited ability to incorporate the material property changes that accompany densification and deformation of the powder and 
the Cam-Clay material model parameters had to be modified in order to model "powder deformation to a limited extend'. The literature review indicates that, for modeling of cold closed-die compaction process, the Shima material model is the one that has been specifically developed for modeling the behavior of metal powders. The Finite Element (FE) simulation in this research uses Shima material model for cold compaction process. 


\section{Chapter 3}

\section{Design and Methodology: Simulation of Cold Compaction Process}

The design phase is the first step in the production of a metal powder part. Here, the application is evaluated carefully to determine the optimum choice of material, die configuration, and, if necessary, any secondary operations needed to achieve specified properties.

The conditions under which the part will operate (e.g. stress state, stress level, temperature) define the combination of properties needed and consequently, the materials capable of meeting those needs. One benefit of PM is its ability to tailor the microstructure to provide specific properties and performance. This can be done by alloying the base powder with additives in the form of elemental or multi-element metallic materials and usually a dry lubricant to facilitate extraction of the part from the die.

Design of the tooling is another important consideration in the design stage. Since most PM parts are produced by pressing, the configuration of the die and punches is very important. In many cases, complex shapes with multi-level surfaces can be formed in a single pressing operation. Consequently, creative tool design is essential in the manufacture of parts with high performance and quality, while maintaining the economic advantage of PM.

Due to increasing computer power and development of new codes based on particle interaction - e.g. discrete element methods, micro mechanical models are emerging as more and more attractive for numerical simulation [3].

This thesis has dealt with the compaction simulations for the purpose of predicting relative density distributions.

\subsection{Different Finite Element (FE) Models}

Following three finite element models are used: 
- Pressure Model: Compaction is due to a uniformly distributed pressure applied at the powder's two free end surfaces as shown in Figure 3.1:

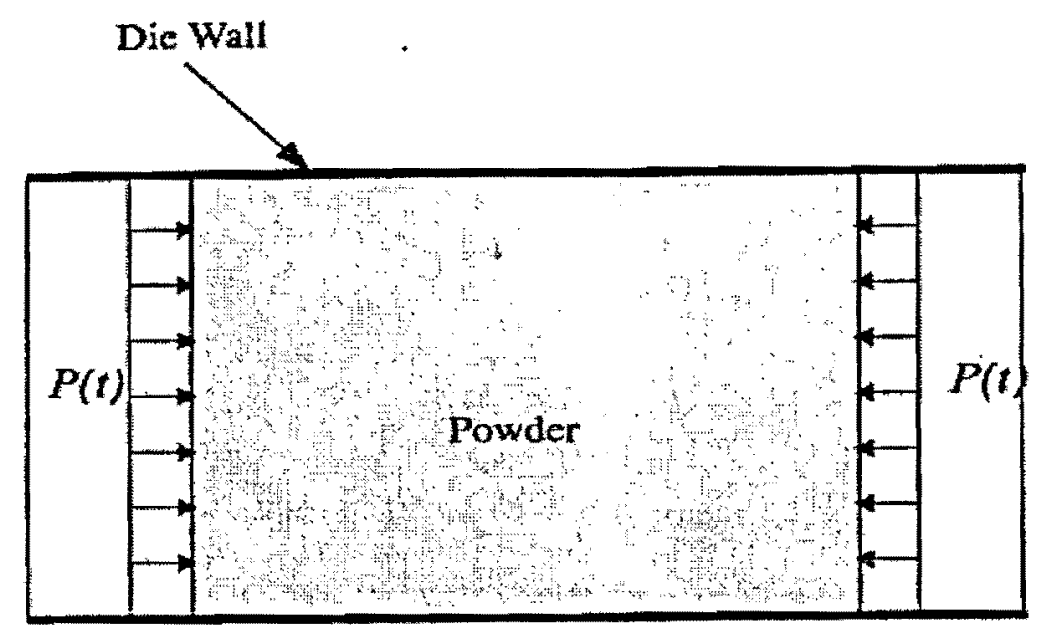

Figure 3.1: The Pressure Model.

- Displacement Model: Compaction is due to a finite (given) displacement on two infinitely rigid surfaces which are in contact with the powder's two free ends as shown in Figure 3.2:

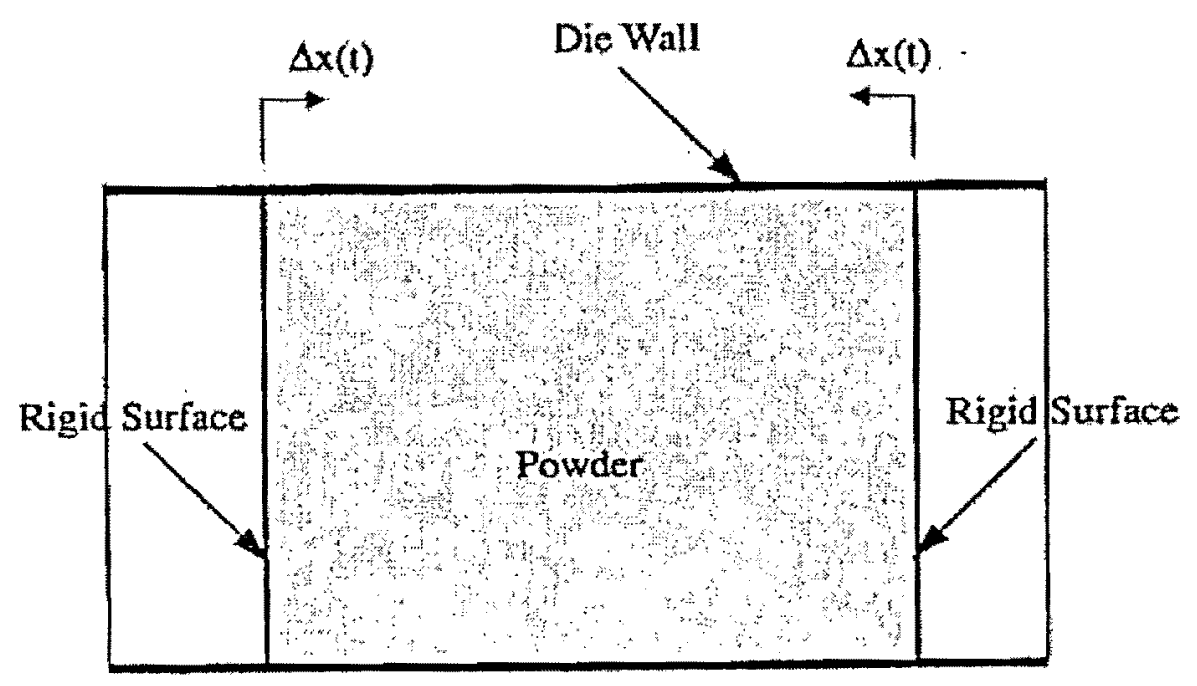

Figure 3.2: The Displacement Model. 
- Pressure-Punch Model: Compaction is due to a uniformly distributed pressure applied on two punches which are also in contact with the powder's two free ends as shown in Figure 3.3:

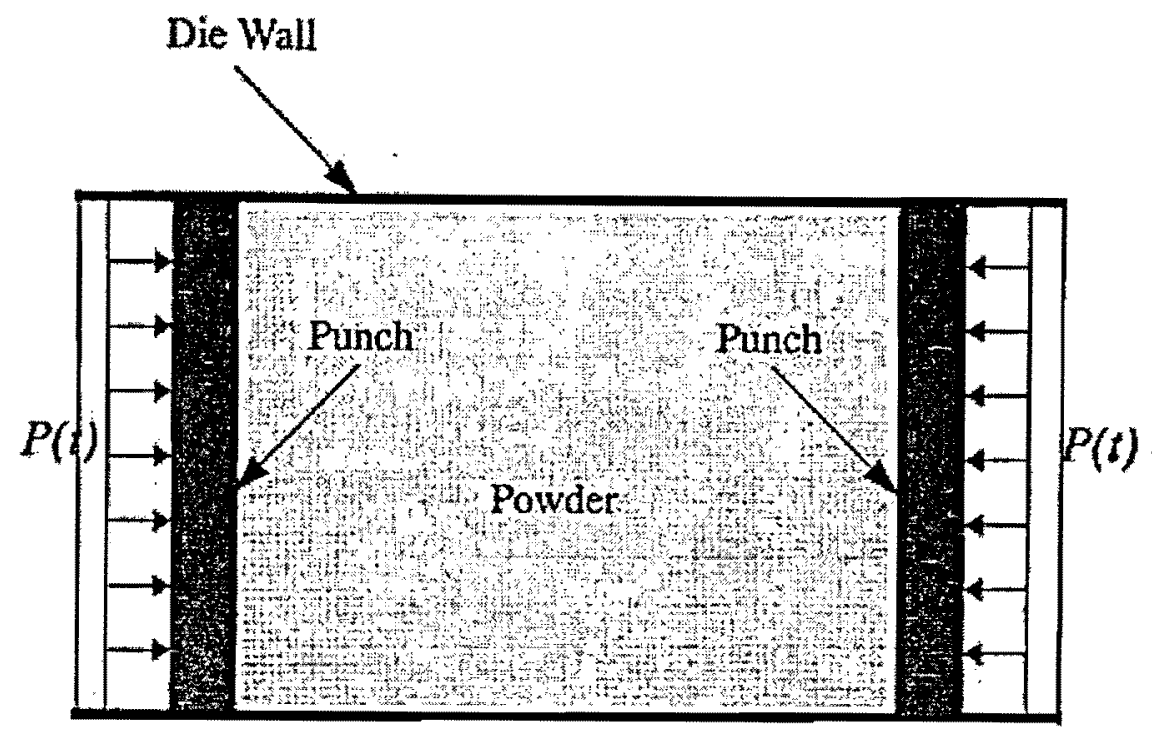

Figure 3.3: The Pressure-Punch Model.

\subsection{Selection of a Material Model and FE Program}

The NIKE and DYNA, the non-linear finite element programs from Lawrence Livermore Laboratory, are incorporated with the Krieg material model. Bandstra, Otto and Massa [30] have used the Krieg material model of NIKE2D to simulate cold closed-die compaction. After comparing their simulation results with the experimental results (obtained at Kennametal facilities, B.C.), the authors noted that the Krieg model does not represent the powder behavior with sufficient accuracy and they recommended it to be modified.

DYNA3D and more recently NIKE2D also offer the Cap material model. Several researchers have used this model to illustrate the behavior of powders during cold closed-die compaction. As noted by Krauss et. al. (1991) [31], the Cap model suffers from limited ability to incorporate the material property changes that accompany densification and deformation of the powder. Therefore, they propose the following enhancements to overcome the deficiencies: 
- Updating the elastic properties of the powder during densification.

- Improving the mathematical description of hardening due to densification and work hardening of the powder.

Nevertheless, the Cap model has been implemented into finite element codes to simulate densification by DiMaggio and Sandler (1971), [12], Crawford and Lindskog (1983), and Trassoras et. al. (1989), [32]. It should be noted that no comparison of simulation results with the experimental results is given in aforementioned references.

Armstrong et. al. (1993) [33] has used the Cam-Clay material model. This material model, like the Cap, is provided in the ABAQUS non-linear finite element program for analyzing soil mechanics problems. The authors had to modify the material parameters in order to model "powder deformation to a limited extend".

The literature review indicates that from the material models used for modeling the cold closed-die compaction process, the Shima model, developed by Shima and Oyane (1976) [21], Shima and Saleh (1992) [34], Zhao (1992) [22], Nakagawa (1992) [35] and Shima (1992), is the one that has been specifically developed for modeling the behavior of powder materials. The Shima model is presently available in the MSC_Marc non-linear finite element program.

\subsection{Solution Schemes for Non-linear Analysis}

Nonlinear analysis is usually more complex and expensive than linear analysis. In general, the solutions of nonlinear problems always require incremental solution schemes and sometimes require iterations (or recycles) within each load/time increment to ensure that equilibrium is satisfied at the end of each step [37]. Superposition cannot be applied in nonlinear problems.

The iterative procedures supported in Marc are: Newton-Raphson, Modified NewtonRaphson, Newton-Raphson with strain correction, and direct substitution. If the R-P flow contribution model is chosen, a direction substitution is used. 
A nonlinear problem does not always have a unique solution. Sometimes a nonlinear problem does not have any solution, although the problem can seem to be defined correctly.

Nonlinear analysis requires good judgment and uses considerable computing time. Several runs are often required. The first run should extract the maximum information with the minimum amount of computing time. Some design considerations for a preliminary analysis are:

- Minimize degrees of freedom whenever possible.

- Halve the number of load increments by doubling the size of each load increment.

- Impose a coarse tolerance on convergence to reduce the number of iterations. A coarse run determines the area of most rapid change where additional load increments might be required. Plan the increment size in the final run by the following rule of thumb: there should be as many load increments as required to fit the nonlinear results by the same number of straight lines.

\section{Full Newton-Raphson Method}

The basis of the Newton-Raphson method in structural analysis is the requirement that equilibrium must be satisfied [37]. Consider the following set of equations:

$$
K(u) \delta u=F-R(u)
$$

Where $u$ is the nodal-displacement vector, $F$ is the extemal nodal-load vector, $R$ is the internal nodal-load vector (following from the internal stresses), and $K$ is the tangentstiffness matrix. The internal nodal-load vector is obtained from the internal stresses as

$$
R=\sum_{\text {elem }} \int_{V} \beta^{T} \sigma d v
$$

In this set of equations, both $R$ and $K$ are functions of $u$. In many cases, $F$ is also a function of $u$ (for example, if $F$ follows from pressure loads, the nodal-load vector is a function of the orientation of the structure). The equations suggest that use of the full NewtonRaphson method is appropriate. 
Suppose that the last obtained approximate solution is termed $\delta u^{i}$, where ${ }^{i}$ indicates the iteration number. Equation 3.1 can then be written as

$$
K\left(u_{n+1}^{i-1}\right) \delta u=F-R\left(u_{n+1}^{i-1}\right)
$$

This equation is solved for $\delta u^{i}$ and the next appropriate solution is obtained by

$$
\Delta u^{i}=\Delta u^{i-1}+\delta u^{i} \text { and } u_{n+1}^{i}=u_{n}+\Delta u^{i}
$$

Solution of this equation completes one iteration, and the process can be repeated. The subscript ${ }_{n}$ denotes the increment number representing the state $t={ }_{n}$. Unless stated otherwise, the subscript $n+1$ is dropped with all quantities referring to the current state.

The full Newton-Raphson method as shown in Figure 3.4 is the default in Marc. The full Newton-Raphson method provides good results for most nonlinear problems, but is expensive for large, three-dimensional problems, when the direct solver is used. The computational problem is less significant when the iterative solvers are used.

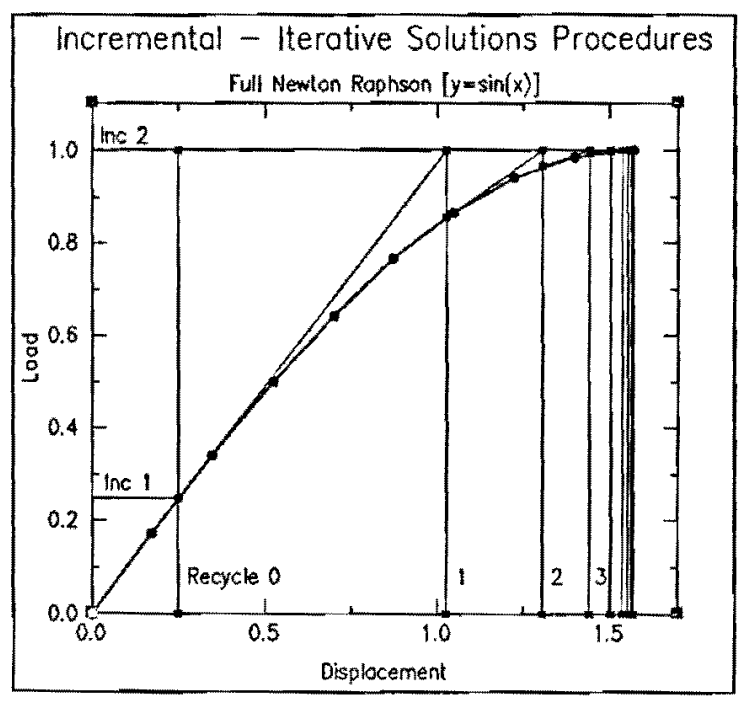

Figure 3.4: Full Newton-Raphson Method. 


\section{Modified Newton-Raphson Method}

The modified Newton-Raphson method is similar to the full Newton-Raphson method, but does not reassemble the stiffness matrix in each iteration [37].

$$
K\left(u^{0}\right) \delta u^{i}=F-R\left(u^{i-1}\right)
$$

The process is computationally inexpensive because the tangent stiffness matrix is formed and decomposed once. From then on, each iteration requires only forming the right-hand side and a backward substitution in the solution process. However, the convergence is only linear, and the potential for a very large number of iterations, or even non-convergence, is quite high. The modified Newton-Raphson method is shown in Figure 3.5.

If contact or sudden material nonlinearities occur, reassembly cannot be avoided. The modified Newton- Raphson method is effective for large-scale, only mildly nonlinear problems. When the iterative solver is employed, simple back substitution is not possible, making this process ineffective. In such cases, the full Newton-Raphson method should be used instead.

If the load is applied incrementally, Marc recalculates the stiffness matrix at the start of each increment or at selected increments, as specified.

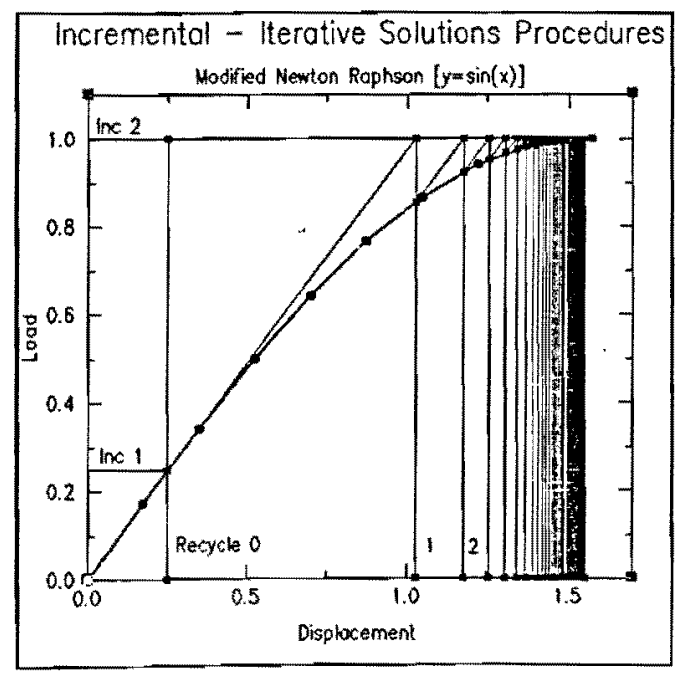

Figure 3.5: Modified Newton-Raphson Method. 


\section{Newton-Raphson Strain Correction Method}

The strain correction method is a variant of the full Newton method [37]. This method uses a linearized strain calculation, with the nonlinear portion of the strain increment applied as an initial strain increment in subsequent iterations and recycles. This method is appropriate for shell and beam problems in which rotations are large, but membrane stresses are small.

In such cases, rotation increments are usually much larger than the strain increments, and, hence, the nonlinear terms can dominate the linear terms. After each displacement update, the new strains $E_{\alpha \beta}^{i+1}$ are calculated from $u^{i}$ and $\delta u\left(=\delta u^{i}\right)$ which yield

$$
E_{\alpha \beta}^{i+1}=E_{\alpha \beta}^{i}+\frac{1}{2}\left(\delta u_{\alpha, \beta}+\delta u_{\beta, \alpha}\right)+u_{\kappa, \alpha}^{i} \delta u_{\kappa, \beta}+\delta u_{\kappa, \alpha} u_{\kappa, \beta}^{i}+\delta u_{\kappa, \alpha} \delta u_{\kappa, \alpha}
$$

This expression is linear except for the last term. Since the iteration procedures start with a fully linearized calculation of the displacement increments, the nonlinear contributions yield strain increments inconsistent with the calculated displacement increments in the first iteration. These errors give rise to either incorrect plasticity calculations (when using small strain plasticity method), or, in the case of elastic material behavior, yields erroneous stresses. These stresses, in their turn, have a dominant effect on the stiffness matrix for subsequent iterations or increments, which then causes the relatively poor performance.

The remedy to this problem is simple and effective. The linear and nonlinear part of the strain increments are calculated separately and only the linear part of

$$
\left(E_{\alpha \beta}^{1}\right)=E_{\alpha \beta}^{i}+\frac{1}{2}\left(\delta u_{\alpha, \beta}+\delta u_{\beta, \alpha}\right)+u_{\kappa, \alpha}^{i} \delta u_{\kappa, \beta}+\delta u_{\kappa, \alpha} u_{\kappa \beta}^{i}
$$

is used for calculation of the stresses. The nonlinear part

$$
\left(E_{\alpha \beta}^{n 1}\right)^{i+1}=\frac{1}{2} \delta u_{\kappa, \alpha} \delta u_{\kappa, \beta}
$$


is used as an "initial strain" in the next iteration or increment, which contributes to the residual load vector defined by

$$
R^{C}=\int_{V_{0}} \delta_{\kappa, \beta} X_{\kappa, \alpha} L^{\alpha \beta \gamma \delta} \Delta E_{\gamma \delta}^{n l} d V
$$

This "strain correction" term is defined by

$$
K\left(u_{n+1}^{i}\right) \delta u=F-R\left(u_{n+1}^{i}\right)-R^{C}
$$

Since the displacement and strain increments are now calculated in a consistent way, the plasticity and/or equilibrium errors are greatly reduced. The performance of the strain correction method is not as good if the displacement increments are (almost) completely prescribed, which is not usually the case. Finally, note that the strain correction method can be considered as a Newton method in which a different stiffness matrix is used.

\section{Direct Substitution}

In the Eulerian formulation, the governing equation of the system can be expressed as

$$
K v=F
$$

Where $v$ is a velocity vector and $F$ is a force vector.

This equation is very nonlinear because $K$ is a nonlinear function of $v$. By default, a direct substitution method is used to solve the problem. If $v^{i}$ is the velocity at iteration $i$, the result of iteration $i+1$ is

$$
K\left(v^{i}\right) v^{i+1}=F
$$

If this method does not converge in 10 iterations, it is possible to switch to a full NewtonRaphson method.

However, in this research, Full Newton_Raphson method is chosen for the FE simulation of cold compaction process, because this method provides good results for most non-linear problems and it also converges well. 


\subsection{FE Simulation with MSC_Marc}

The cylindrical green is used here, the diameter of green $\mathrm{D}$ is $10 \mathrm{~mm}$ and the initial height of the powder body $\mathrm{H}_{0}$ is $10 \mathrm{~mm}$. Because of the symmetry of the load and geometry, the powder compaction can be simplified to the problem of axis-symmetric deformation. It should be noted that material properties (like material model parameters $\beta$ and $\gamma$, Young's Modulus $E$ and Poisson's ratio $v$ etc.) found in the literature and recent articles are being used, as the experimental set-up is not yet available. The following two simulation geometries are considered (refer Figure 3.6 and Figure 3.7):

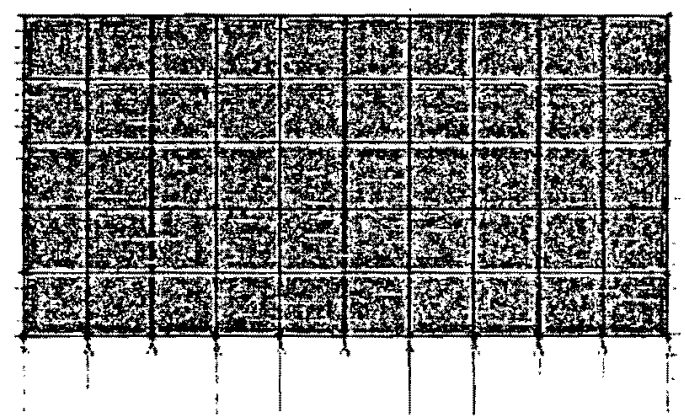

Figure 3.6: Cylindrical Geometry (50 axis-symmetric elements).

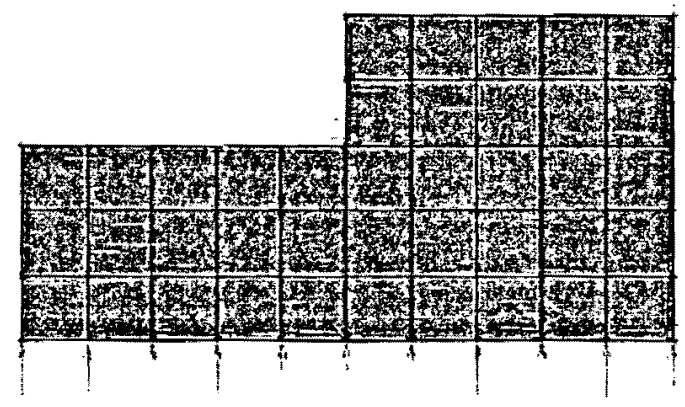

Figure 3.7: Stepped Cylindrical Geometry (40 axis-symmetric elements).

\section{The Solver used in FE simulation}

The finite element formulation leads to a set of linear equations. The solution is obtained through numerically inverting the system. Most analyses result in a system which is real, symmetric, and positive definite [37]. While this is true for linear structural problems, 
assuming adequate boundary conditions, it is not true for all analyses. Marc has two main modes of solvers - direct and iterative.

\section{Direct Solver:}

Traditionally, the solution of a system of linear equations was accomplished using direct solution procedures, such as Cholesky decomposition and the Crout reduction method. These methods are usually reliable, in that they give accurate results for virtually all problems at a predictable cost. For positive definite systems, there are no computational difficulties. For poorly conditioned systems, however, the results can degenerate but the cost remains the same. The problem with these direct methods is that a large amount of memory (or disk space) is required, and the computational costs become very large.

\section{Iterative Solver:}

Marc offers iterative solvers as a viable alternative for the solution of large systems. These iterative methods are based on preconditioned conjugate gradient methods. The single biggest advantage of these iterative methods is that they allow the solution of very large systems at a reduced computational cost. This is true regardless of the hardware configuration. The disadvantage of these methods is that the solution time is dependent not only upon the size of the problem, but also the numerical conditioning of the system. A poorly conditioned system leads to slow convergence - hence increased computation costs.

In this research, direct profile solver has been chosen for the FE simulation of cold compaction process on all powder models, because this is reliable and gives accurate results for at a reasonable cost.

\section{The Mesh Generation}

This preprocessing task is considered a significant part of the finite element analysis process. In fact, at times it may be the most complex and time consuming part of the entire job. For this reason it is important to determine, in advance, the objective of analysis [39].

MSC_Marc Mentat distinguishes two techniques to build a mesh. The first is the direct or manual approach where finite elements are generated from bottom up. The second is the 
geometric approach where the model is first generated using geometric entities followed by a conversion step in which these entities are converted to finite elements. The two techniques are by no means mutually exclusive and often the best results are obtained by alternating between the two.

\section{The Direct Meshing Technique:}

Elements are used as the basic building blocks to generate a coarse mesh that can be refined later using the tools provided by Mentat specifically for this purpose. This approach is particularly suitable for a domain with a simple geometry. The direct meshing technique is not based on an algorithm but consists of the enumeration of the most coarse mesh that still represents the desired geometry. To define the building blocks, the ADD button of the element and node panels in the mesh generation menu is used.

Once a coarse model is generated, it can be refined (locally) to the desired level using the processors SUBDIVIDE, EXPAND, DUPLICATE, SYMMETRY, MOVE, SWEEP and RENUMBER etc.

\section{The Geometric Meshing Technique:}

The basic building blocks for this technique are geometric entities rather than mesh entities. The geometric entities available in Mentat are points, curves, surfaces, and solids. They may be converted to mesh entities after the geometric model is completed. This approach is more complex than the direct meshing technique as it involves the extra layer of geometric entities. However, the advantage of the geometric meshing technique is that increased complexity is offset by increased flexibility in generating geometries of complex shape. It is important to differentiate mesh entities from geometric entities; for example, a two-noded line element is not the same as a line curve, and a node is not the same as a point.

The models in this simulation use axis-symmetric quad-4 element with four edges and four nodes (element 10 in the MSC_Marc element library). There are 5 layers elements in the direction of diameter and 10 layers elements in the direction of height. Thus, the total number of elements is 50 . In the case of stepped cylindrical green, the total number of elements is reduced to 40 . 
Fe-based powder material properties [36] are as follows:

Table 3.1: Fe-based material properties

\begin{tabular}{|c|c|}
\hline Material Properties & \\
\hline The Young's Modulus, $E$ & $20,000 \mathrm{MPa}=20,000 \mathrm{~N} / \mathrm{mm}^{2}$ \\
\hline The Poisson's Ratio, $\nu$ & 0.3 \\
\hline The Initial Mass Density, $\rho$ & $5460 \mathrm{~kg} / \mathrm{m}^{3}=5.46 \times 10^{-6} \mathrm{~kg} / \mathrm{mm}^{3}$ \\
\hline
\end{tabular}

The other parameters considered for this FE simulation [40] are as follows:

Table 3.2: The other parameters used in FE simulation

\begin{tabular}{|c|c|}
\hline Other Properties & 0.7 \\
\hline The initial relative density, $\hat{\rho}$ & 0.3 \\
\hline $\begin{array}{c}\text { The co-efficient of friction } \\
\text { (without lubrication), } \mu\end{array}$ & $6000 \mathrm{MPa}=6000 \mathrm{~N} / \mathrm{mm}^{2}$ \\
\hline The initial yield stress, $\sigma_{y}$ & 50,000 stokes \\
\hline The kinematic viscosity, $\vartheta$ & $\gamma=0.140617, \beta=0.730296$ \\
\hline The Material Model Parameters &
\end{tabular}

The FE models considered for this thesis are given below:

Cylindrical pressure models:

The cylindrical green is compacted by applying two different time varying loads (pressure) on the RH edge of the powder compact. The simple case (case 1) involves free boundary on the upper surface (i.e. no die) and no friction condition anywhere. This model is pressed by applying the pressure load 1 which is shown in Figure 3.8. The same model is considered next, except the loading (case 2), which is pressed by applying a time varying load called the pressure load 2 that is shown in Figure 3.9. Then the die-walls are added to the powder compact and it is pressed with the pressure load 2 without friction between the powder and the die-walls (case 3). The last model is same as the previous one except the frictional condition, a coulomb friction $(\mu=0.3)$ is considered between the powder and the die-walls (case 4). 


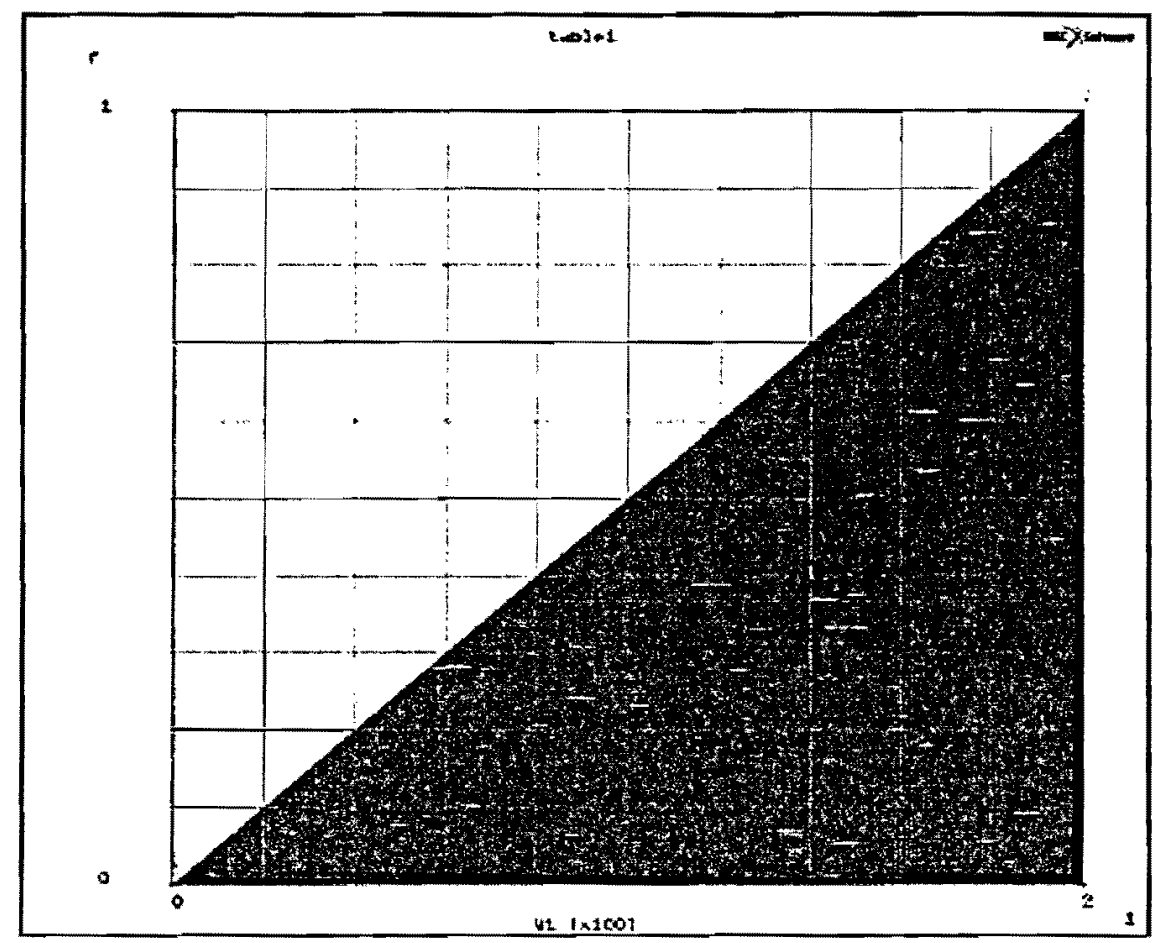

Figure 3.8: Pressure load 1 - Edge Load of $8000 \mathrm{~N} / \mathrm{mm}^{2}$ applied on RH WALL in 200 seconds at an increment of $800 \mathrm{~N} / \mathrm{mm}^{2}$ in 10 steps.

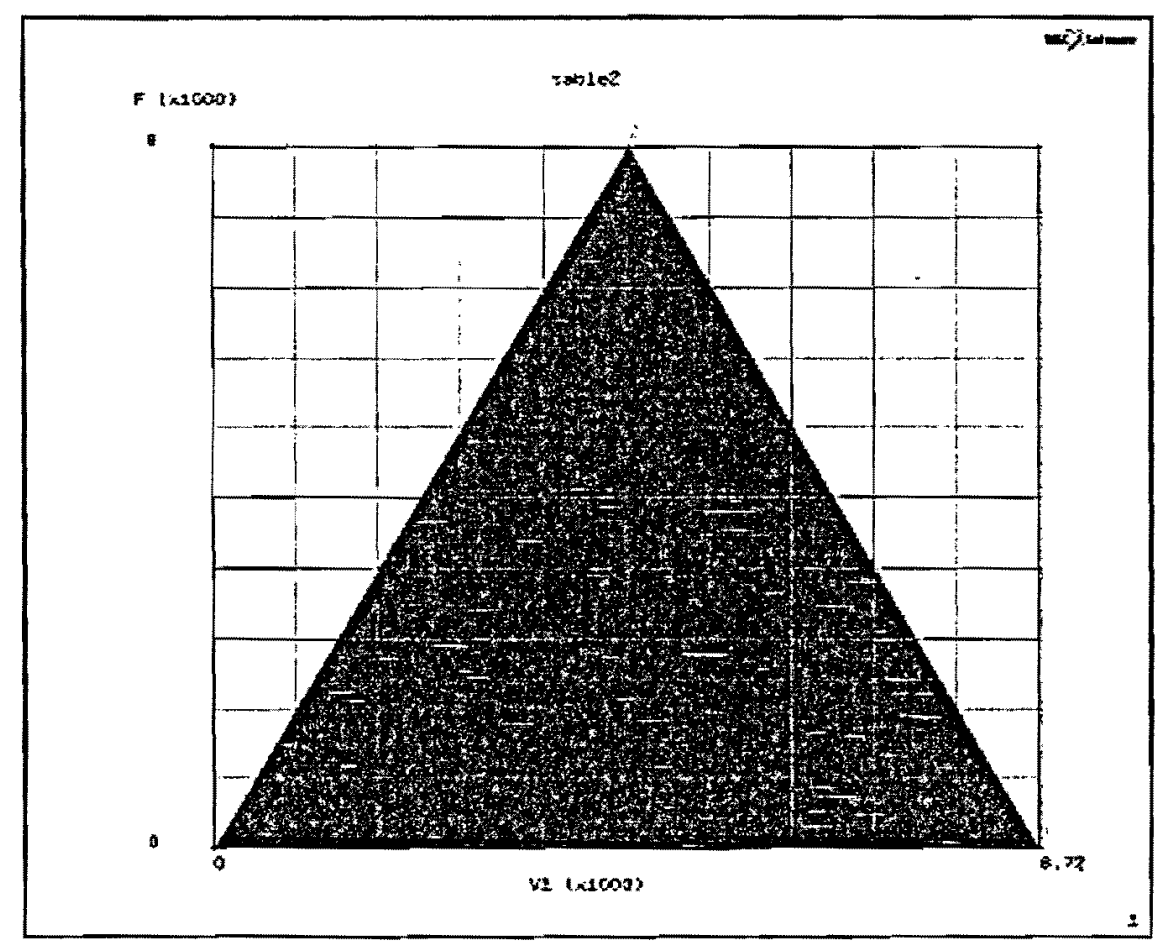

Figure 3.9: Pressure load 2 - Edge Load of $8000 \mathrm{~N} / \mathrm{mm}^{2}$ applied on RH WALL in 4400 seconds and then released in 4320 seconds. 
Cylindrical displacement models:

The cylindrical green is compacted by applying an incremental displacement of $2.4 \mathrm{~mm}$ in the -ve $x$ direction with a single-punch in 20 seconds and then released to $0.87 \mathrm{~mm}$ in another 20 seconds (case 5). The displacement load 1 is shown in Figure 3.10. Here the effect of friction $(\mu=0.3)$ is considered between the powder $\&$ the die-walls and also at the powder-punch interface. The same model is considered next without friction at the powder-punch interface (case 6).

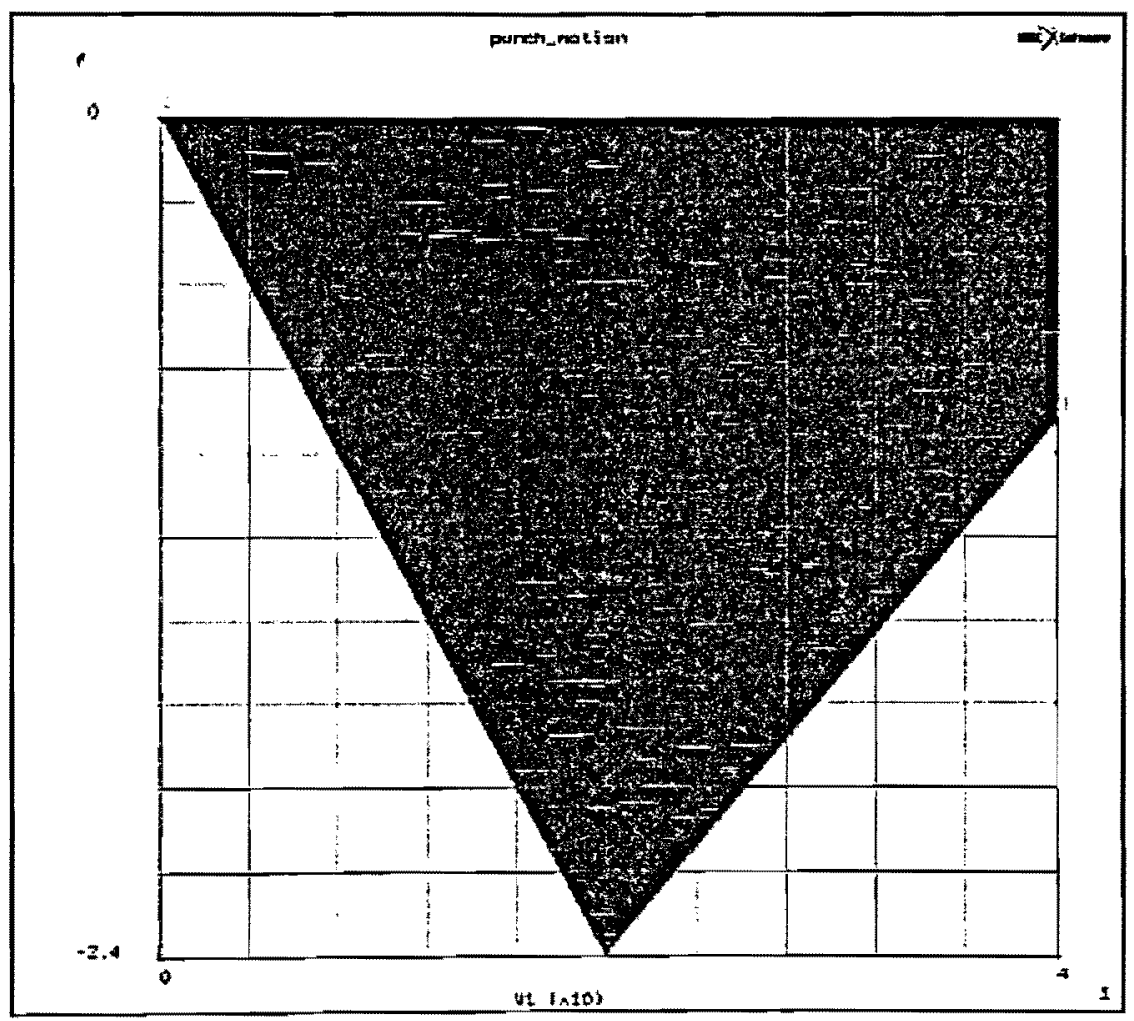

Figure 3.10: Displacement load 1 - an incremental displacement of $2.4 \mathrm{~mm}$ applied in the -ve $\mathrm{x}$ direction with a single-punch in 20 seconds and then released to $0.87 \mathrm{~mm}$ in another 20 seconds.

Stepped Cylindrical displacement models:

The stepped cylindrical green is pressed by the displacement load 2 (shown in Figure 3.11), which applies $1.2 \mathrm{~mm}$ displacement the -ve $\mathrm{x}$ direction with a single-punch in 20 seconds and then releases to $0.44 \mathrm{~mm}$ in another 20 seconds whereas friction between the powder \& the 
die-walls and also at the powder-punch interface is considered (case 7). The next model is the same as the previous one except that no friction is considered for comparison purposes in the relative density distribution (case 8 ). The last model is pressed by a double-punch. Incremental displacement of $1.2 \mathrm{~mm}$ is given in the both directions and then released to 0.44 $\mathrm{mm}$ with friction between the powder \& the die-walls and also at the powder-punch interface (case 9).

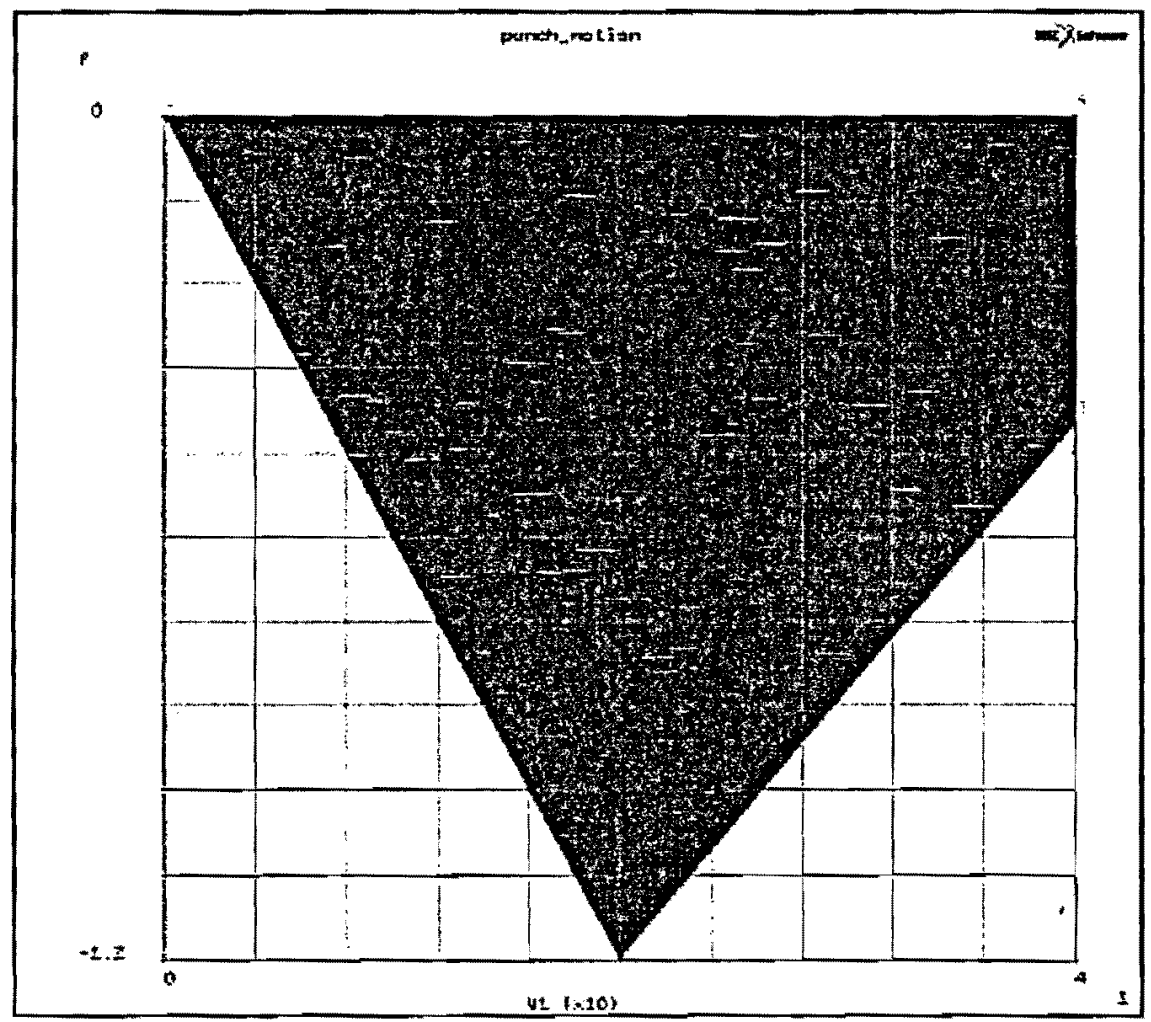

Figure 3.11: Displacement load 2- an incremental displacement of $1.2 \mathrm{~mm}$ applied in the -ve $x$ direction with a single-punch in 20 seconds and then released to $0.44 \mathrm{~mm}$ in another 20 seconds.

The FE simulation results i.e. the relative density distributions of the cold compaction process for the cylindrical and stepped cylindrical models are depicted in chapter 4 . 


\section{Chapter 4}

\section{FE Simulation Results}

The results of the finite element analysis using the MSC_Marc program are sought. In these simulations of cold closed-die compaction, various options of the MSC_Marc program have been tested. Because of the symmetry of the load and geometry, the powder compaction can be simplified to the problem of axis-symmetric deformation. In addition, die geometry and load application methods are also studied. The simulation results for different FE models are categorized as follows:

\subsection{Cylindrical Pressure Models}

1. CASE 1: This pressure model uses no die (i.e. the upper surface is free) and no friction as well. The powder is compacted by an edge load of $8000 \mathrm{~N} / \mathrm{mm}^{2}$ in 200 seconds. Refer Figure 4.1 and 4.2. The powder compact expands laterally as expected and the relative density variation should be of no practical concern since it is very small.

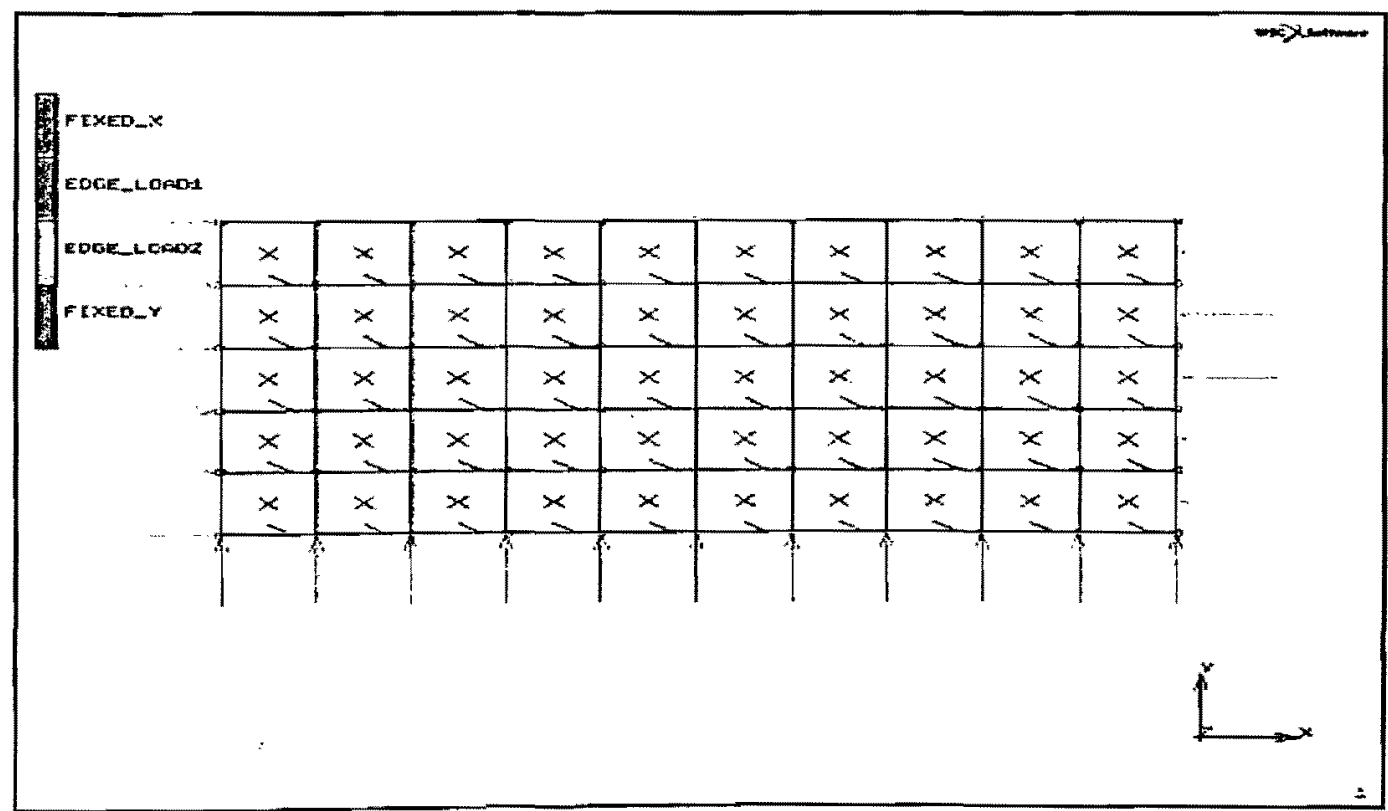

Figure 4.1: Pressure Model 1- Edge Load of $8000 \mathrm{~N} / \mathrm{mm}^{2}$ applied on RH WALL in 200 seconds at an increment of $800 \mathrm{~N} / \mathrm{mm}^{2}$ in 10 steps. 
From the following Figure, it is noted that relative density varies from 0.7080 to 0.7237 which is of no significant importance. A major portion of the green compact (right half) has the constant density (0.7111).

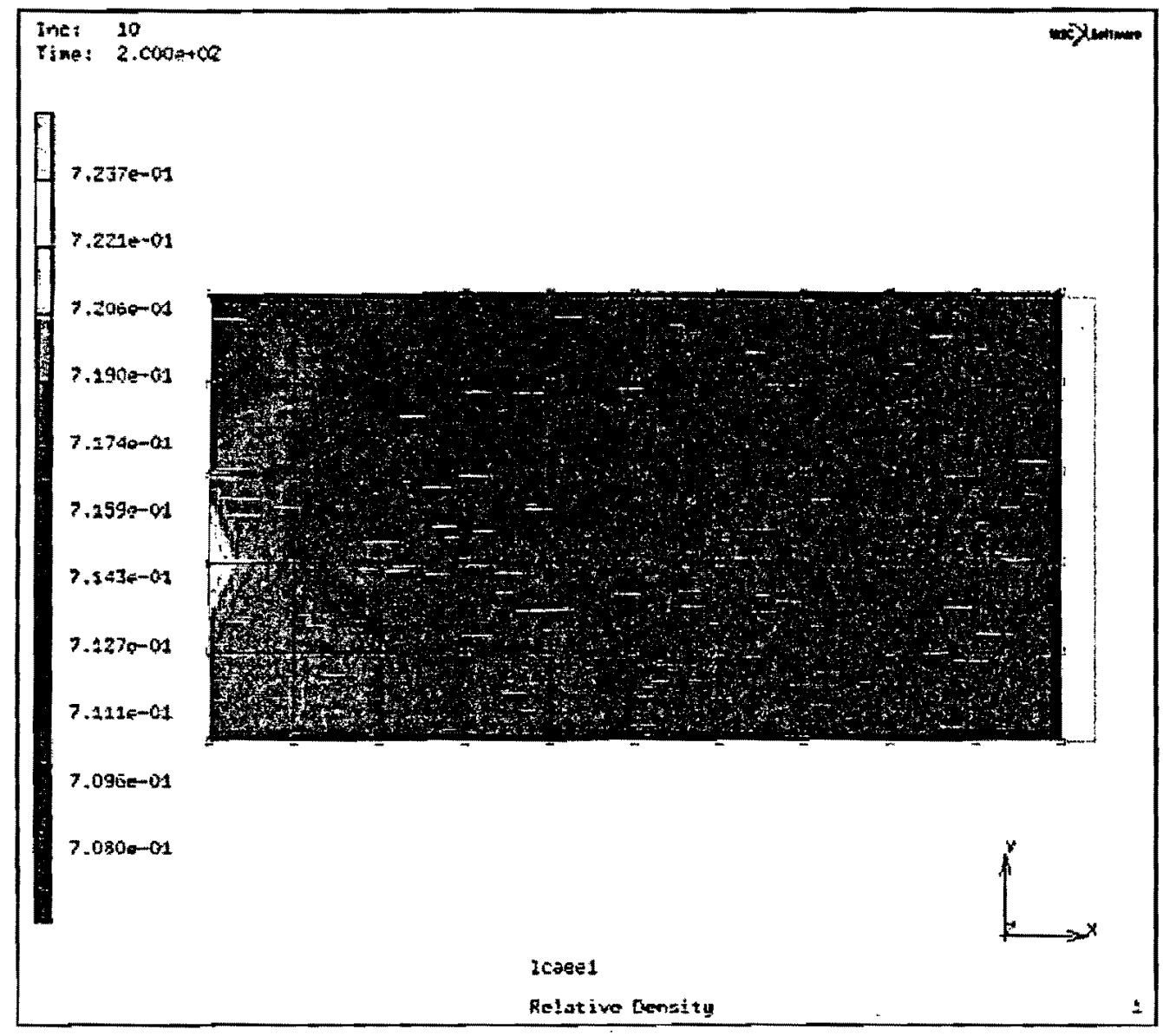

Figure 4.2: Relative Density Distribution of the Pressure Model 1 (at increment 10) as shown in Figure 4.1.

The timing information for this simulation is given in Table 4.1:

Table 4.1: Timing Information for Pressure Model 1

\begin{tabular}{|l|l|l|}
\hline Timing Information & Wall Time (in minutes) & CPU Time (in minutes) \\
\hline Total time for input & 0.02 & 0.02 \\
\hline Total time for stiffness assembly & 0.04 & 0.03 \\
\hline Total time for stress recovery & 0.02 & 0.01 \\
\hline Total time for matrix solution & 0.02 & 0.00 \\
\hline Total time for output & 0.40 & 0.06 \\
\hline Total time for miscellaneous & 0.57 & 0.12 \\
\hline Total time & 1.07 & 0.24 \\
\hline
\end{tabular}


2. CASE 2: This is the same model as the previous one, except the loading. The powder is compacted by an edge load of $8000 \mathrm{~N} / \mathrm{mm}^{2}$ in 4400 seconds and then released in another 4320 seconds. Refer Figure 4.3 to 4.7 . As expected the powder expands laterally and there is practically no significant relative density variation $(0.888$ to 0.889 when compacted at increment $20 \& 0.783$ to 0.784 when load released at increment 40 ). The final density is almost constant.

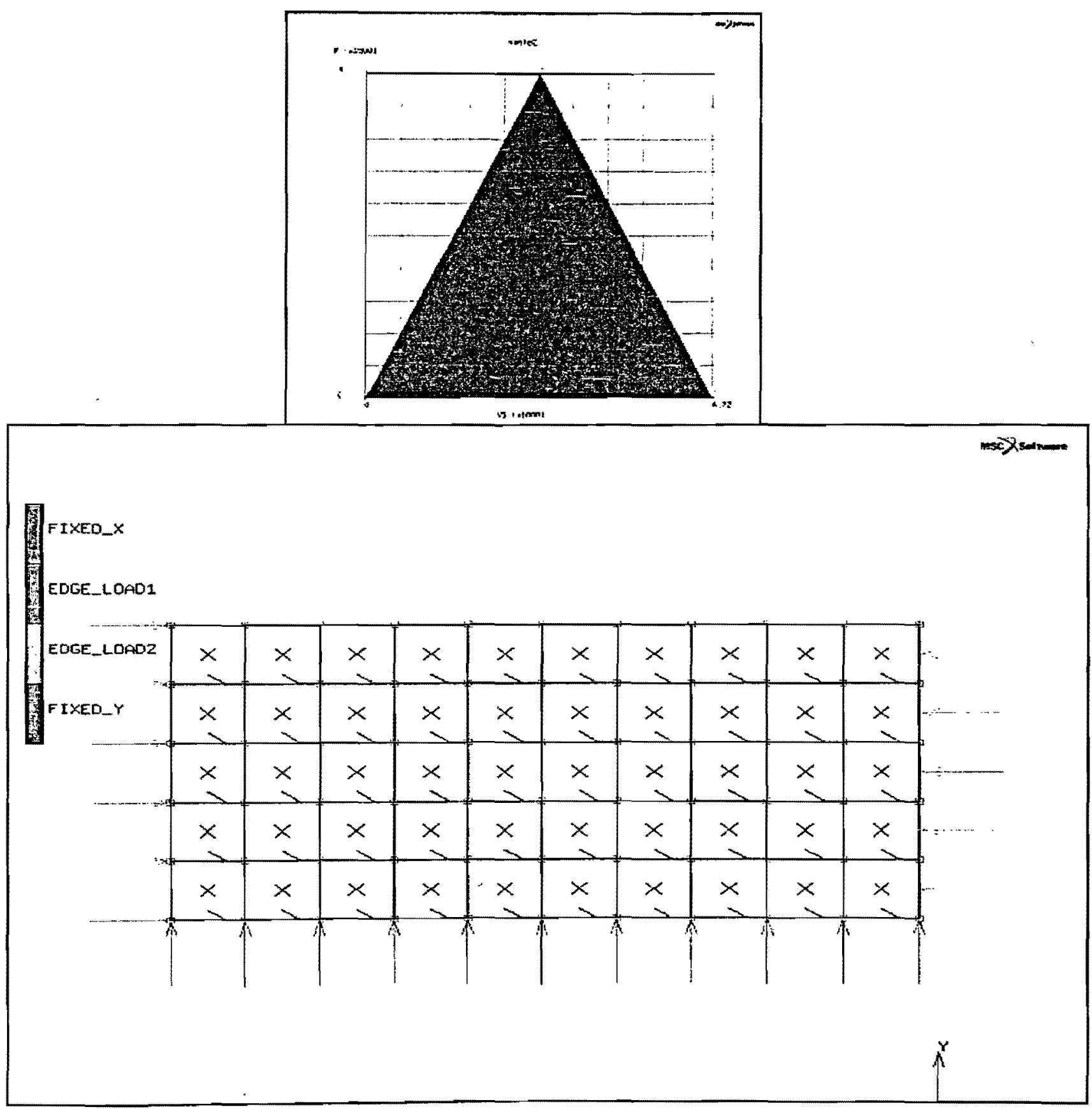

Figure 4.3: Pressure Model 2- Edge Load of $8000 \mathrm{~N} / \mathrm{mm}^{2}$ applied on RH WALL in 4400 seconds and then released in 4320 seconds. 
Figure 4.4 shows the relative density distribution of the Pressure Model 2 at time increment 10 (i.e. at 2200 seconds). The density varies from 0.7981 to 0.7983 which is of very small significance.

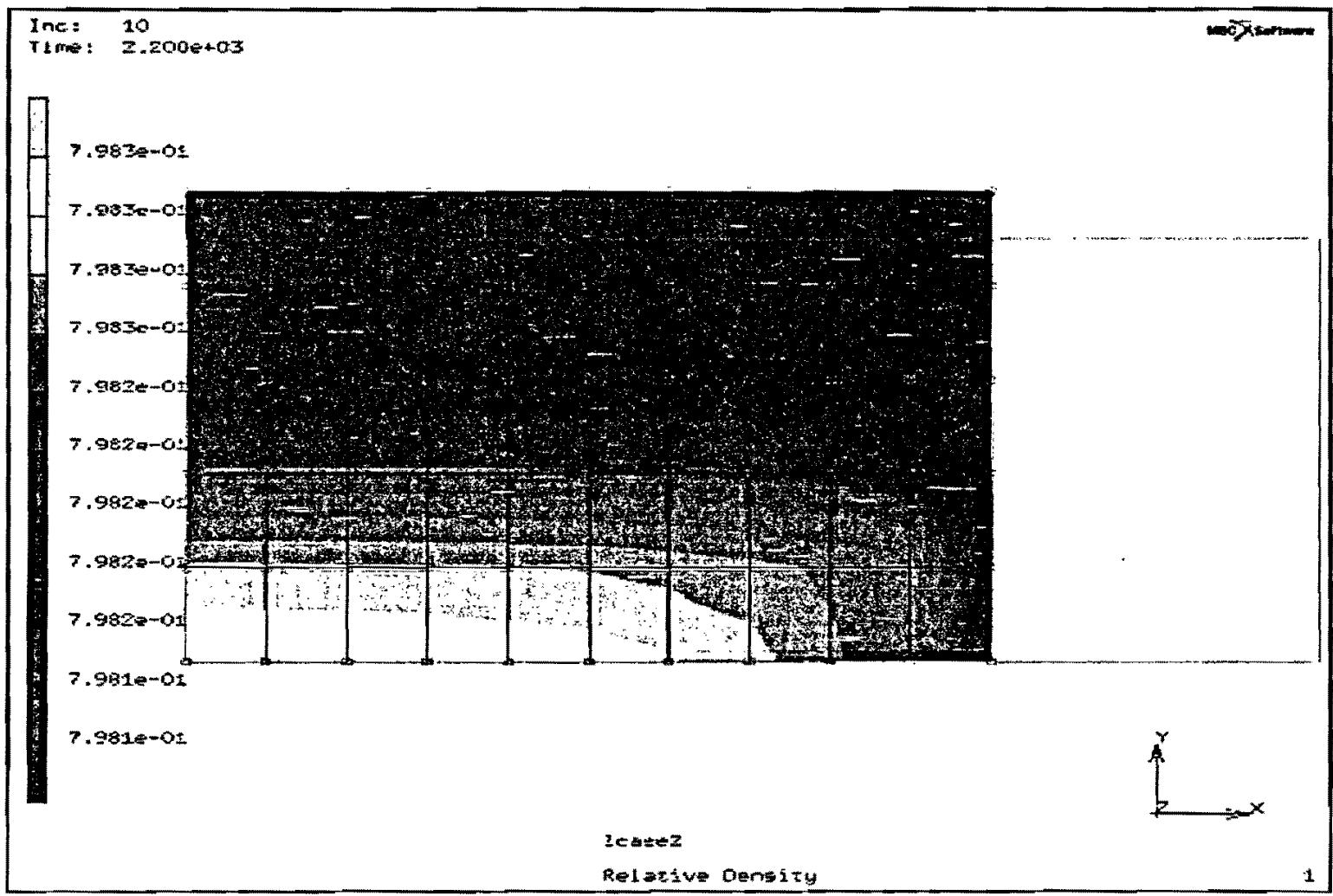

Figure 4.4: Relative Density Distribution of the Pressure Model 2 (at increment 10) as shown in Figure 4.3.

The timing information for this simulation is given in Table 4.2:

Table 4.2: Timing Information for Pressure Model 2

\begin{tabular}{|l|l|l|}
\hline Timing Information & Wall Time (in minutes) & CPU Time (in minutes) \\
\hline Total time for input & 0.03 & 0.01 \\
\hline Total time for stiffness assembly & 0.18 & 0.18 \\
\hline Total time for stress recovery & 0.12 & 0.06 \\
\hline Total time for matrix solution & 0.04 & 0.07 \\
\hline Total time for output & 1.64 & 0.17 \\
\hline Total time for miscellaneous & 0.61 & 0.15 \\
\hline Total time & 2.62 & 0.64 \\
\hline
\end{tabular}




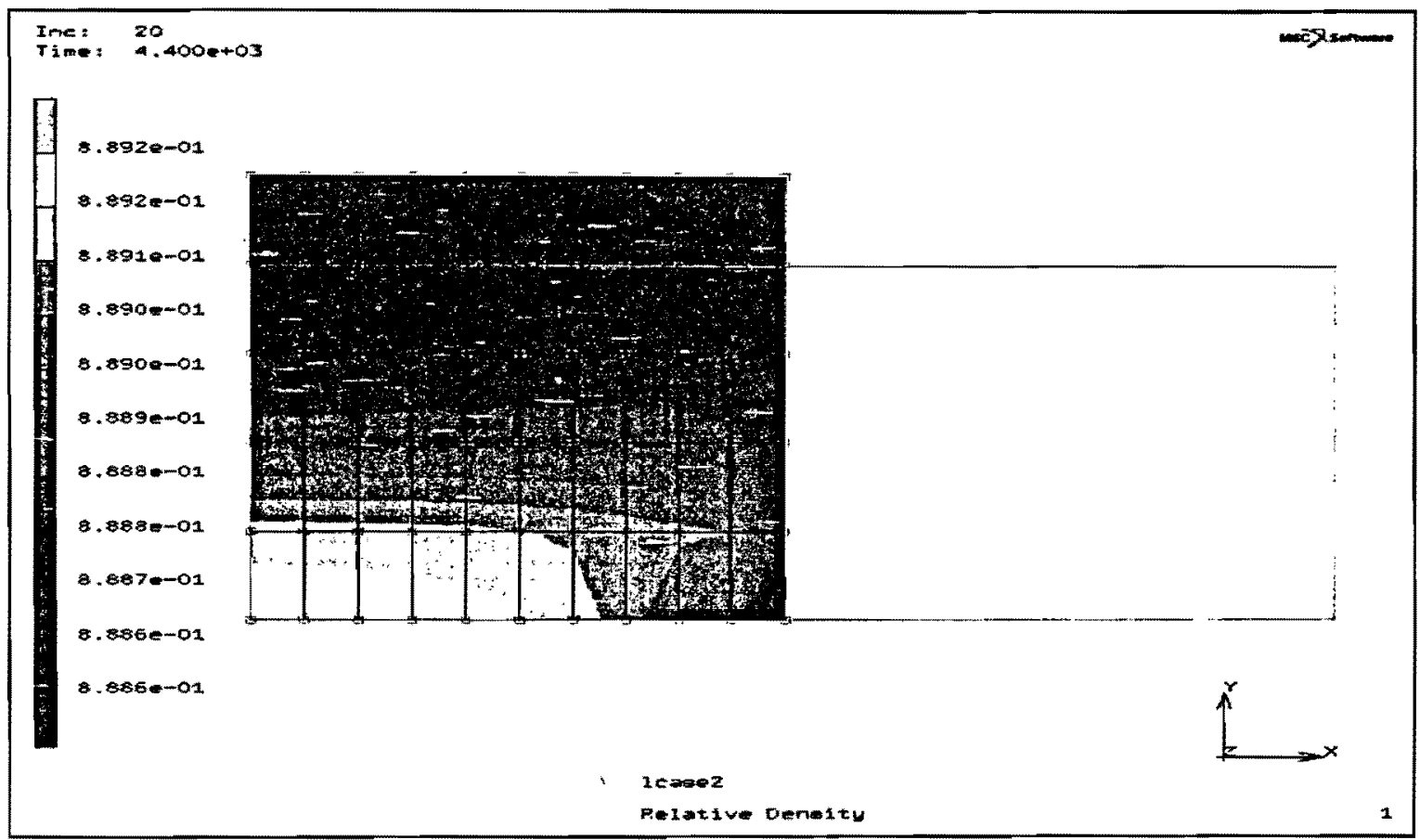

Figure 4.5: Relative Density Distribution of the Pressure Model 2 (at increment 20) as shown in Figure 4.3.

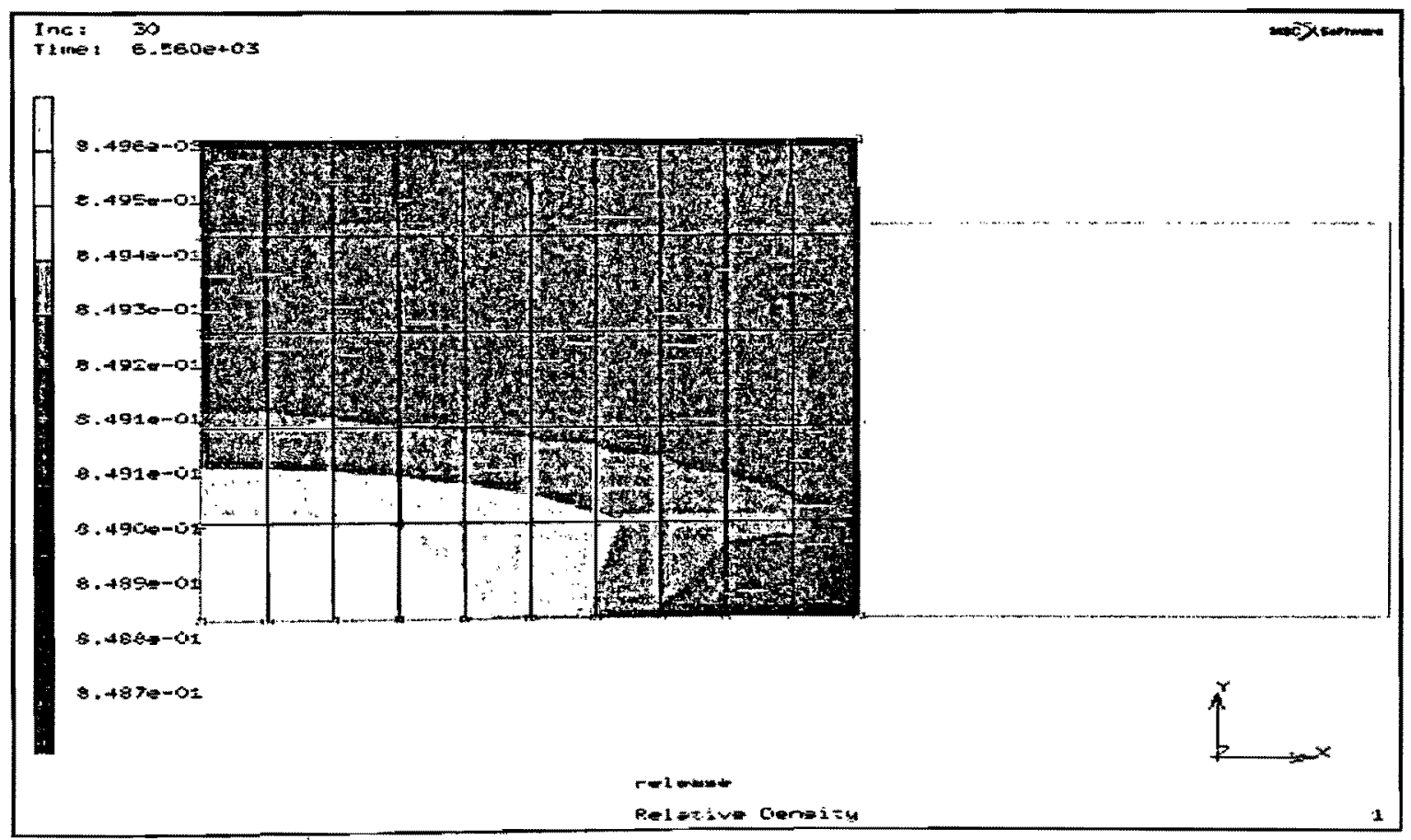

Figure 4.6: Relative Density Distribution of the Pressure Model 2 (at increment 30) as shown in Figure 4.3. 


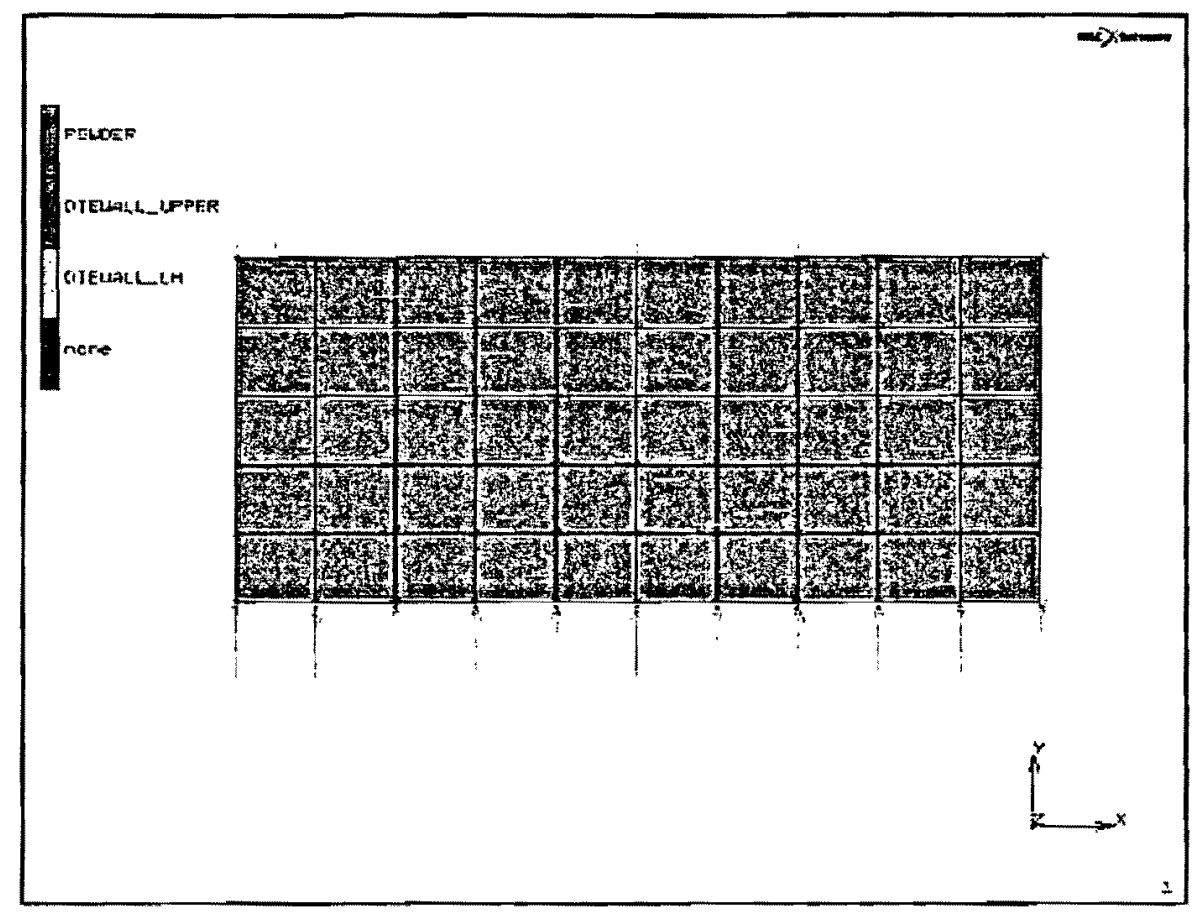

Figure 4.8: Pressure Model 3- Edge Load of $8000 \mathrm{~N} / \mathrm{mm}^{2}$ applied on RH WALL in 4400 seconds and then released in 4320 seconds with added Die-walls.

Figure 4.9 below shows that Pressure Model 3 has constant relative density (0.8373) at time increment 10 (i.e. at 2200 seconds).

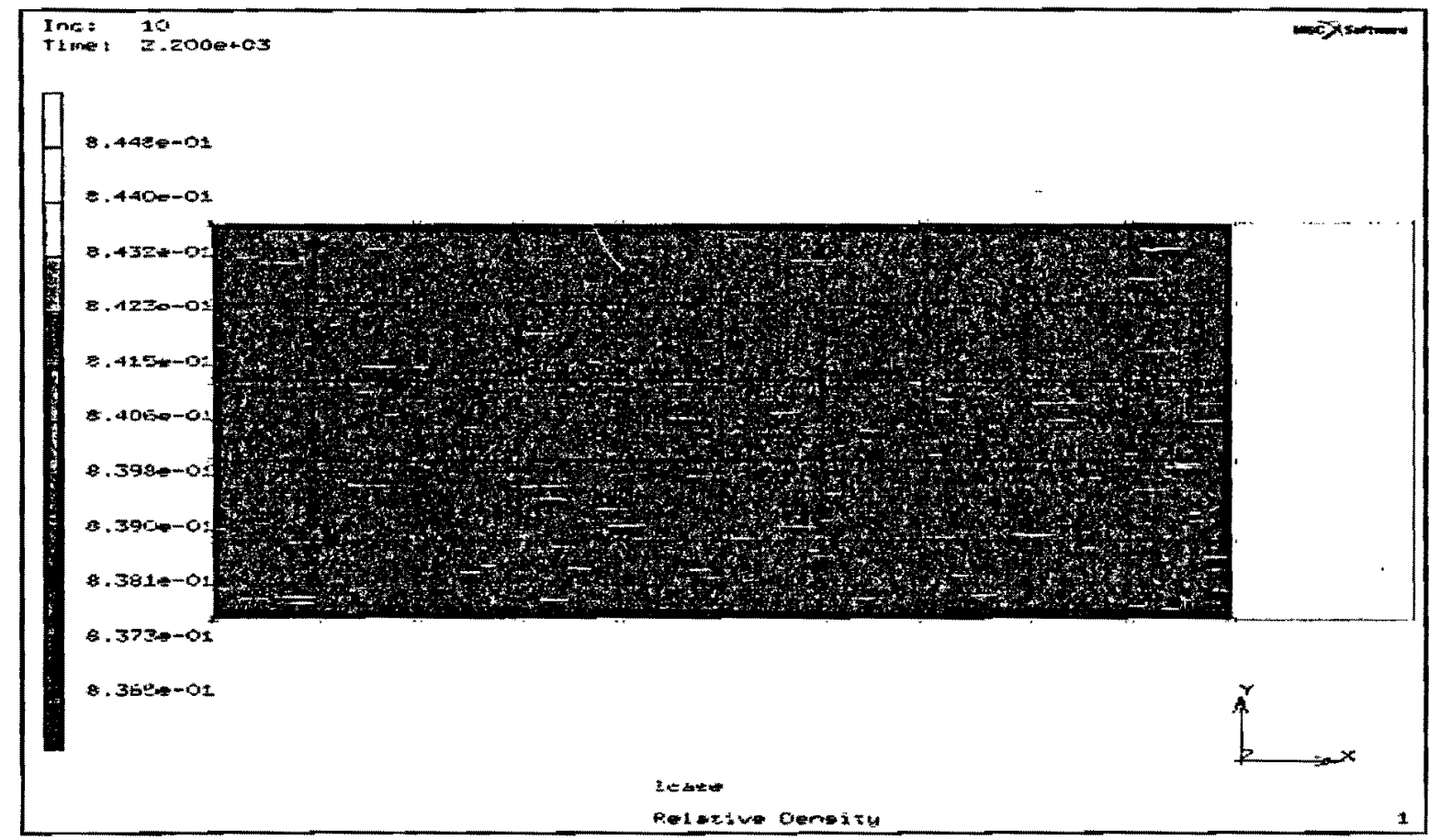

Figure 4.9: Relative Density Distribution of the Pressure Model 3 (at increment 10) as shown in Figure 4.8. 


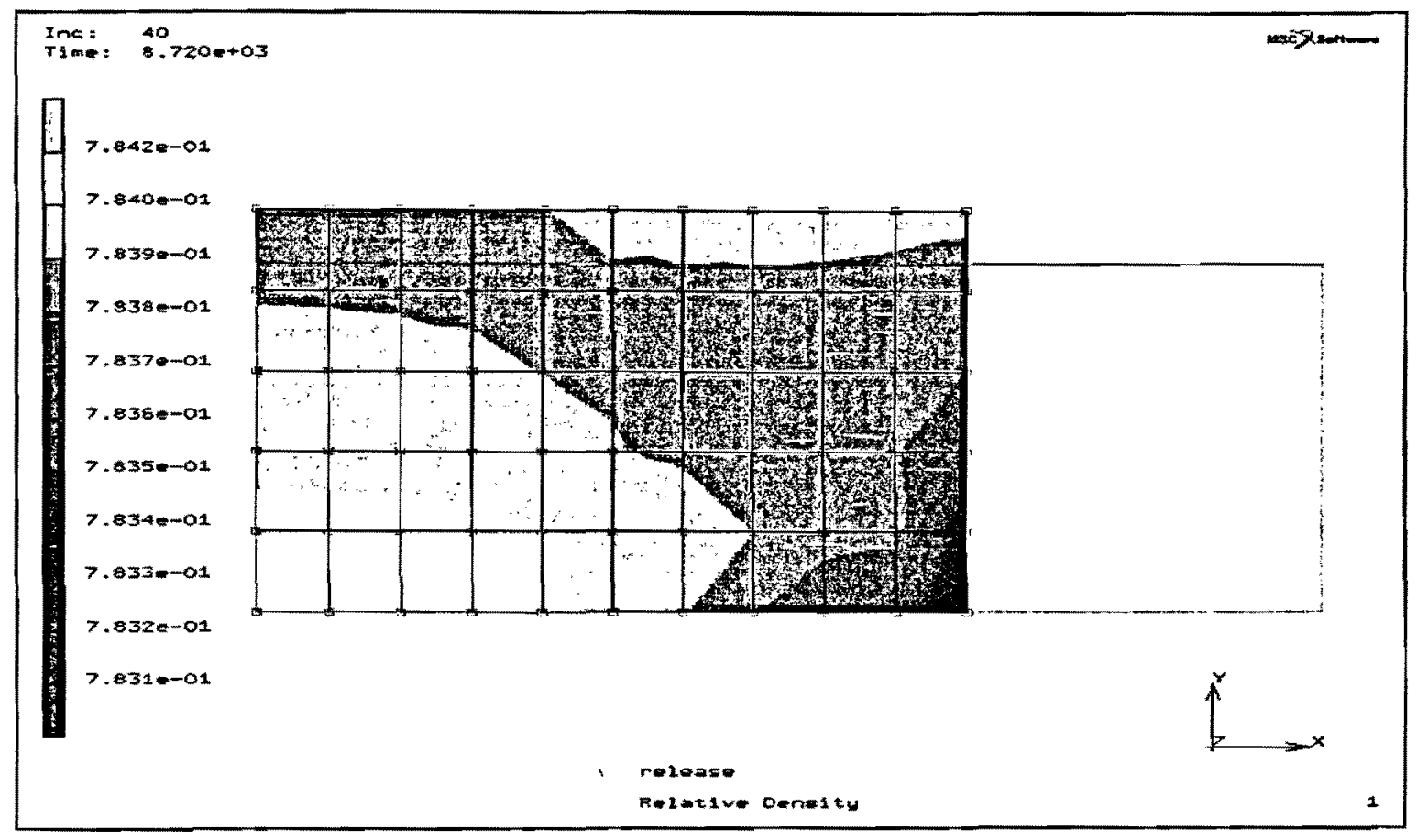

Figure 4.7: Relative Density Distribution of the Pressure Model 2 (at increment 40) as shown in Figure 4.3.

3. CASE 3: This is the same model as the previous one, except in that a die-wall has been added to the upper surface. Refer Figure 4.8 to 4.12 . In the absence of friction and due to the geometry of the die, the resulting relative density distribution is uniform as expected.

The timing information for this simulation is given in Table 4.3:

Table 4.3: Timing Information for Pressure Model 3

\begin{tabular}{|l|l|l|}
\hline Timing Information & Wall Time (in minutes) & CPU Time (in minutes) \\
\hline Total time for input & 0.04 & 0.03 \\
\hline Total time for stiffness assembly & 0.21 & 0.22 \\
\hline Total time for stress recovery & 0.10 & 0.05 \\
\hline Total time for matrix solution & 0.04 & 0.03 \\
\hline Total time for contact & 0.01 & 0.00 \\
\hline Total time for output & 1.62 & 0.17 \\
\hline Total time for miscellaneous & 0.70 & 0.16 \\
\hline Total time & 2.73 & 0.66 \\
\hline
\end{tabular}




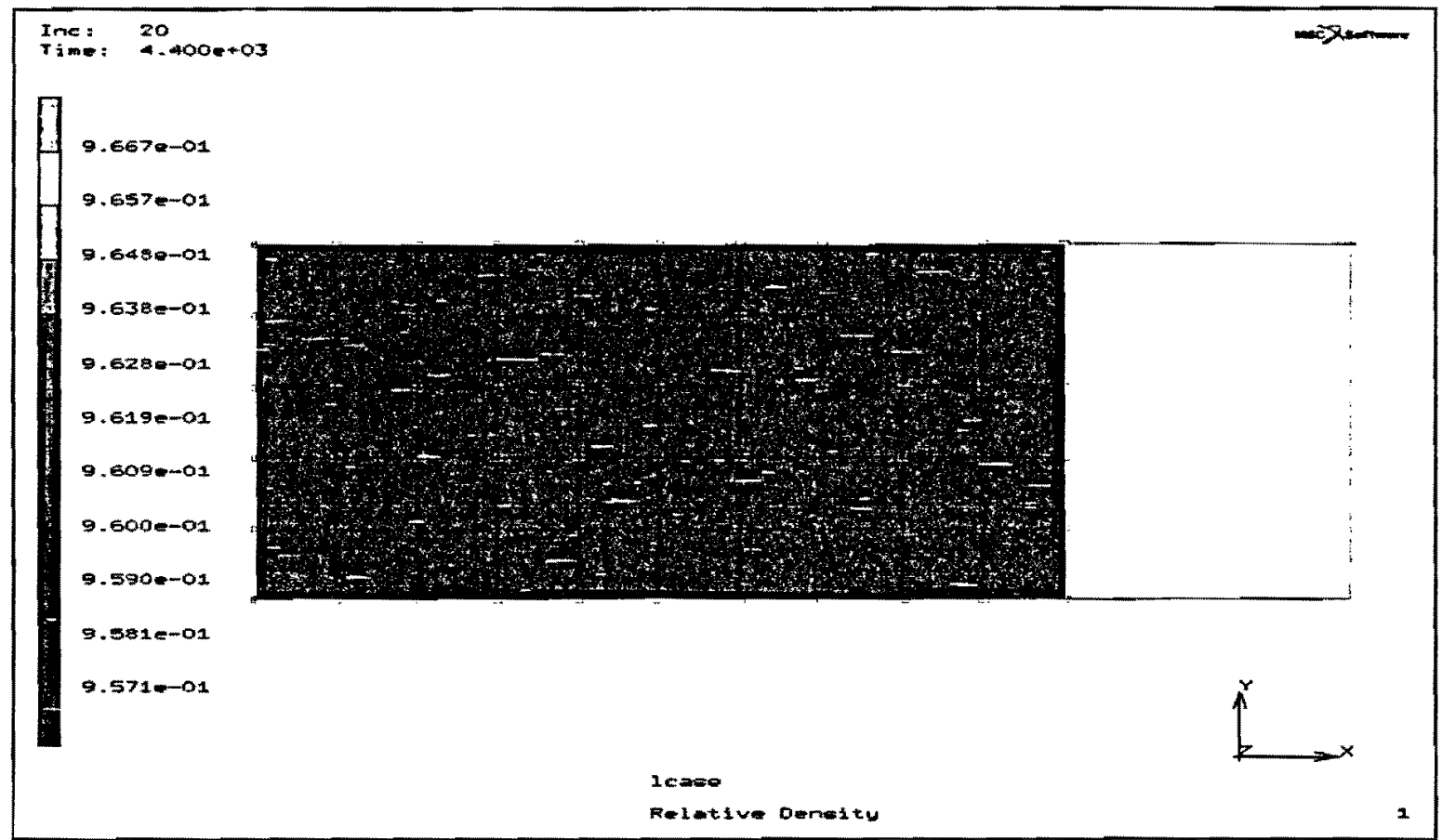

Figure 4.10: Relative Density Distribution of the Pressure Model 3 (at increment 20) as shown in Figure 4.8.

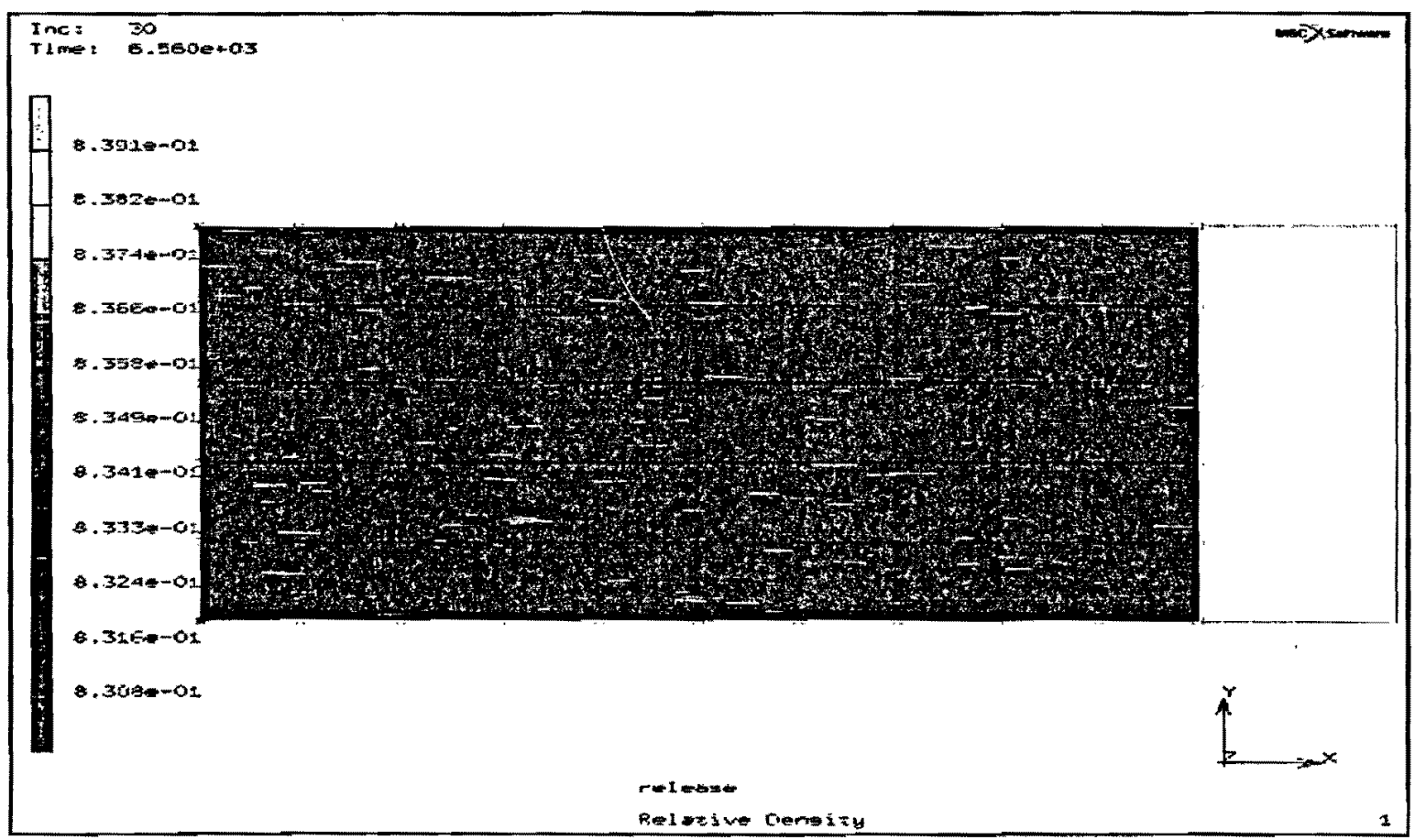

Figure 4.11: Relative Density Distribution of the Pressure Model 3 (at increment 30) as shown in Figure 4.8. 


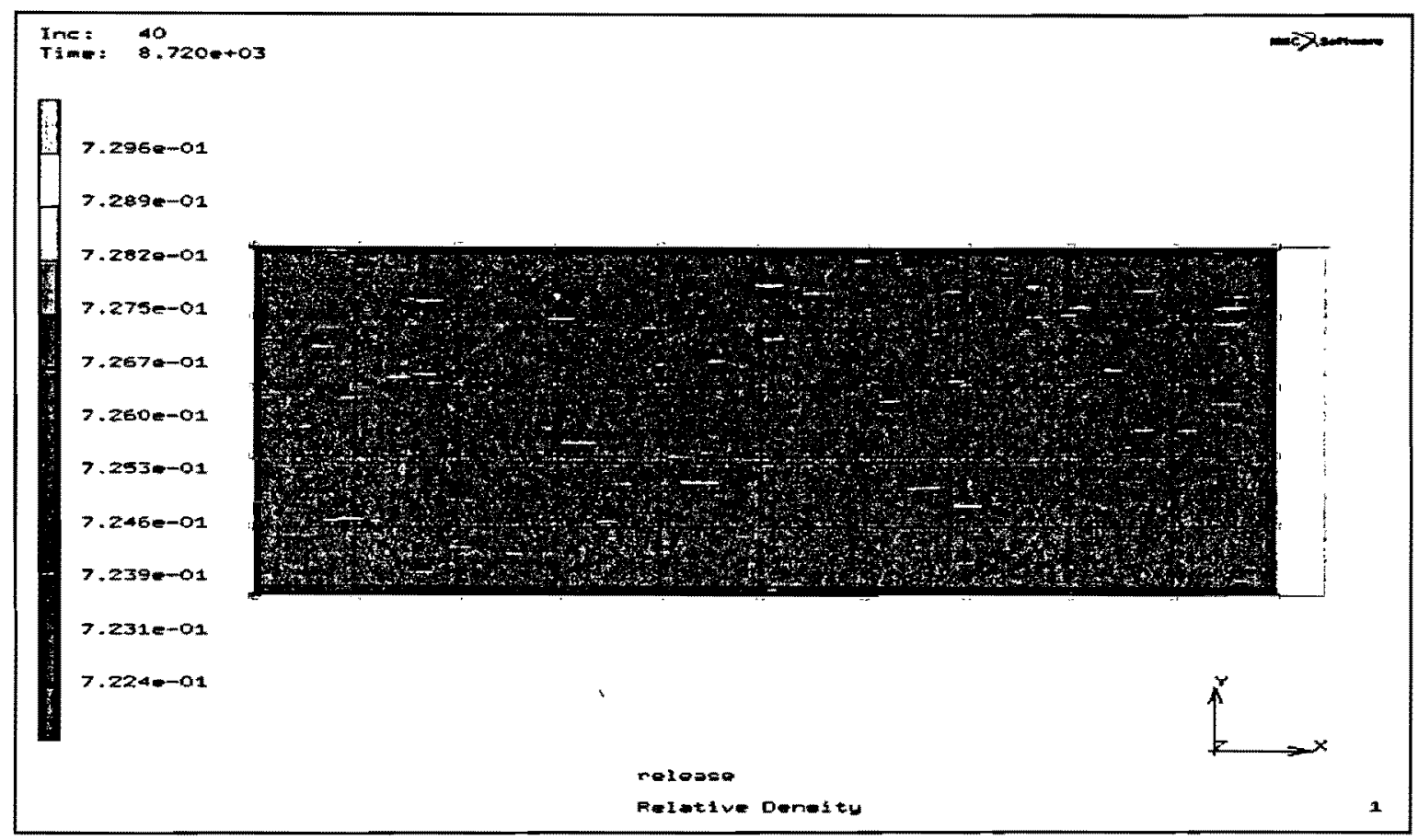

Figure 4.12: Relative Density Distribution of the Pressure Model 3 (at increment 40) as shown in Figure 4.8.

The relative density distribution for the Pressure Model 3 as shown in Figure 4.10, 4.11 and 4.12 reveals that the cylindrical green has constant density of $0.9581,0.8316$ and 0.7231 at time increment 20,30 and 40 respectively. The fact here is that there is no friction between the powder and the die-walls. The friction effect becomes apparent in case 4.

4. CASE 4: The effect of friction between the powder and the die-wall become apparent in Figures 4.13 to 4.16 (compare to Figures 4.9 to 4.12 ). It is important to note at this point the moving surface does not remain straight during loading. This does not correspond to the physics of the actual process where the moving surface is forced by the punch to remain straight. Here the relative density distribution is no longer uniform while loading and unloading. This problem was overcome by the use of displacement model later. 
The timing information for this simulation is given in Table 4.4:

Table 4.4: Timing Information for Pressure Model 4

\begin{tabular}{|l|l|l|}
\hline Timing Information & Wall Time (in minutes) & CPU Time (in minutes) \\
\hline Total time for input & 0.03 & 0.02 \\
\hline Total time for stiffness assembly & 0.40 & 0.39 \\
\hline Total time for stress recovery & 0.22 & 0.18 \\
\hline Total time for matrix solution & 0.11 & 0.12 \\
\hline Total time for contact & 0.03 & 0.00 \\
\hline Total time for output & 1.59 & 0.19 \\
\hline Total time for miscellaneous & 0.65 & 0.16 \\
\hline Total time & 3.03 & 1.06 \\
\hline
\end{tabular}

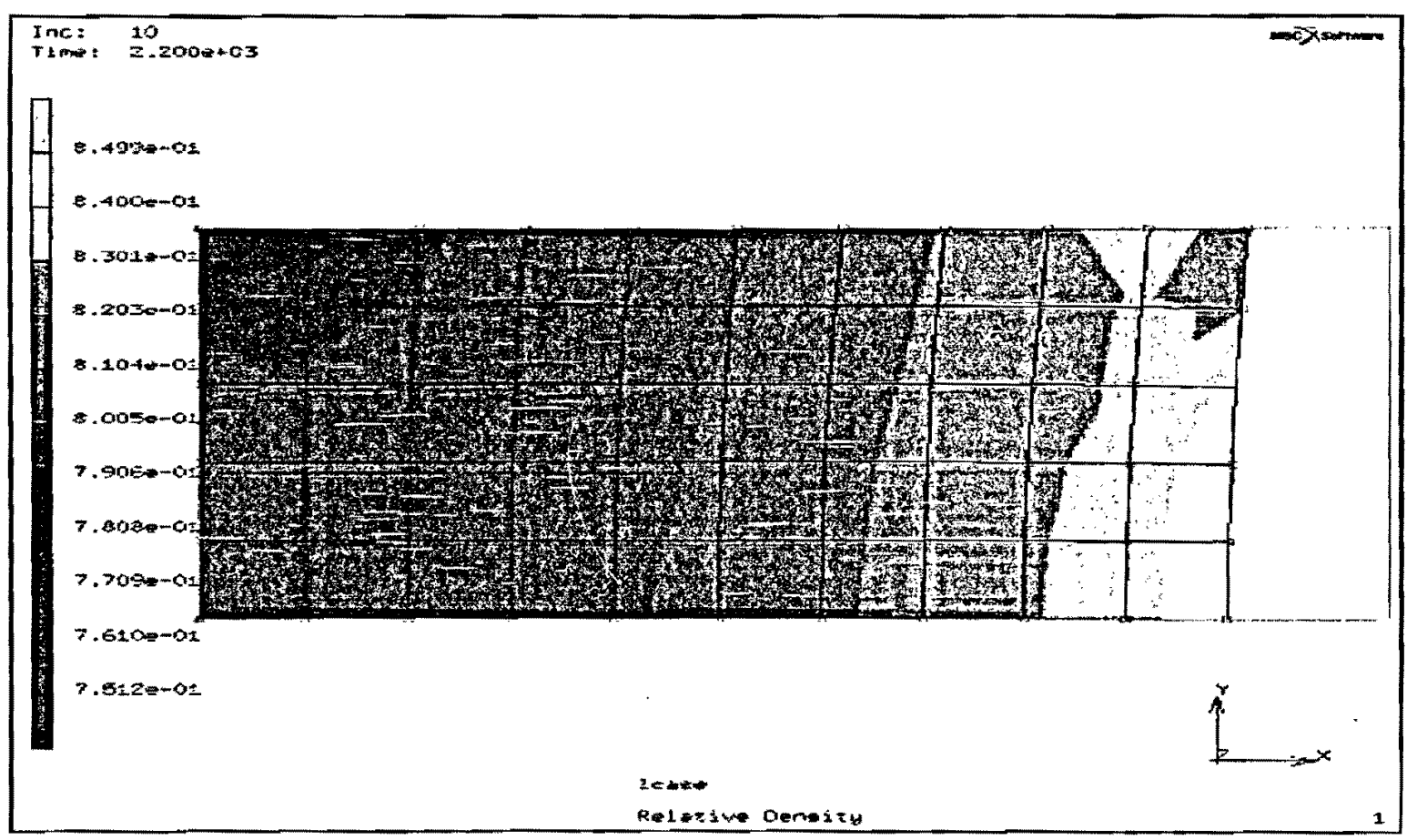

Figure 4.13: Pressure Model 4- Relative Density Distribution of the Pressure Model 3 (at increment 10 ) as shown in Figure 4.8 with Friction on the Die-walls. 


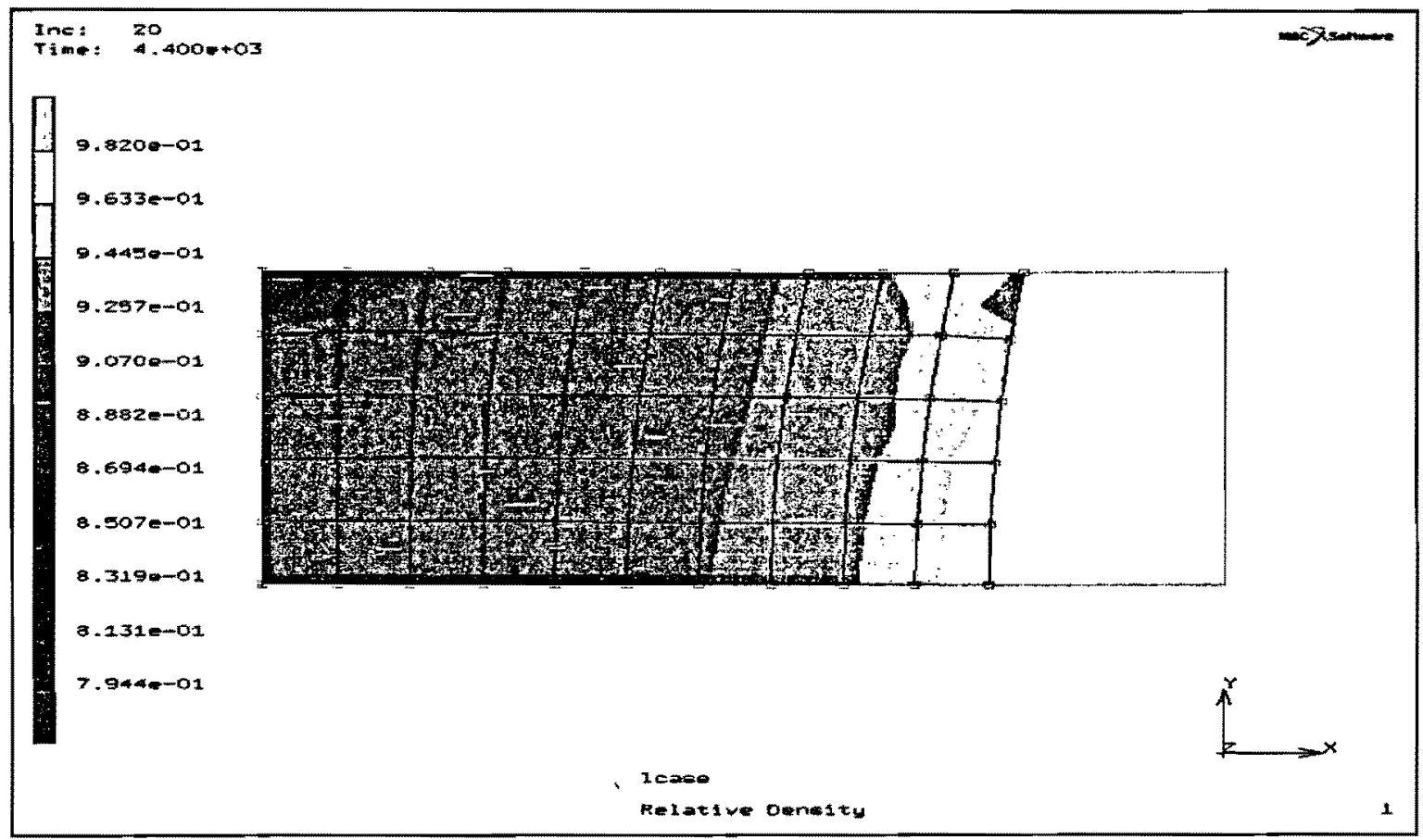

Figure 4.14: Relative Density Distribution of the Pressure Model 4 (at increment 20) as shown in Figure 4.13 with Friction on the Die-walls.

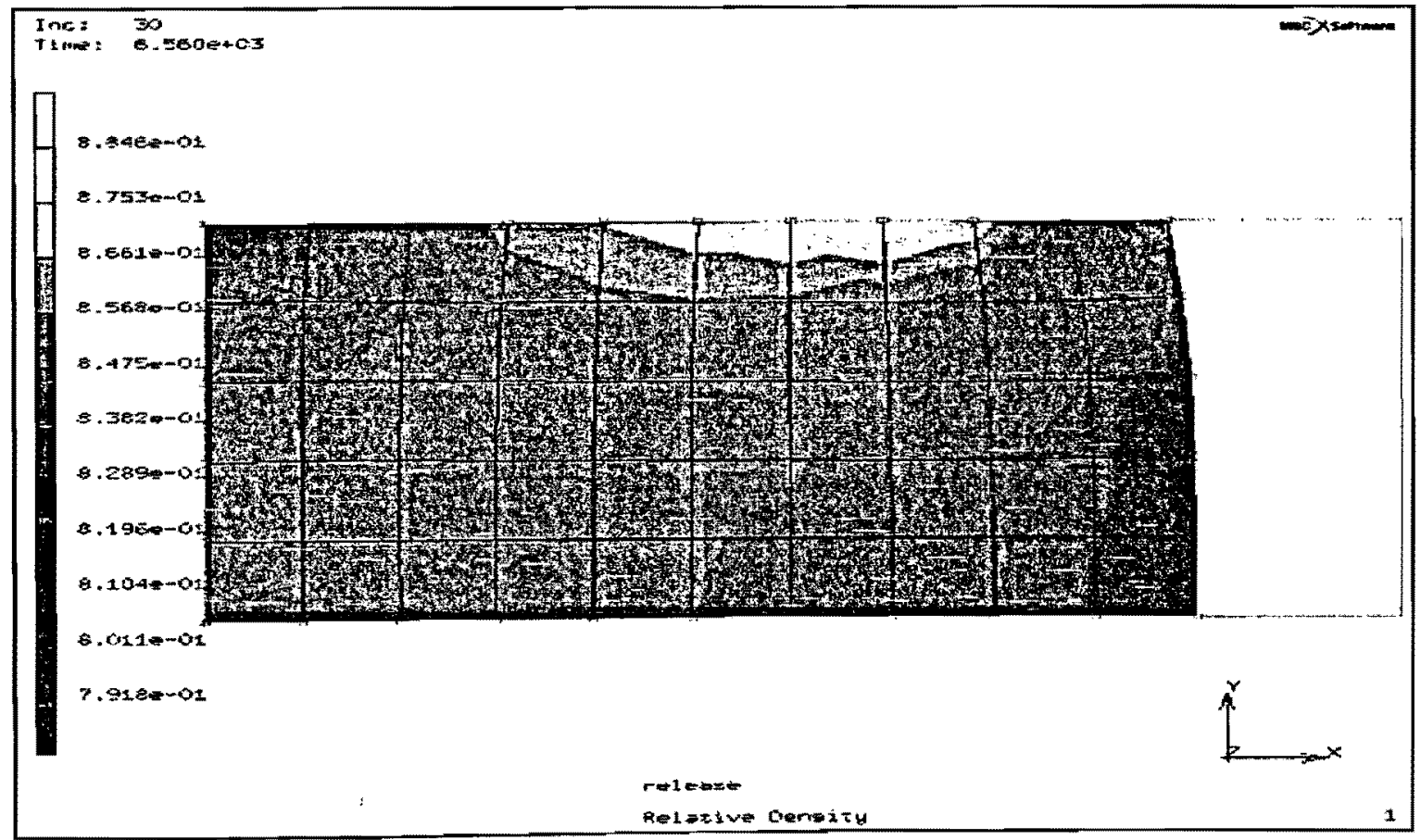

Figure 4.15: Relative Density Distribution of the Pressure Model 4 (at increment 30) as shown in Figure 4.13 with Friction on the Die-walls. 


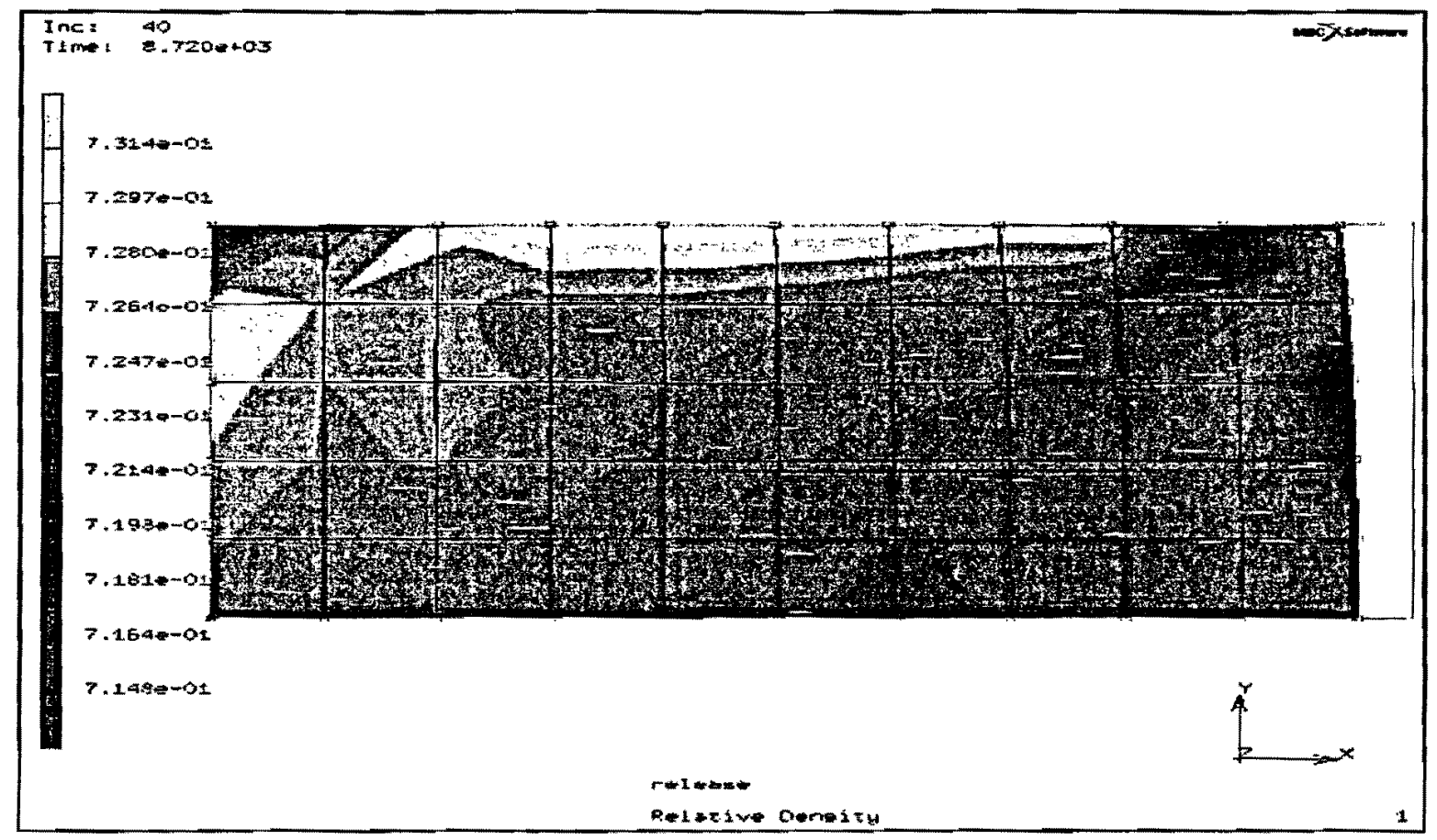

Figure 4.16: Relative Density Distribution of the Pressure Model 4 (at increment 40) as shown in Figure 4.13 with Friction on the Die-walls.

The relative density distribution for the Pressure Model 4 as shown in Figure 4.13 to Figure 4.16 shows that the variation is moderate i.e. from 0.7512 to 0.8400 , from 0.7944 to 0.9633 , from 0.7918 to 0.8846 and from 0.7148 to 0.7297 at time increment $10,20,30$ and 40 respectively. It is also noted here that the moving surface does not remain straight during loading, which violates the physics of the actual process. However, this problem is overcome by the displacement models.

\subsection{Cylindrical Displacement Models}

1. CASE 5: This is the displacement model with added die-walls where the friction is considered between the powder and the die-walls and also at the powder-punch interface. Refer Figure 4.17 to 4.21 . Here the powder is compacted by an incremental displacement of $2.4 \mathrm{~mm}$ in the -ve $\mathrm{x}$ direction with a single punch in 20 seconds and then released to $0.87 \mathrm{~mm}$ in another 20 seconds. The relative density of the green at radius $3 \mathrm{~mm}$ from the axis of symmetry varies reasonably (it varies from 0.899 to 0.962 at time step 20 ). 


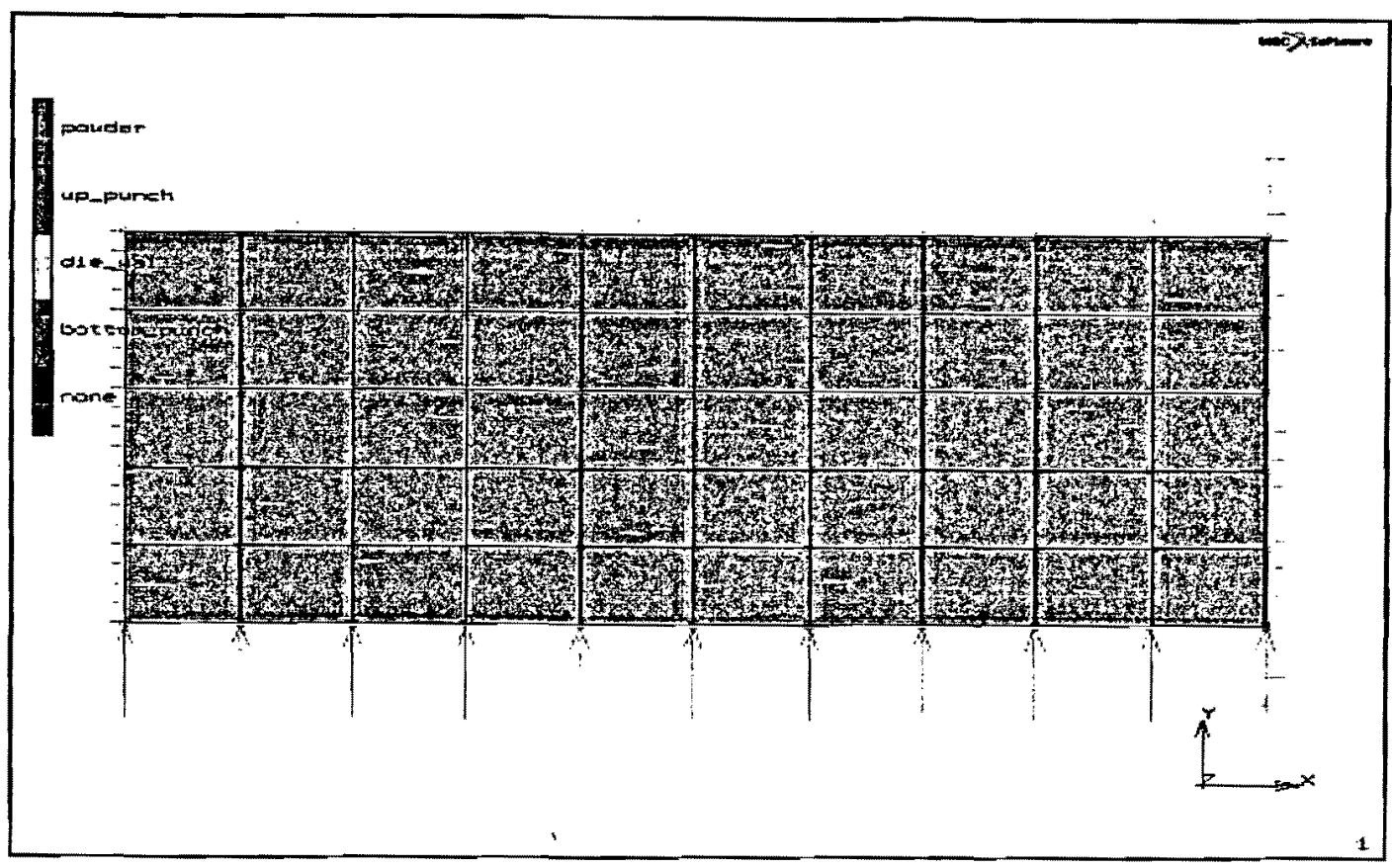

Figure 4.17: Displacement Model 1- Incremental Displacement of $2.4 \mathrm{~mm}$ applied in -ve $\mathrm{x}$ direction with a Single-Punch in 20 seconds and then released to $0.87 \mathrm{~mm}$ in another 20 seconds.

The timing information for this simulation is given in Table 4.5:

Table 4.5: Timing Information for Displacement Model 1

\begin{tabular}{|l|l|l|}
\hline Timing Information & Wall Time (in minutes) & CPU Time (in minutes) \\
\hline Total time for input & 0.65 & 0.05 \\
\hline Total time for stiffness assembly & 0.61 & 0.35 \\
\hline Total time for stress recovery & 0.23 & 0.29 \\
\hline Total time for matrix solution & 0.31 & 0.06 \\
\hline Total time for contact & 0.03 & 0.02 \\
\hline Total time for output & 1.86 & 0.18 \\
\hline Total time for miscellaneous & 1.99 & 0.21 \\
\hline Total time & 5.69 & 1.16 \\
\hline
\end{tabular}




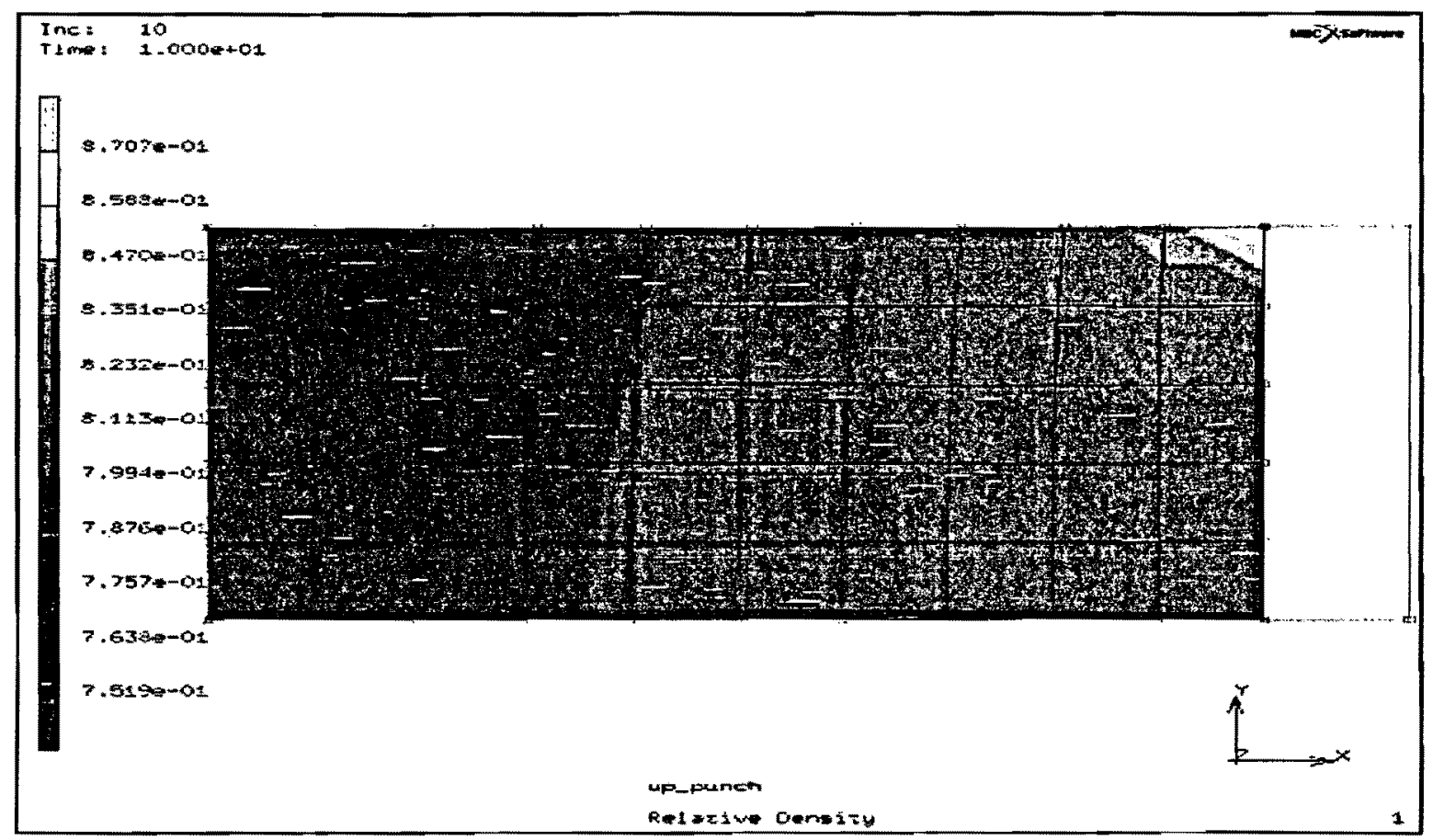

Figure 4.18: Relative Density Distribution of the Displacement Model 1 (at increment 10) as shown in Figure 4.17 with friction on the Die-walls and also at powder-punch interface.

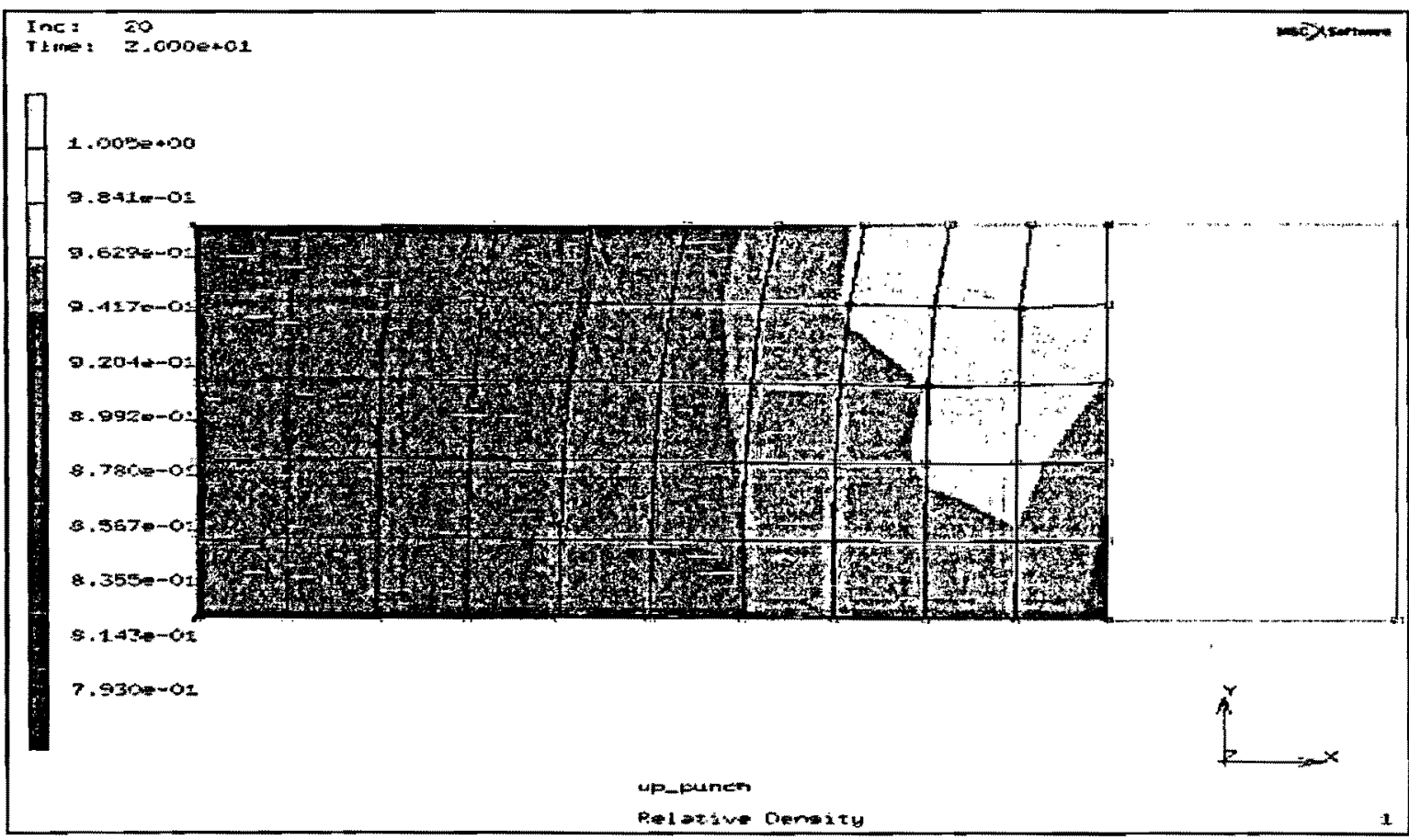

Figure 4.19: Relative Density Distribution of the Displacement Model 1 (at increment 20) as shown in Figure 4.17 with friction on the Die-walls and also at powder-punch interface. 


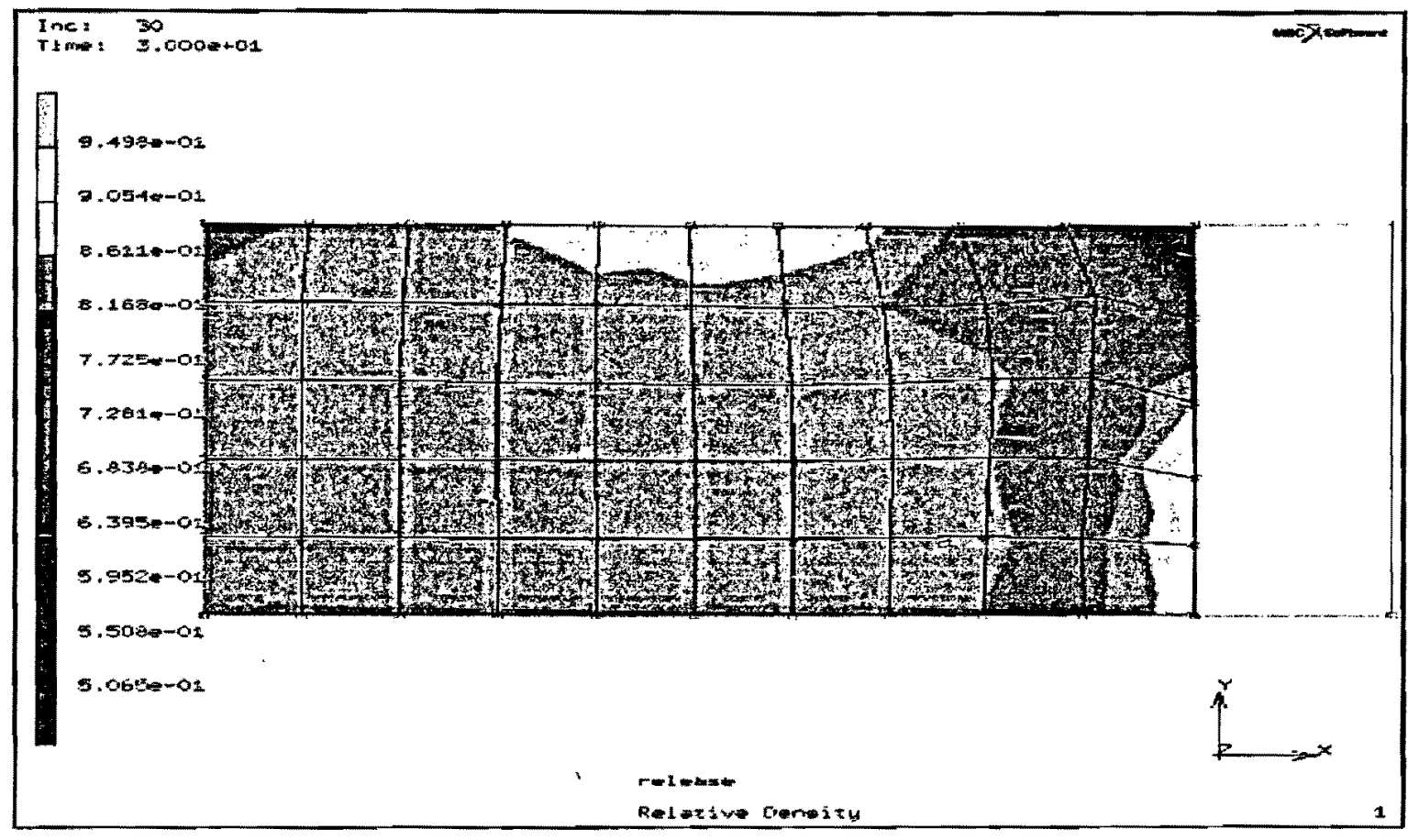

Figure 4.20: Relative Density Distribution of the Displacement Model 1 (at increment 30) as shown in Figure 4.17 with friction on the Die-walls and also at powder-punch interface.

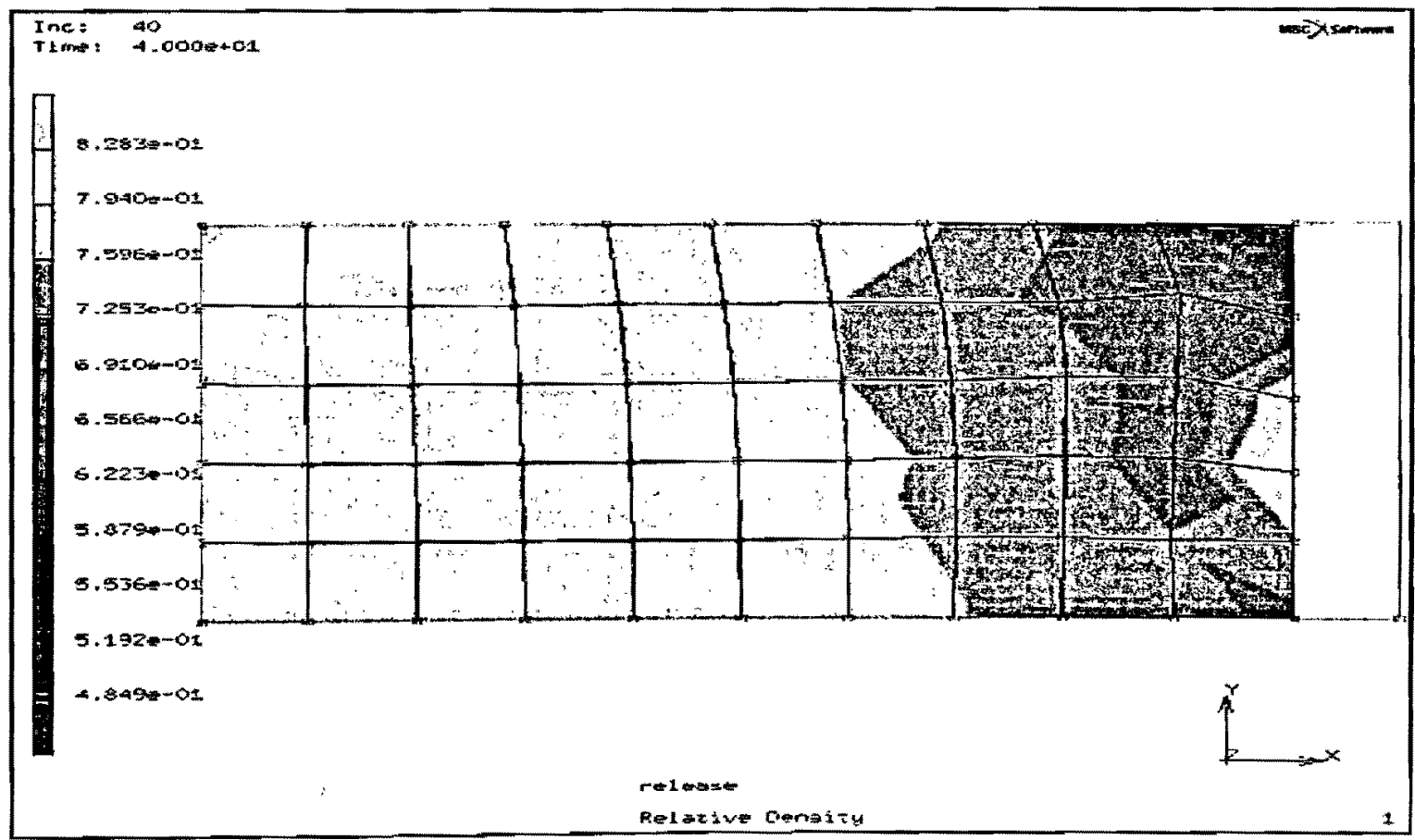

Figure 4.21: Relative Density Distribution of the Displacement Model 1 (at increment 40) as shown in Figure 4.17 with friction on the Die-walls and also at powder-punch interface. 
For the case of Cylindrical Displacement Model 1, Figure 4.18 to Figure 4.21 shows that the relative density varies from 0.7519 to 0.8588 (at time step 10), from 0.7930 to 0.9841 (at time step 20), from 0.5065 to 0.9054 (at time step 30) and from 0.4849 to 0.7940 (at time step 40 ). It is to be noted that the elements and the nodal points near the moving surface deform significantly due to friction at the powder-punch interface.

2. CASE 6: This Displacement Model 2 is the same model as the previous one except the friction here is ignored at the powder-punch interface. Refer Figure 4.22 to 4.25. It gives almost the similar density distribution as the previous case. One thing to be noted here is that the deformation of the elements and nodal points near the moving surface is reasonable whereas the deformation in the previous case was a bit significant.

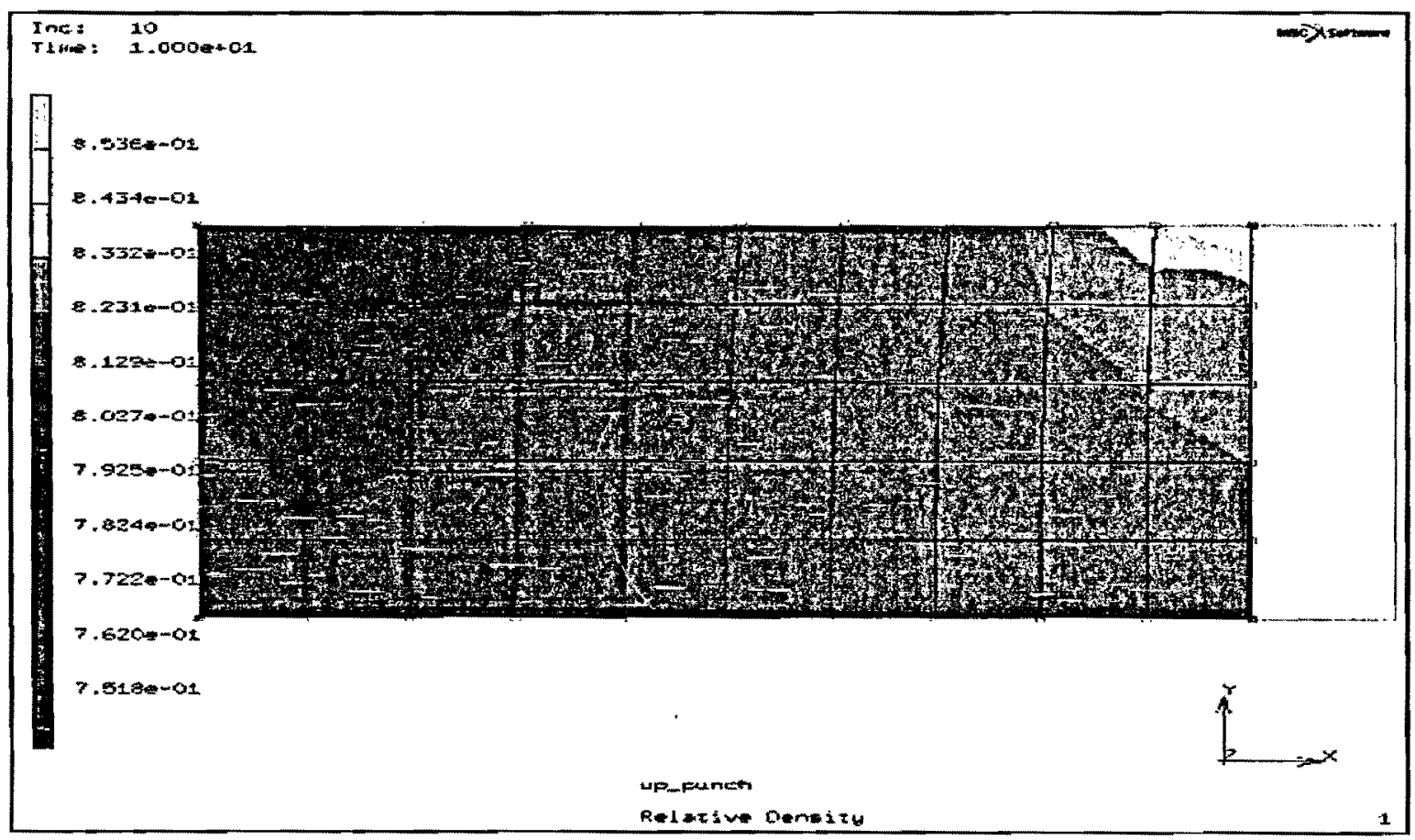

Figure 4.22: Displacement Model 2- Relative Density Distribution of the Displacement Model 1 (at increment 10) as shown in Figure 4.17 with Friction on the Die-walls only. 
The timing information for this simulation is given in Table 4.6:

Table 4.6: Timing Information for Displacement Model 2

\begin{tabular}{|l|l|l|}
\hline Timing Information & Wall Time (in minutes) & CPU Time (in minutes) \\
\hline Total time for input & 0.06 & 0.04 \\
\hline Total time for stiffness assembly & 0.59 & 0.32 \\
\hline Total time for stress recovery & 0.20 & 0.16 \\
\hline Total time for matrix solution & 0.31 & 0.04 \\
\hline Total time for contact & 0.03 & 0.00 \\
\hline Total time for output & 1.54 & 0.12 \\
\hline Total time for miscellaneous & 1.07 & 0.20 \\
\hline Total time & 3.80 & 0.88 \\
\hline
\end{tabular}

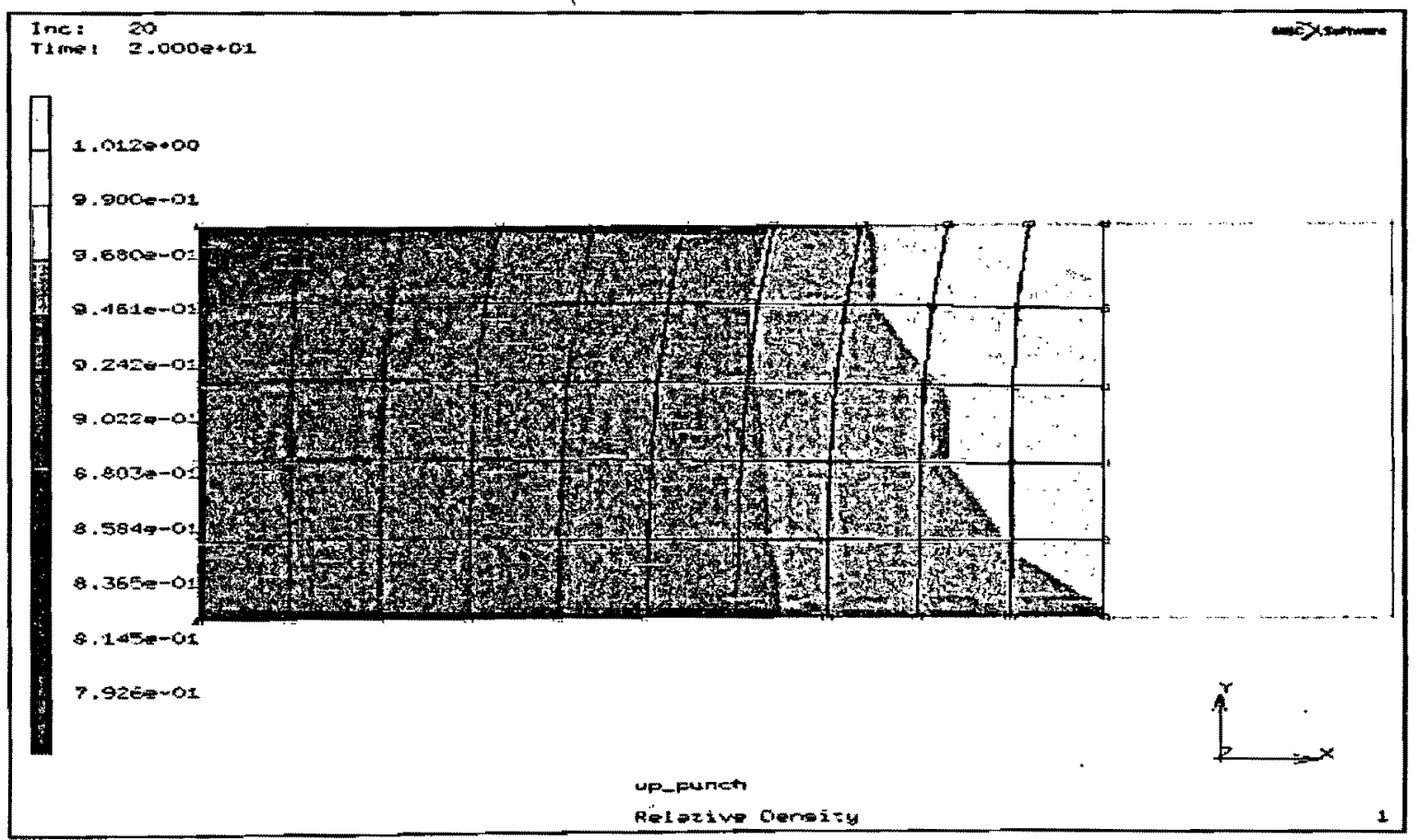

Figure 4.23: Relative Density Distribution of the Displacement Model 2 (at increment 20) as shown in Figure 4.22 with Friction on the Die-walls only. 


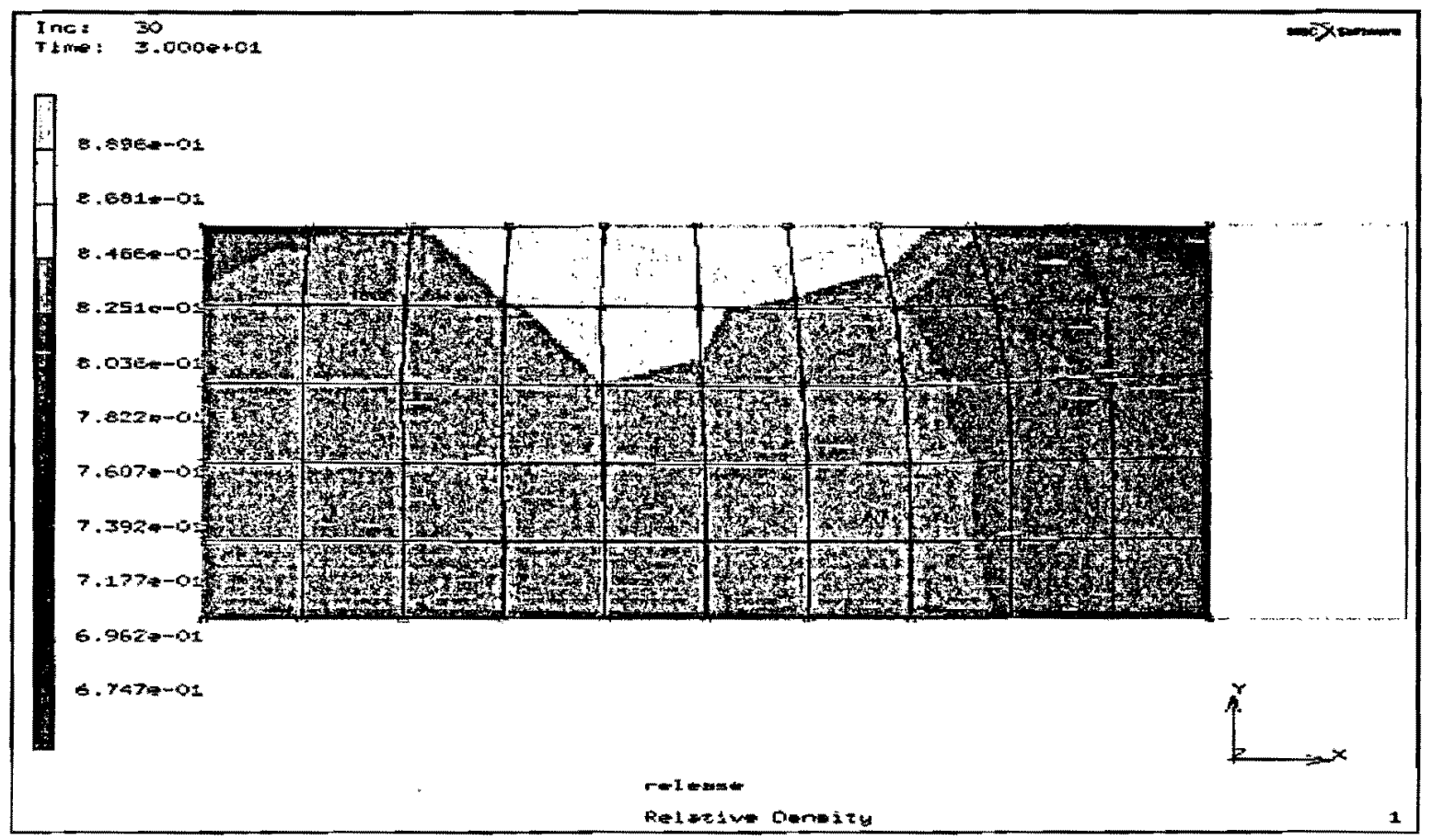

Figure 4.24: Relative Density Distribution of the Displacement Model 2 (at increment 30) as shown in Figure 4.22 with Friction on the Die-walls only.

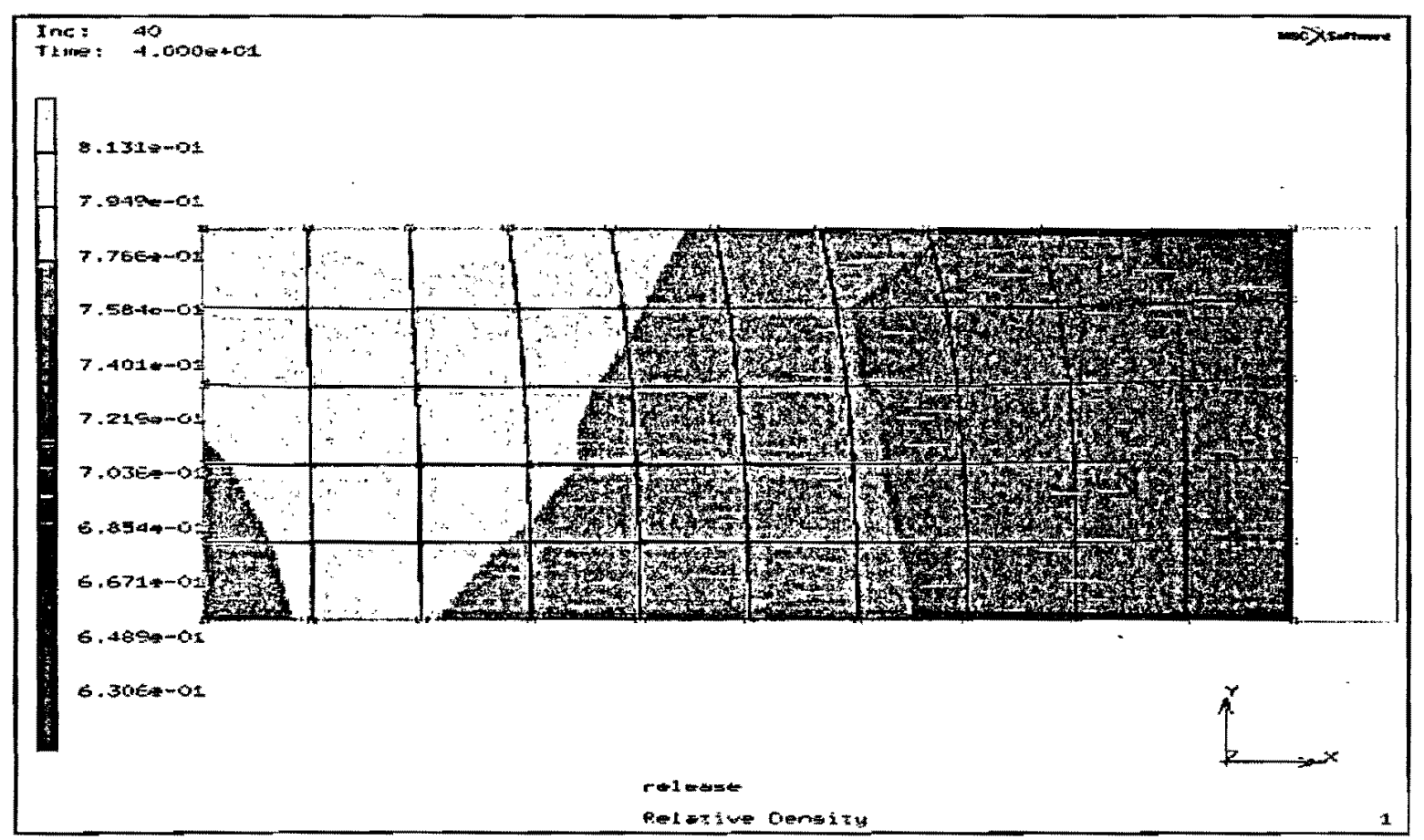

Figure 4.25: Relative Density Distribution of the Displacement Model 2 (at increment 40) as shown in Figure 4.22 with Friction on the Die-walls only. 
For the case of Cylindrical Displacement Model 2, Figure 4.22 to Figure 4.25 shows that the relative density varies from 0.7518 to 0.8536 (at time step 10), from 0.7926 to 0.9900 (at time step 20), from 0.6747 to 0.8651 (at time step 30) and from 0.6306 to 0.7949 (at time step 40).

The results from the aforementioned simulations (Figure 4.18 to Figure 4.25 ) show that the relative density is minimum in the corner furthest away from the center-line and the moving surface and maximum in the corner closest to the die-wall and moving surface. These results agree with observations made in practice.

\subsection{Stepped Cylindrical Displacement Models}

The capabilities of MSC_Marc are further tested by considering a more complex geometry of a cylindrical compact with a step. All simulations of this complex compact use the displacement model.

1. CASE 7: Here the number of elements is reduced to 40 . The powder is pressed using a single punch from RH edge by an incremental displacement of $1.2 \mathrm{~mm}$ in the -ve $\mathrm{x}$ direction in 20 seconds and then released to $0.44 \mathrm{~mm}$ in another 20 seconds. Refer Figures 4.26 to 4.30 . Friction is considered between the powder and all the contacting surfaces. As expected the resulting density distribution is not uniform due to complex geometry of the green compact.

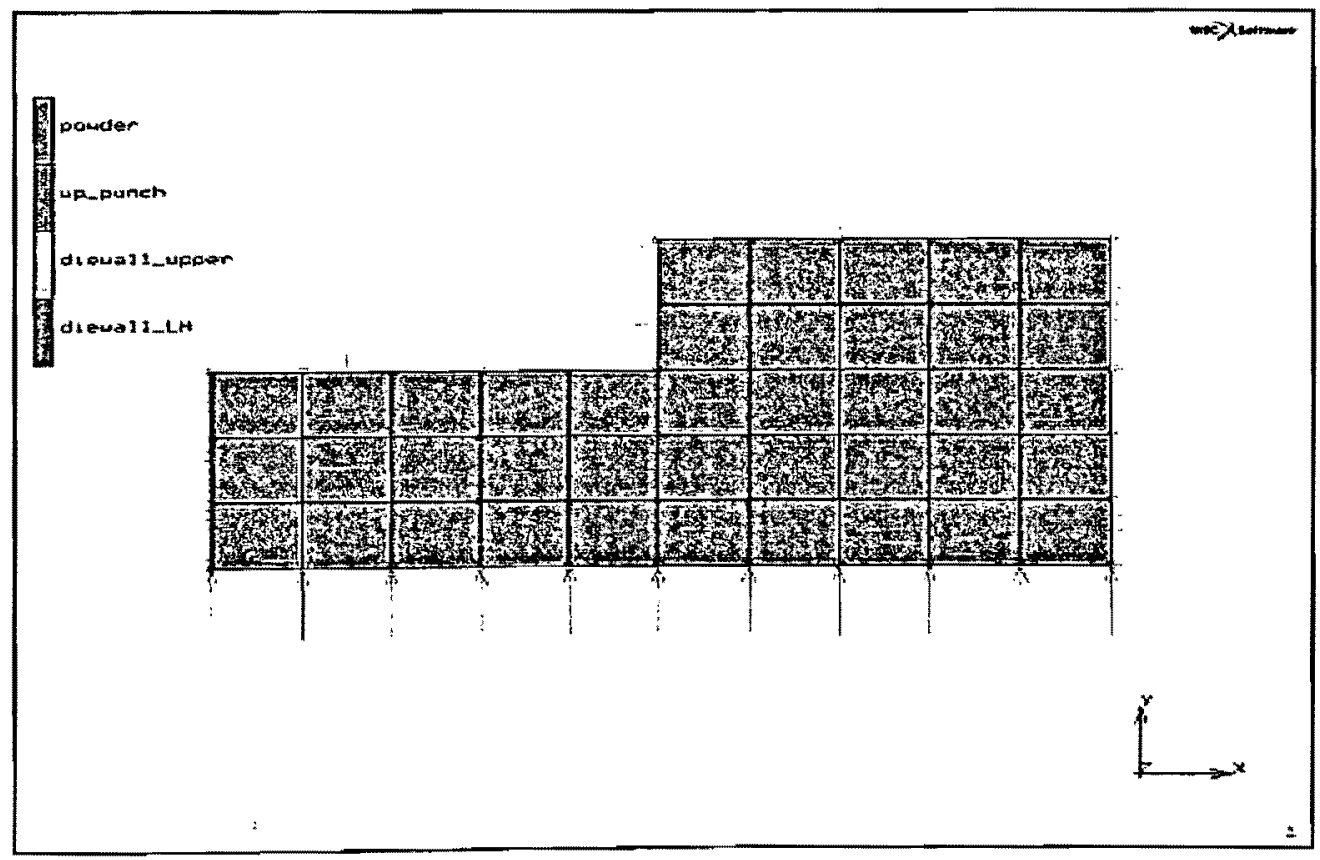

Figure 4.26: Stepped Cylindrical Model 1- Incremental Displacement of $1.2 \mathrm{~mm}$ applied in ve $x$ direction with a Single-Punch in 20 seconds and then released to $0.44 \mathrm{~mm}$ in another 20 seconds. 


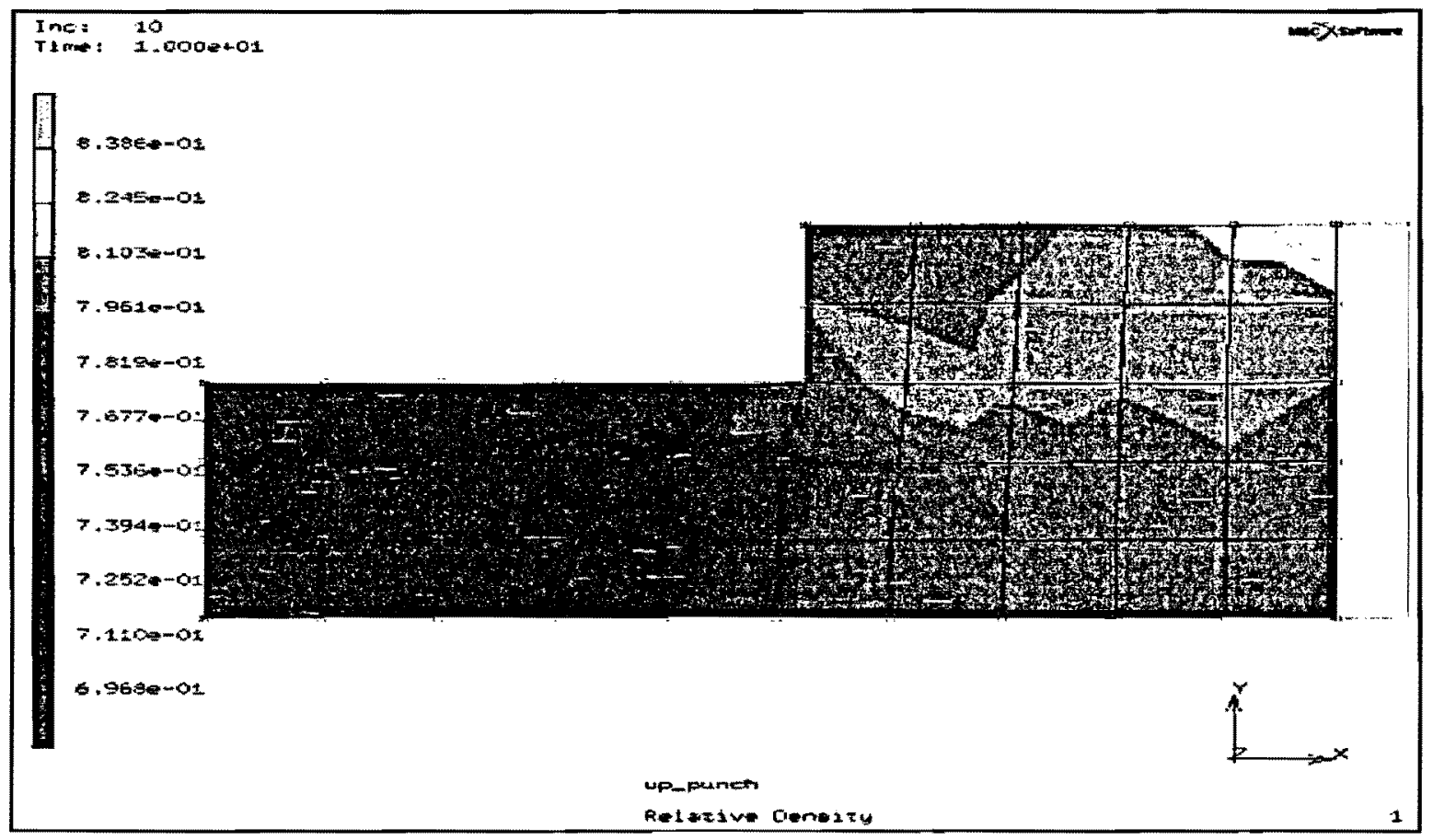

Figure 4.27: Relative Density Distribution of the Stepped Cylindrical Model 1(at increment 10 ) as shown in Figure 4.26 with Friction on the Die-walls and also at Powder-Punch interface.

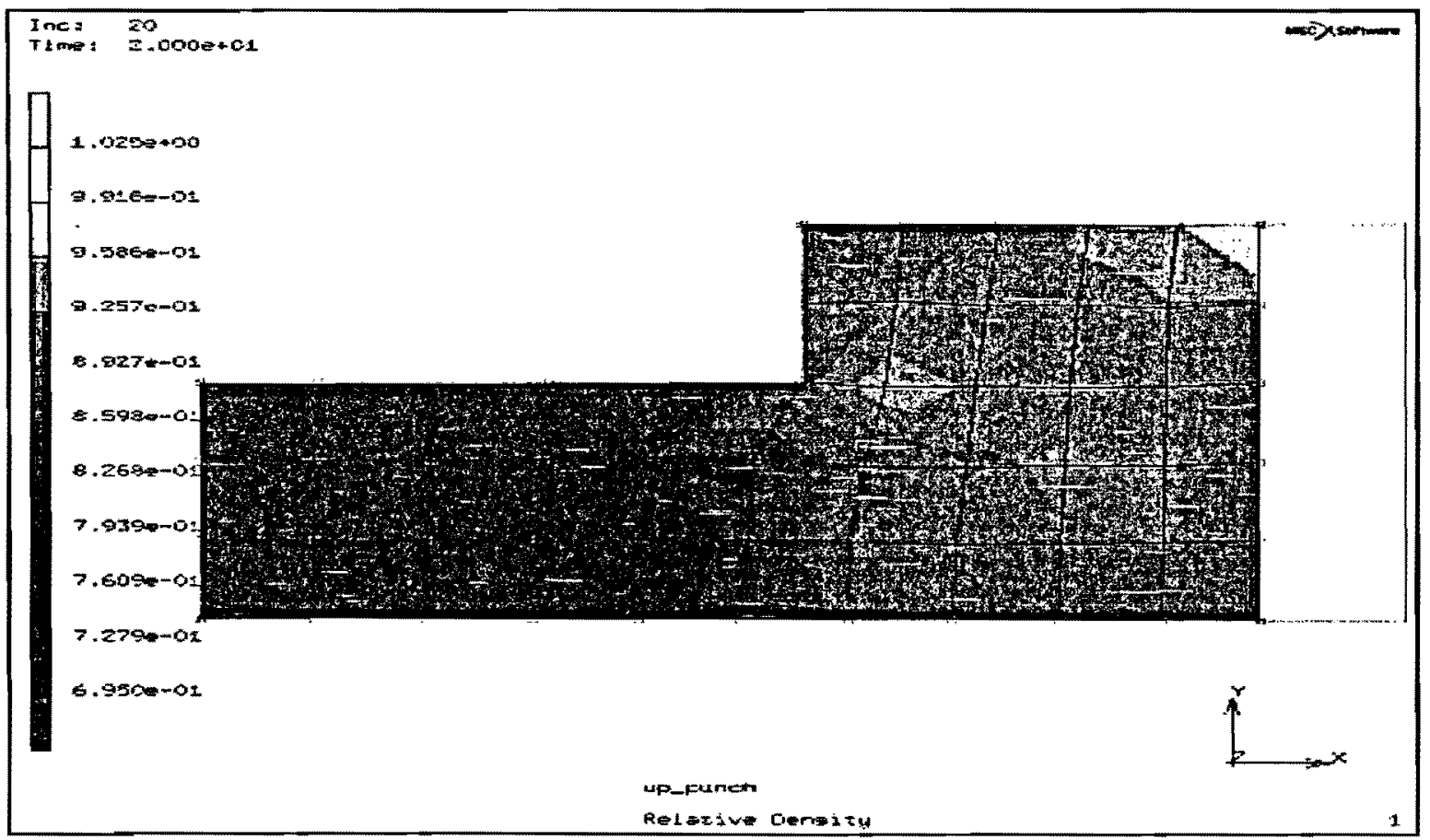

Figure 4.28: Relative Density Distribution of the Stepped Cylindrical Model 1(at increment 20 ) as shown in Figure 4.26 with Friction on the Die-walls and also at Powder-Punch interface. 


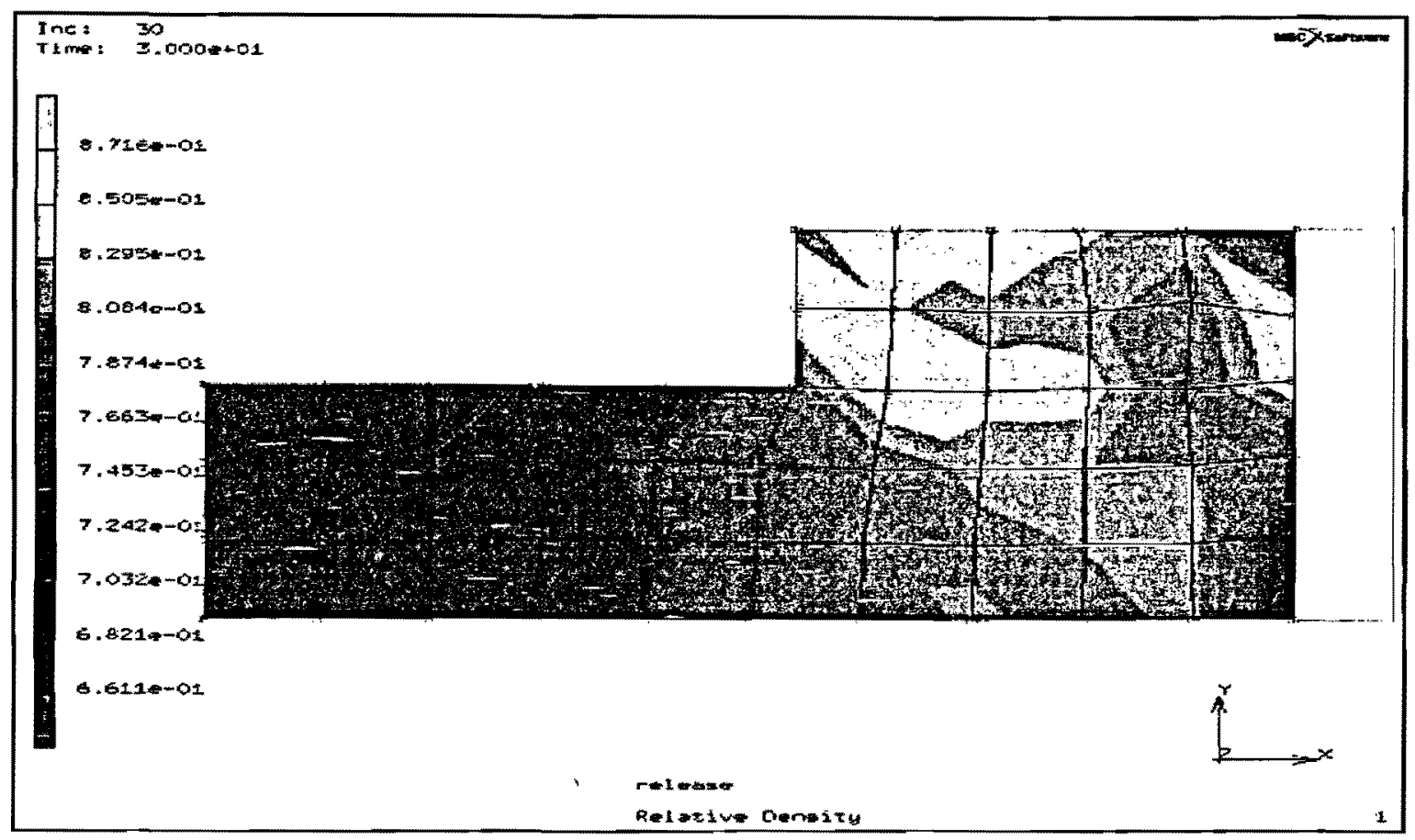

Figure 4.29: Relative Density Distribution of the Stepped Cylindrical Model 1(at increment 30) as shown in Figure 4.26 with Friction on the Die-walls and also at Powder-Punch interface.

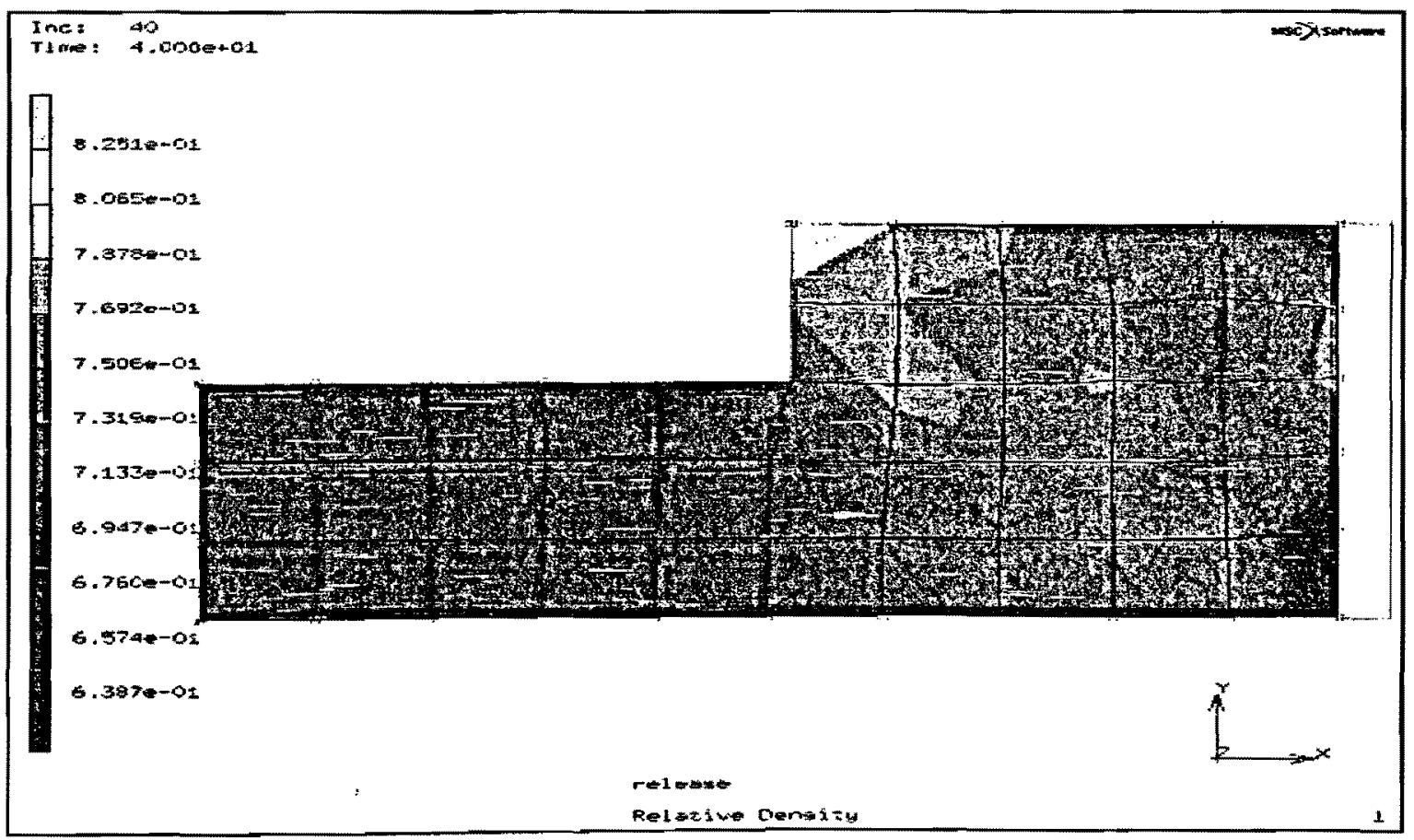

Figure 4.30: Relative Density Distribution of the Stepped Cylindrical Model 1(at increment 40 ) as shown in Figure 4.26 with Friction on the Die-walls and also at Powder-Punch interface. 
The timing information for this simulation is given in Table 4.7:

Table 4.7: Timing Information for Stepped Cylindrical Model 1

\begin{tabular}{|l|l|l|}
\hline Timing Information & Wall Time (in minutes) & CPU Time (in minutes) \\
\hline Total time for input & 0.05 & 0.05 \\
\hline Total time for stiffness assembly & 0.31 & 0.21 \\
\hline Total time for stress recovery & 0.17 & 0.12 \\
\hline Total time for matrix solution & 0.07 & 0.12 \\
\hline Total time for contact & 0.05 & 0.04 \\
\hline Total time for output & 1.52 & 0.12 \\
\hline Total time for miscellaneous & 0.96 & 0.14 \\
\hline Total time & 3.13 & 0.80 \\
\hline
\end{tabular}

2. CASE 8: This is the same model as the previous one; only except the friction here is ignored between powder \& the die-walls \& the moving surface and the number of elements has been increased to 160 . Refer Figure 4.31 to 4.33. Even in the absence of friction, the resulting density distribution is not uniform due to the complex geometry of the die.

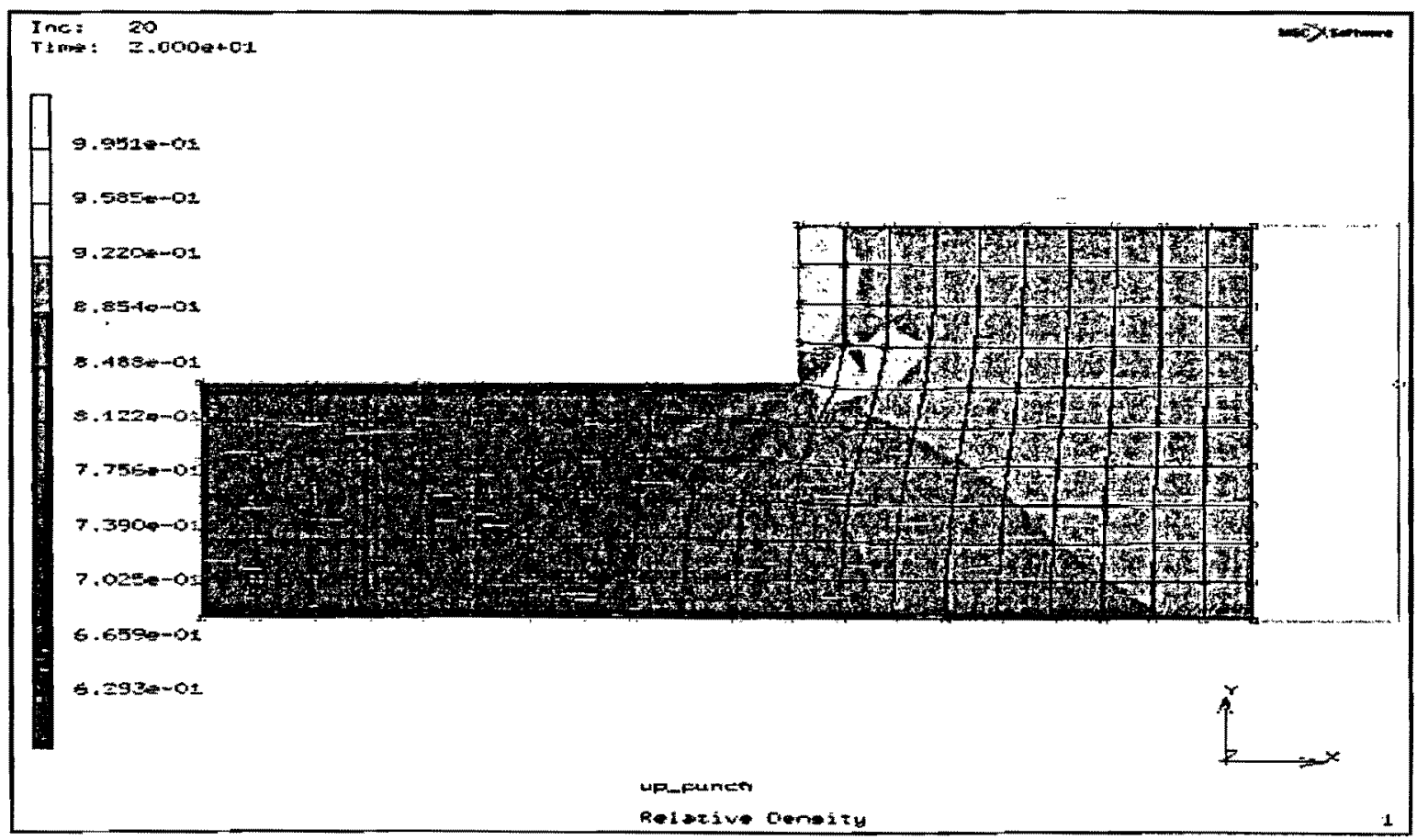

Figure 4.31: Stepped Cylindrical Model 2- Relative Density Distribution of the Stepped Cylindrical Model 1 (increment 20) as shown in Figure 4.26 without Friction anywhere. 
The timing information for this simulation is given in Table 4.8:

Table 4.8: Timing Information for Stepped Cylindrical Model 2

\begin{tabular}{|l|l|l|}
\hline Timing Information & Wall Time (in minutes) & CPU Time (in minutes) \\
\hline Total time for input & 0.08 & 0.06 \\
\hline Total time for stiffness assembly & 0.61 & 0.55 \\
\hline Total time for stress recovery & 0.30 & 0.31 \\
\hline Total time for matrix solution & 0.18 & 0.15 \\
\hline Total time for contact & 0.03 & 0.01 \\
\hline Total time for output & 2.48 & 0.39 \\
\hline Total time for miscellaneous & 0.75 & 0.23 \\
\hline Total time & 4.42 & 1.70 \\
\hline
\end{tabular}

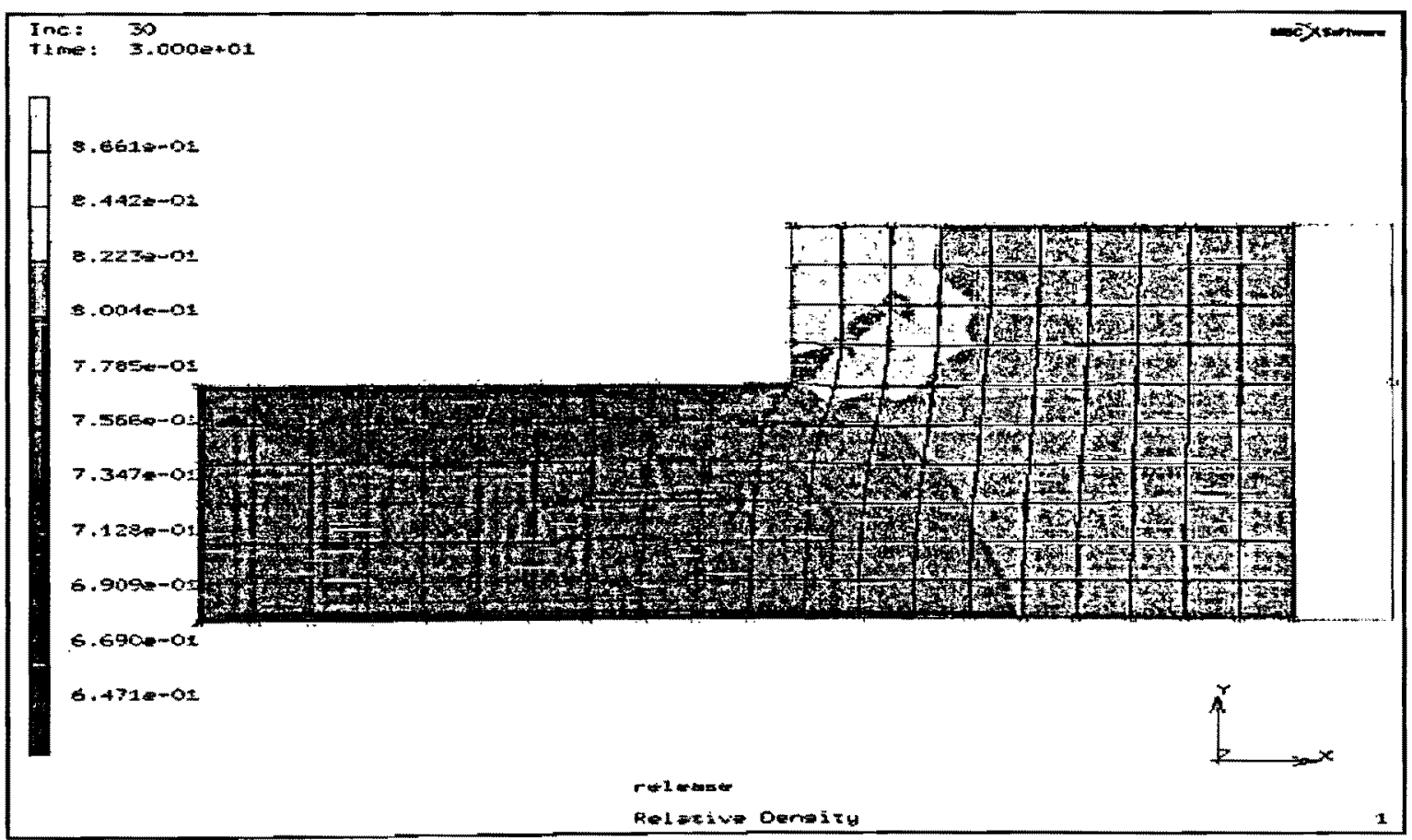

Figure 4.32: Relative Density Distribution of the Stepped Cylindrical Model 2 (at increment 30 ) as shown in Figure 4.31 without Friction anywhere. 


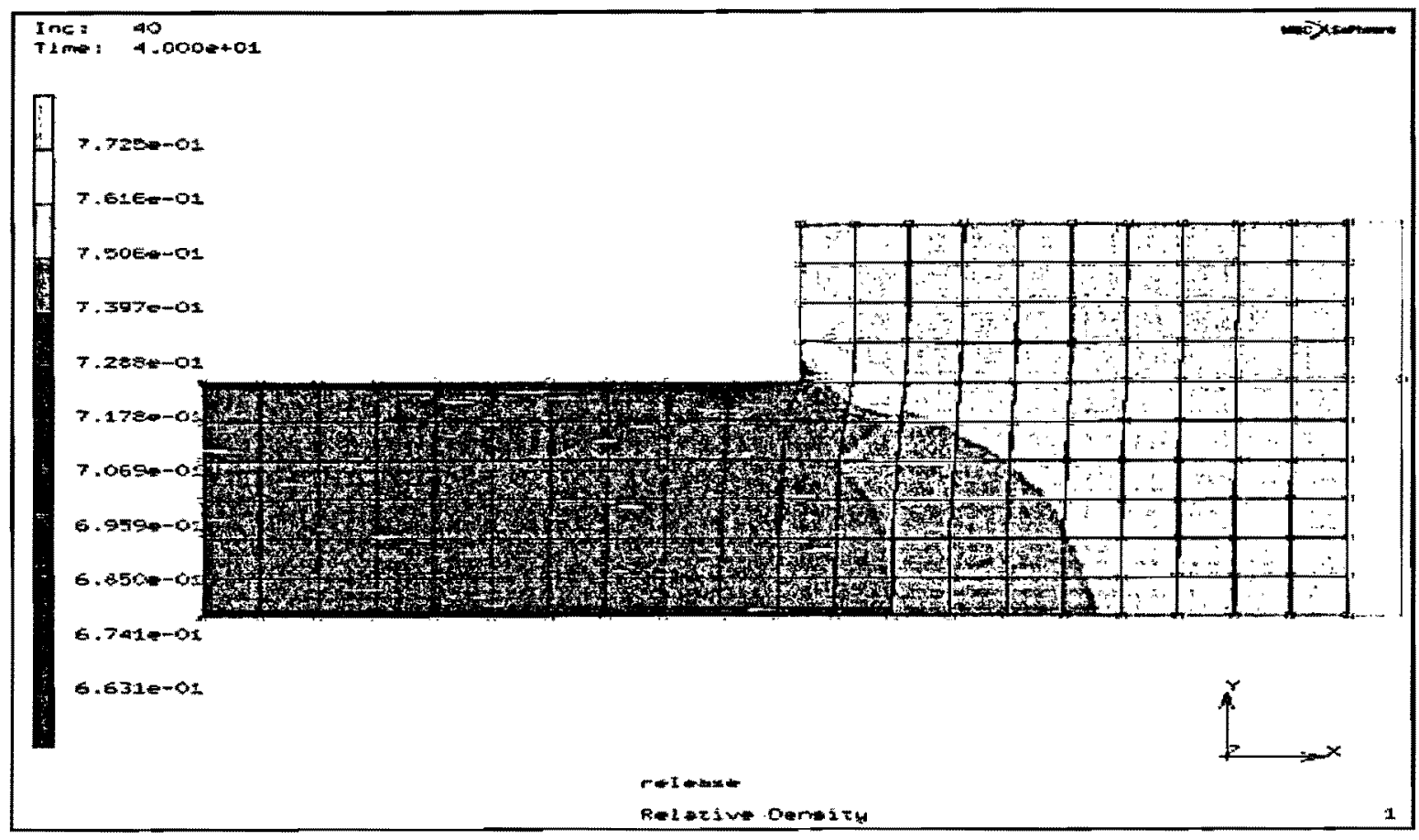

Figure 4.33: Relative Density Distribution of the Stepped Cylindrical Model 2 (at increment 40) as shown in Figure 4.31 without Friction anywhere.

3. CASE 9: The results using a double-punch are shown in Figures 4.34 to 4.38 . Here the powder compact is pressed using a double-punch by an incremental displacement of $1.2 \mathrm{~mm}$ in the both direction in 20 seconds and then released to $0.44 \mathrm{~mm}$ in another 20 seconds. The advantages of using a double-punch for complex compact geometries become apparent when one compares Figures 4.28 and 4.36 . The density variation using the double-punch is from 0.819 to .998 whereas for the single-punch the density variation is from 0.695 to 0.991 . These results also agree with observations made in practice.

The timing information for this simulation is given in Table 4.9:

Table 4.9: Timing Information for Stepped Cylindrical Model 3

\begin{tabular}{|l|l|l|}
\hline Timing Information & Wall Time (in minutes) & CPU Time (in minutes) \\
\hline Total time for input & 0.07 & 0.04 \\
\hline Total time for stiffness assembly & 0.32 & 0.20 \\
\hline Total time for stress recovery & 0.18 & 0.16 \\
\hline Total time for matrix solution & 0.06 & 0.08 \\
\hline Total time for contact & 0.03 & 0.02 \\
\hline Total time for output & 1.47 & 0.14 \\
\hline Total time for miscellaneous & 1.01 & 0.22 \\
\hline Total time & 3.13 & 0.87 \\
\hline
\end{tabular}




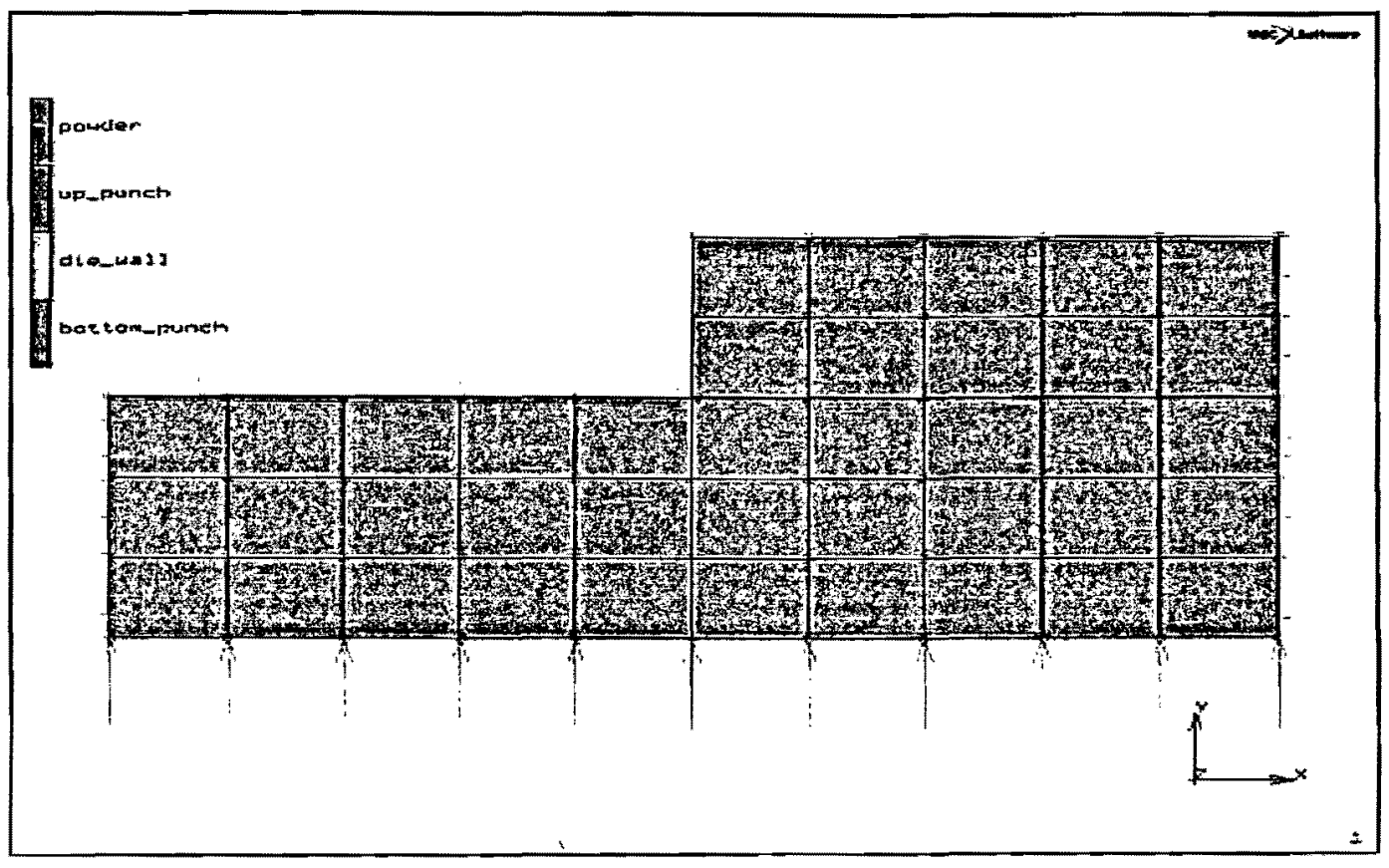

Figure 4.34: Stepped Cylindrical Model 3- Incremental Displacement of $1.2 \mathrm{~mm}$ applied in both directions with a Double-Punch in 20 seconds and then released to $0.44 \mathrm{~mm}$ in another 20 seconds.

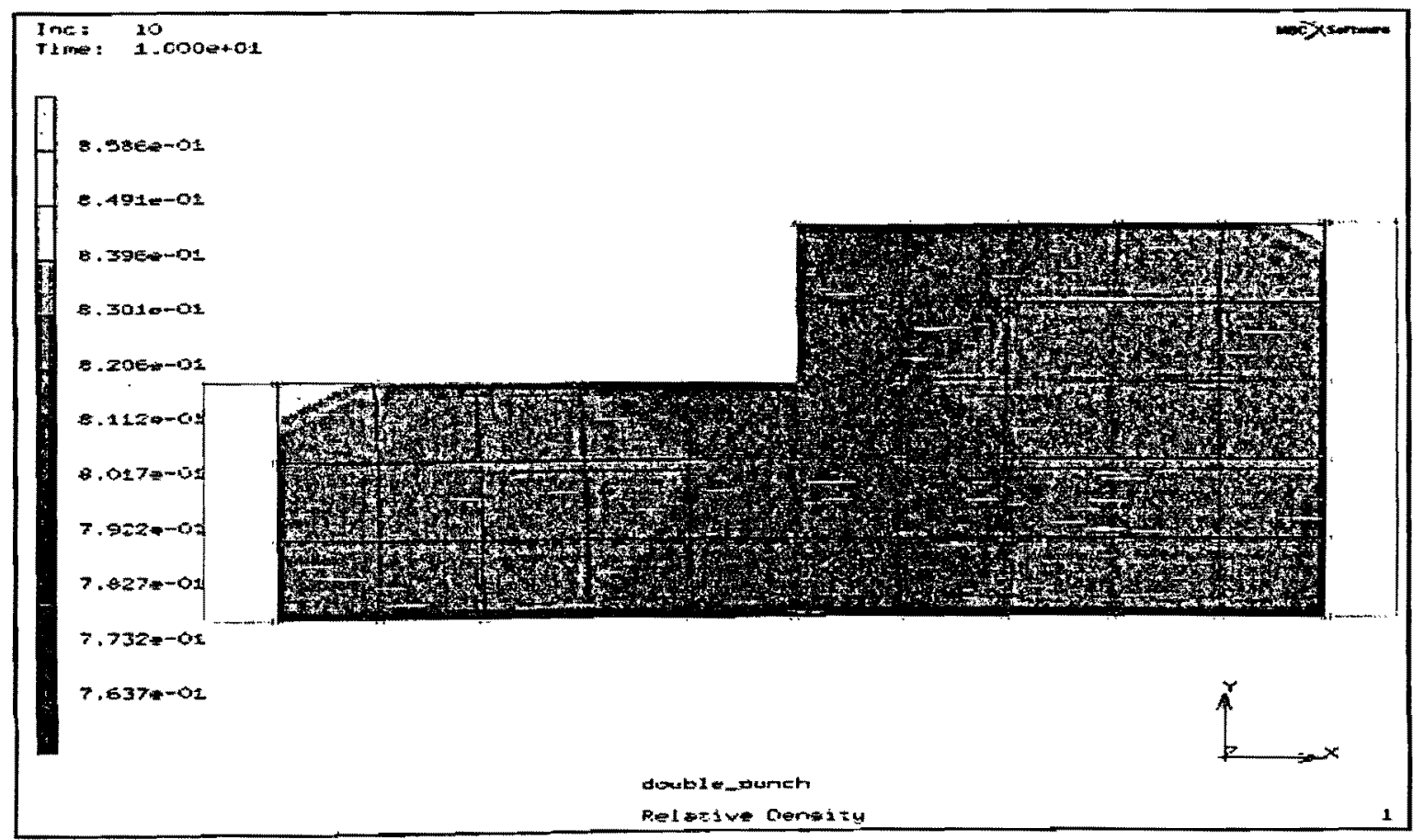

Figure 4.35: Relative Density Distribution of the Stepped Cylindrical Model 3 (at increment 10) as shown in Figure 4.34 with Friction on the Die-walls and also at Powder-Punch interface. 


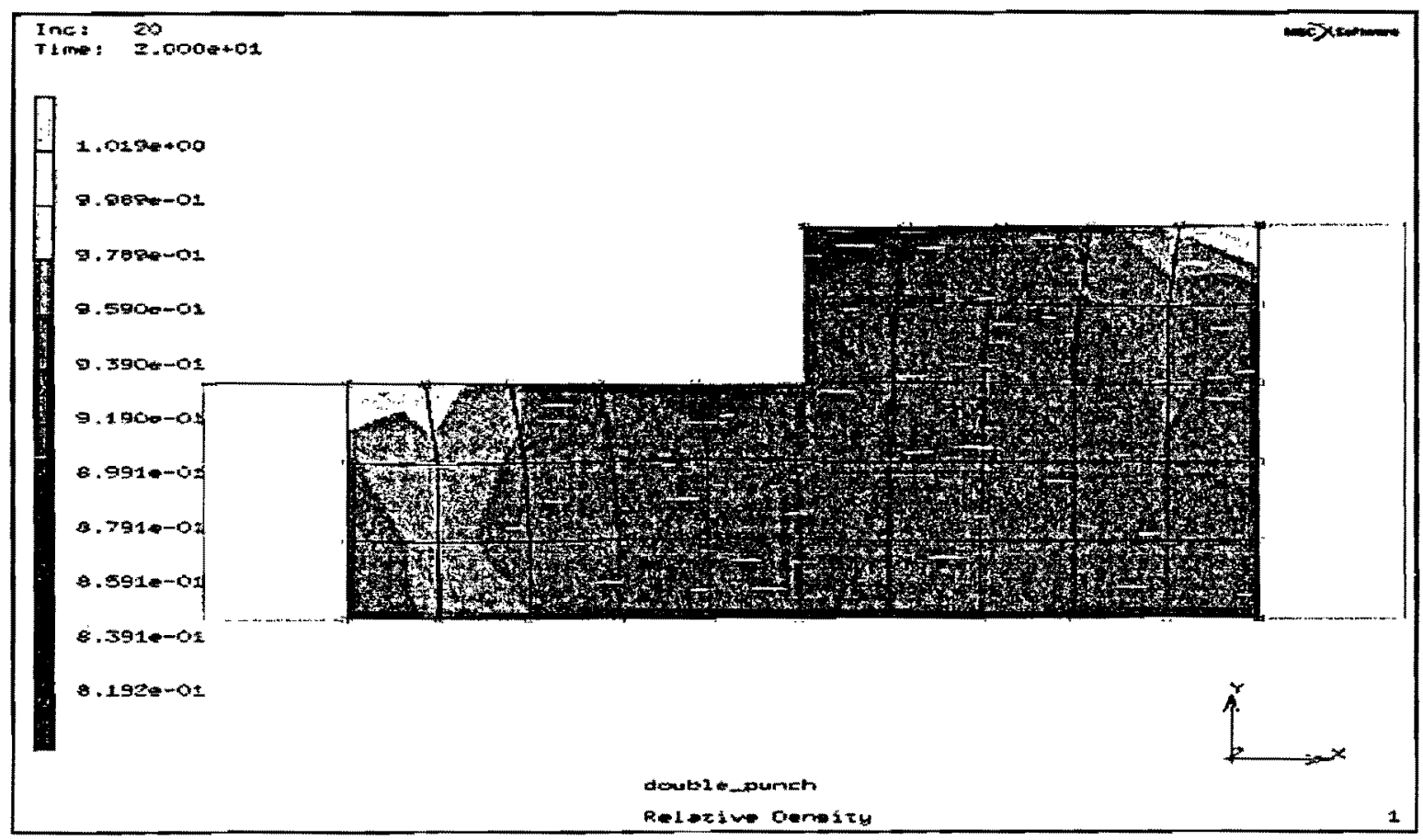

Figure 4.36: Relative Density Distribution of the Stepped Cylindrical Model 3 (at increment 20 ) as shown in Figure 4.34 with Friction on the Die-walls and also at Powder-Punch interface.

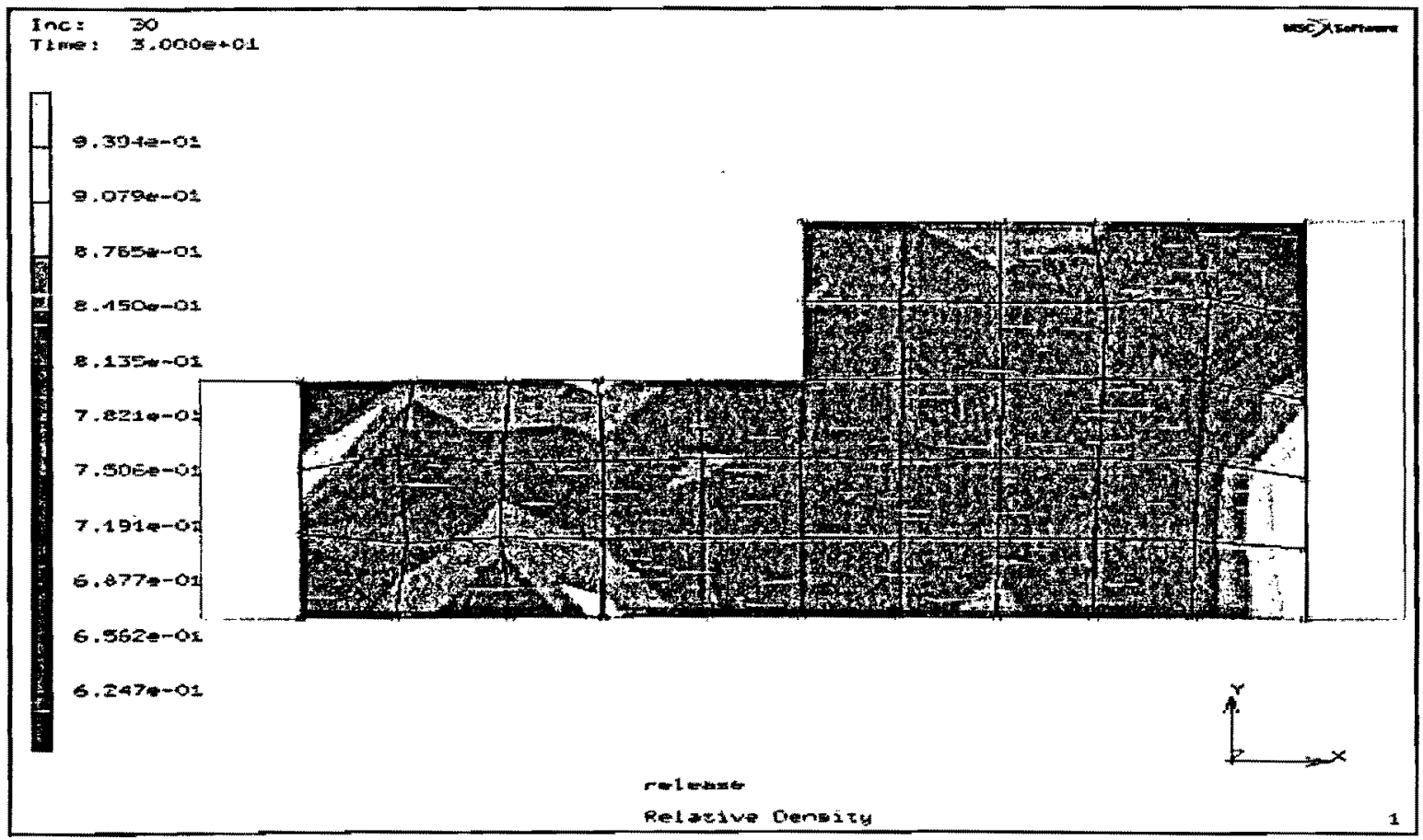

Figure 4.37: Relative Density Distribution of the Stepped Cylindrical Model 3 (at increment 30 ) as shown in Figure 4.34 with Friction on the Die-walls and also at Powder-Punch interface. 


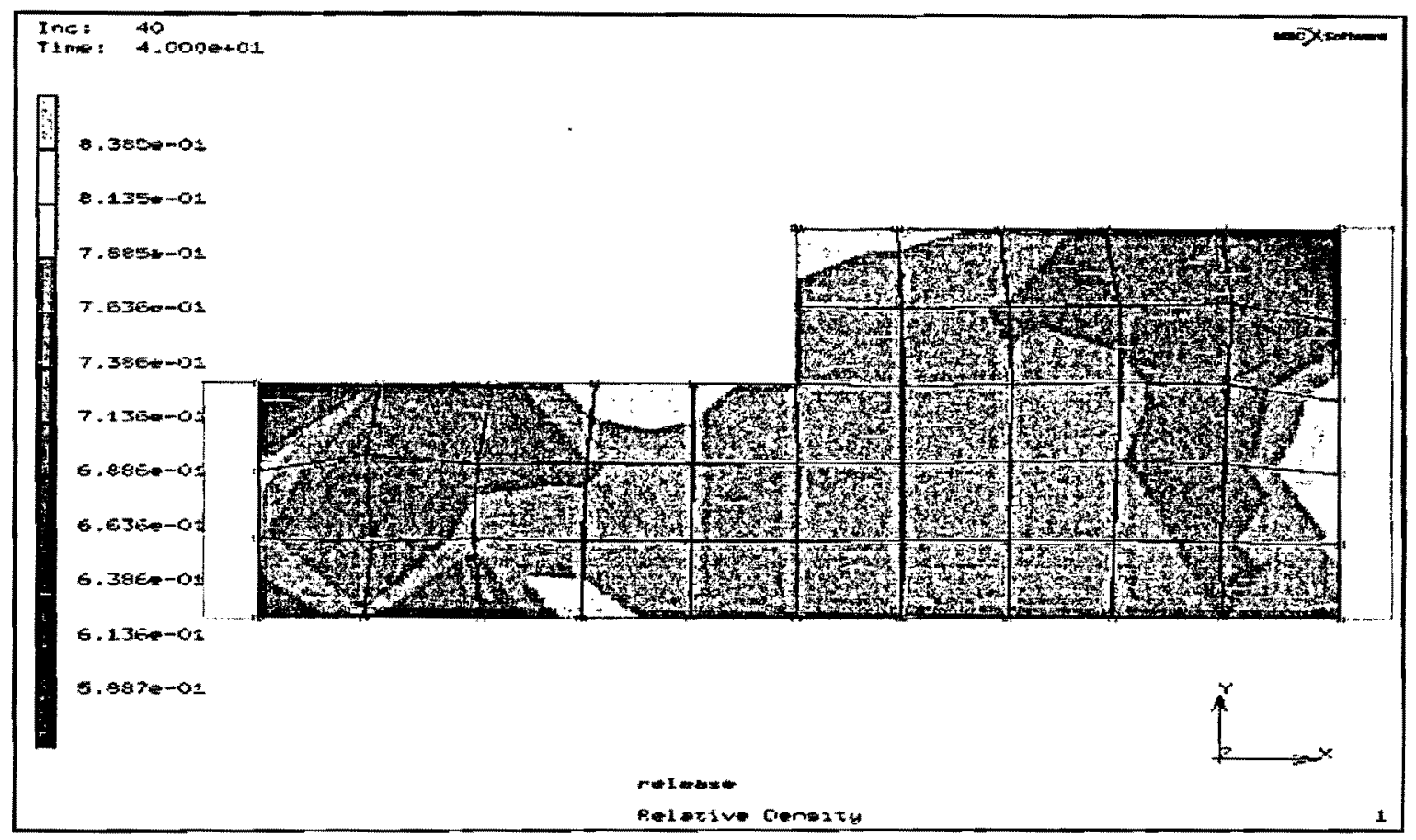

Figure 4.38: Relative Density Distribution of the Stepped Cylindrical Model 3 (at increment 40 ) as shown in Figure 4.34 with Friction on the Die-walls and also at Powder-Punch interface.

\subsection{Comparison of Results}

1. The comparison between the pressure model and the displacement model of the cylindrical green compact is under consideration (refer Figure 4.14 and Figure 4.23). Both models have the same geometry and friction is also considered between the powder and die-walls, but the loading is different. The first one is compacted with a pressure of $8000 \mathrm{~N} / \mathrm{mm}^{2}$ in 4400 seconds and the second one is pressed with incremental displacement load of $2.4 \mathrm{~mm}$ in 20 seconds using a single-punch. The relative density distribution along the height at $3 \mathrm{~mm}$ radius for both models is shown in Figure 4.39. The variation is almost similar, but the displacement model shows higher density distribution than the pressure model. This means calibration of the punch motion can result a powder compact with a more reliable green strength. 


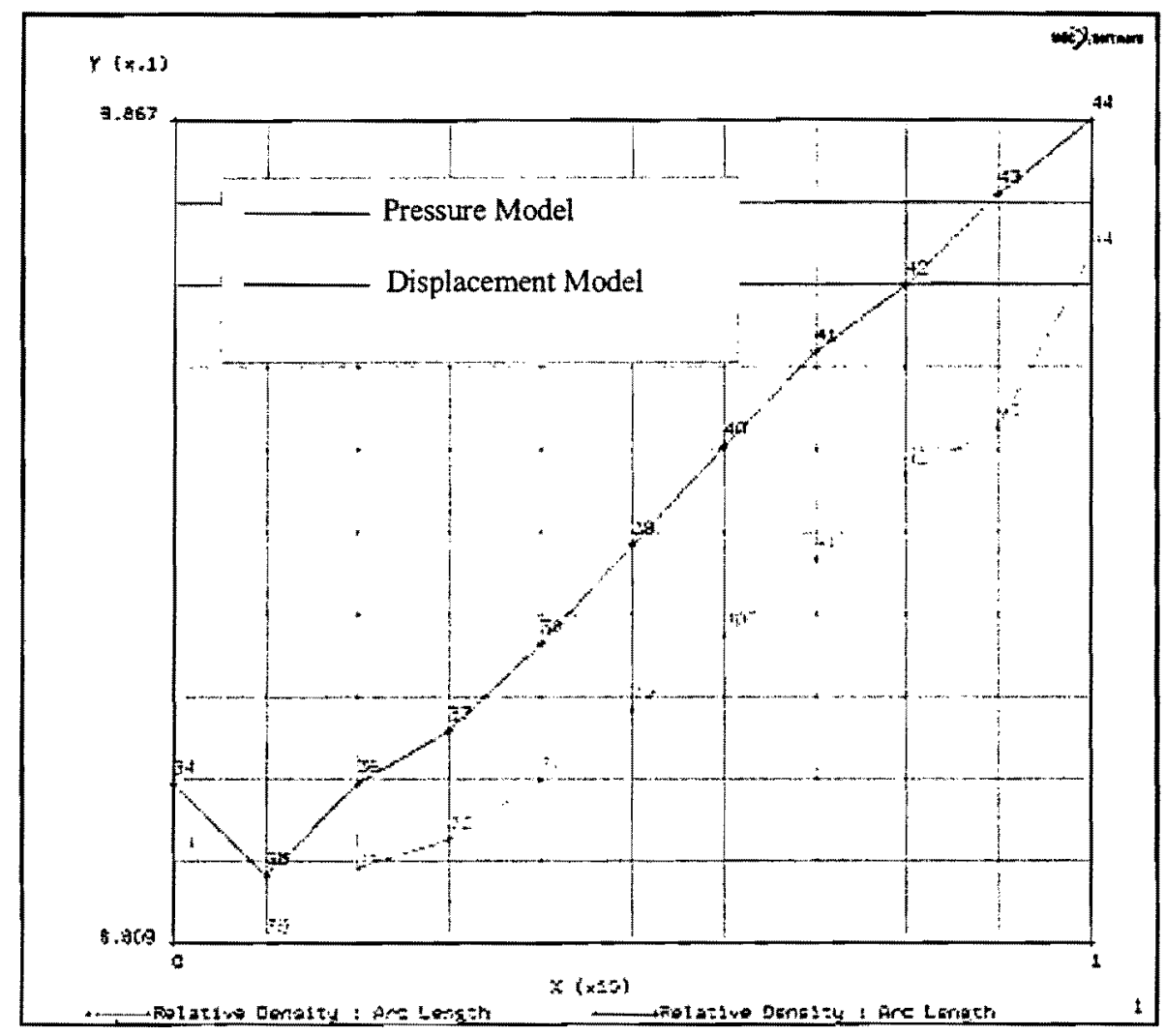

Figure 4.39: Comparison of Relative Density Distribution of the pressure model and the displacement model.

2. The comparison of powder compaction of the stepped cylindrical model using a single-punch and a double-punch is being considered here (refer Figure 4.28 and Figure 4.36). The advantage of using a double-punch becomes apparent when one compares the relative density distribution of the green compact along the height at a radius of $2 \mathrm{~mm}$ which is shown in Figure 4.40. The relative density varies from 0.9021 to 0.9714 (the overall variation is 0.0693 ) in the case of double-punch configuration whereas the relative density varies from 0.7406 to 0.9021 (the overall variation is 0.1615 ) in the case of single-punch configuration. So it can be concluded that doubleended pressing can result stronger and uniform compact. 


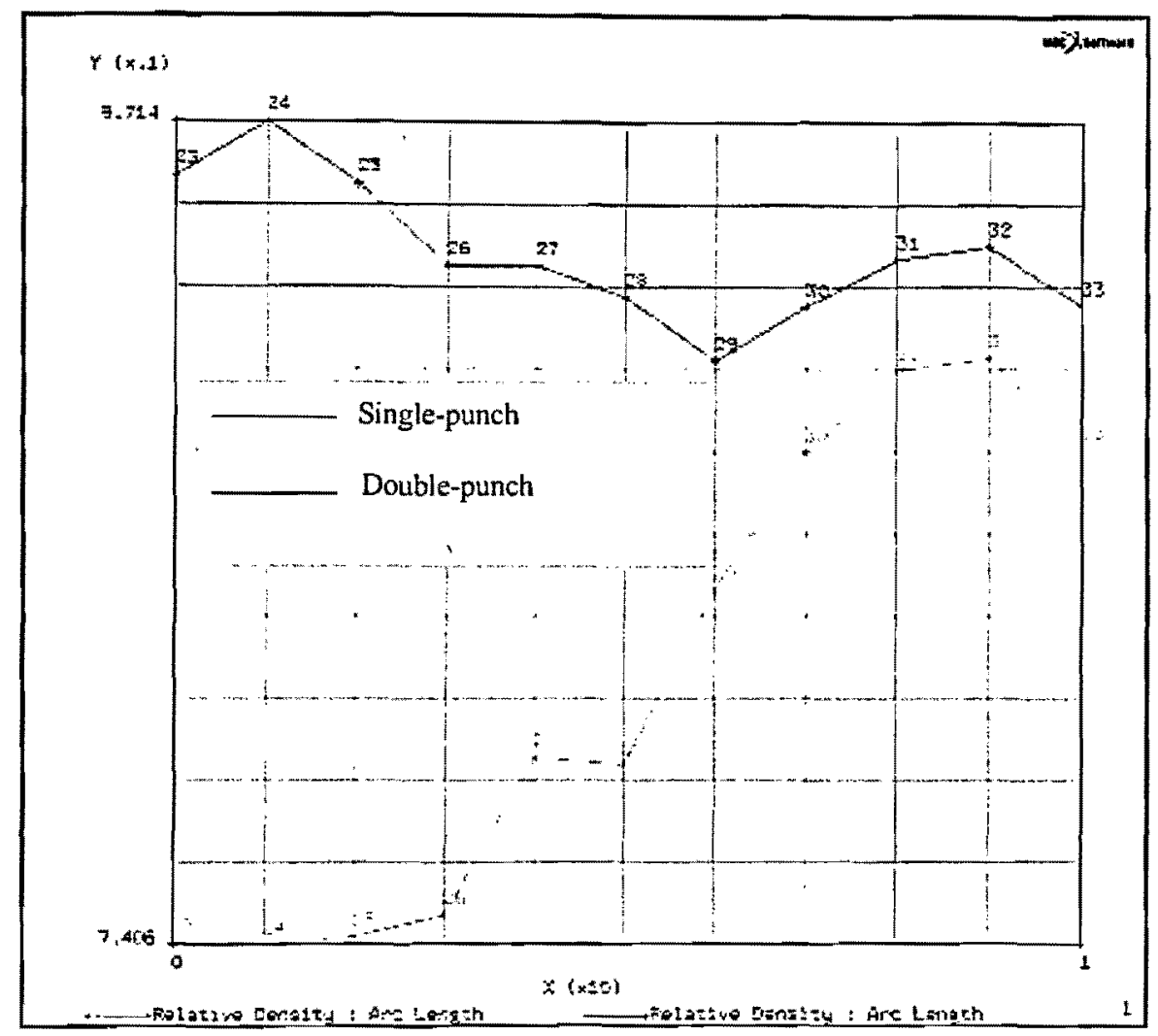

Figure 4.40: Comparison of Relative Density Distribution of the stepped cylindrical model using a single-punch and a double-punch.

After an extensive review of the FE simulation results of cold compaction process, it can be concluded that the results agree well with observations made in practice. It indicates that the material model and the non-linear FE procedure in MSC_Marc hold promise in determining the relative density distribution and punch-die loads. 


\section{Chapter 5}

\section{Conclusions}

\subsection{Conclusions}

The generation of a defect-free green compact is a fundamental requirement for the production of a quality, high strength finished part. Usually the powder compaction in a die does not yield a homogeneous density distribution in the pressed part and this may result in cracks or localized deformation. However, the success of the powder compaction process (PCP) is largely dependent on the proper selection of the process parameters such as die shape, upper and lower punch displacements, sequential tool motions etc.

FE simulation of PCP is carried out with a view to generate a crack-free green compact. Firstly, the pressure models are considered. The cylindrical green is compacted by applying different pressure load considering free boundary without friction, then with added die-walls without friction and finally added die-walls with friction. It is noted that the powder expands laterally and the variation in relative density distribution is minimal in the case of die-free models. With added die-walls, but no friction considered; the compaction results in a uniform density distribution. Then the effect of friction between powder and the die-wall becomes apparent (Figure 4.13 to 4.16 ), the moving surface does not remain straight while loading, which does not correspond to the actual physics, and the relative density distribution is no longer uniform while loading and unloading. This problem was overcome by considering displacement models.

Secondly, the displacement models are considered. The cylindrical green with added die-walls is compacted by applying incremental displacement load using a single-punch considering friction between the powder \& the die-walls and also at the powder-punch interface. The relative density variation is reasonable here, but the elements and the nodal points near the moving surface deforms significantly. Whereas with the same model without friction at the powder-punch interface, the relative density distribution is almost similar, but the deformation of the elements and nodal points near the moving surface is insignificant. In the case of 
displacement models, the moving surface also remains straight. The aforementioned simulation results (Figure 4.18 to Figure 4.25 ) show that the relative density is minimum in the corner furthest away from the center-line and the moving surface and maximum in the corner closest to the die-wall and moving surface. These results agree well with observations made in practice.

Finally, to test the capabilities of MSC_Marc program, a more complex geometry of a cylindrical compact with a step is considered. The stepped cylindrical green is compacted by applying incremental displacement load using a single-punch by considering friction on all contacting surfaces in one case and no friction in the other case. In both cases, the relative density distribution (Figure 4.27 to Figure 4.33 ) is not uniform due to the complex geometry. The advantage of using a double-punch for complex green compact becomes apparent in Figures 4.34 to 4.38 . The density variation using a double-punch is less than that of using a single-punch and the overall distribution is more acceptable.

In this research, the application of FE simulation of the powder compaction process for the cylindrical green has shown to be successful and provides results that agree well with observations made in practice. It indicates that the material model and the non-linear FE procedure in MSC_Marc hold promise in determining the relative density distribution and punch-die loads.

\subsection{Future Work}

This project has a lot to advance in the future. The material model parameters i.e. $\gamma$ and $\beta$ can be obtained experimentally, which will enhance the FE simulation of the powder compaction process (PCP) and result in more accurate relative density distribution in the green compact. 3D solid modeling (limited license in MSC_Marc) can also be simulated to have a better picture of the green compact whether any crack propagation is due or not.

Use of lubricants improves the pressure transmission by reducing the frictional effects [5]. Many workers have shown that the application of lubricant to the die walls is effective in improving the green density. Despite some disadvantages in the addition of lubricant to the 
powder, it is standard commercial practice to mix lubricants with the powder. Apart from improving density distribution, the correct choice of type and quantity of lubricant improves die-life and also decrease the load required to attain a specific density, so that the overall pressure requirements are lowered. Thus, the FE simulation would be more effective if proper use of lubricant is considered.

Contact between a deformable-body and a rigid body is insured such that the nodes do not penetrate the rigid surface. It is possible that an edge of an element penetrates a rigid surface, especially where high curvature is present because of the finite element discretization. The use of the adaptive mesh generation procedure can be used to reduce these problems [37]. When a node comes into contact, the elements associated with that node are refined. This results in a greater number of elements and nodes on the exterior region where contact occurs. This can lead to a substantial improvement in the accuracy of the solution. Simulation of the stepped cylindrical compact can be improved further by the use of adaptive meshing at the sharp corner. 


\section{References}

[1] European Powder Metallurgy Association EPMA internet, www.epma.com 2005.

[2] Riedel, H., Kraft, T., Simulation in Powder Technology, Continuum Scale Simulation of Engineering Materials, 2004 Wiley-VCH Verlag GmbH \& Co. KgaA.

[3] Brewin, Peter R. (Editor). Modeling of Powder Die Compaction, London, GBR: Springer London, 2007, Copyright (C) 2007.

[4] Stylianou, M.C., Belanger, L., Tabarrok, B., Cold Closed-Die Powder Compaction, Mechanical Engineering, University of Victoria, Victoria, B.C., March, 1995.

[5] Sands, R.L., Shakespeare, C.R., Powder Metallurgy, Practice and Applications, 1966.

[6] Li, S., Khosrovabadi, P.B., Kolster, B.H., New Compaction equation for Powder Materials, The International Journal of Powder Metallurgy, Vol. 30, No. 1, pp 47-57 (1994).

[7] German, R.M., Particle Packing Characteristics, Metal Powder Industries Federation, Princeton, New Jersey (1989).

[8] German, R.M., A Review of Numerical and Computational Techniques in Powder Metallurgy, Proceedings: Advances in Powder Metallurgy and Particulate Materials, Vol. 3, pp 1-18 (1993).

[9] German, R.M., Powder Metallurgy Science, $2^{\text {nd }}$ Edition, Metal Powder Industries Federation, Princeton, New Jersey (1994).

[10] Cocks, A.C.F., Gethin, D.T., Häggblad; H.- $\AA .$, Kraft, T., and Coube, O., Compaction Models, Chapter 4, pp 43-64, Brewin, Peter R. (Editor). Modeling of Powder Die Compaction, London, GBR: Springer London, 2007, Copyright (C 2007.

[11] Drucker, D.C., Prager, W., Soils Mechanics and Plastic Analysis of Limit Design, Quaterly Appl Math, Vol. 10, pp 157-164 (1952).

[12] DiMaggio, F.L., Sandler, I.S., Material Model for Granular Soils; J Eng Mech Div 97, pp 935-950 (1971).

[13] Coube, O., Riedel, H., Numerical Simulation of Metal Powder Die Compaction with Special Consideration of Cracking; Powder Metallurgy, Vol. 43, pp 123-131 (2000).

[14] Coube, O., Riedel, H., Modeling of Metal Powder Behavior under Low and High Pressure, Advances in Powder Metallurgy \& Particulate (2002), Part 9, Amhold V, Chu C-L, 
Jandeska WF, Jr. and Sanderow HI (eds). Metal Powder Industries Federation, Princeton, NJ, pp 199-208.

[15] Riedel, H., Kraft, T., Simulations in Powder Technology, Continuum Scale Simulation of Engineering Materials: Fundamentals - Microstructures - Process Applications, eds D Raabe, F Roters, F Barlat, LQ Chen, Wiley-VCH, Berlin, pp 641- 658 (2004).

[16] PM Modnet Computer Modeling Group, Comparison of computer models representing powder compaction process, Powder Metallurgy, Vol. 42, pp 301-311 (1999).

[17] Schofield, A., Wroth, C.P., Critical State Soil Mechanics, McGraw-Hill, London (1968).

[18] Roscoe, K.H., Burland, J.B., On the generalized stress-strain behavior of "wet" clay; Eng Plast, pp 535-609 (1968).

[19] Krieg, R.D., A Simple Constitutive Description of Cellular Concrete, Sandia National Laboratories, Albuquerque, N.M., Rept. SC-DR-72-08843 (1972).

[20] Hehenberger, M., Samuelson, P., Alm, O., Nilson, L., Olofsson, T., Experimental and Theoretical Studies of Powder Compaction, In proc. IUTAM Conference on Deformation and Failure of Granular Materials, Delft (Eds. P.A. Vermeer, H.J. Luger), pp 381-390, A.A. Balkema, Rotterdam, (1982).

[21] Shima S., Oyane M., Plasticity Theory for Porous Metals, Mechanical Science, Vol 18, pp 285-291 (1976).

[22] Zhao, K, Finite Element Analysis in Hot Isostatic Pressing Applications, Proceedings: Advances in Powder Metallurgy and Particulate Materials (1992).

[23] Shima, S., Constitutive Equation of Compressible Materials and its Application to Simulation of Powder Forming Processes (1992).

[24] Shima, S., Kortera, H., Constitutive equations for Granular Materials Undergoing Compaction with Internal Friction, Proceedings: Advances in Powder Metallurgy and Particulate Materials, Vol. 7, pp 71-82 (1994).

[25] Abouaf, M., Chenot, J.L., Finite Element Simulation of Hot Isostatic Pressing of Metal Powders, International Journal for Numerical Method in Engineering, Vol. 25, pp 191-212 (1988).

[26] Gethin, D.T., Tran, V.D., Lewis, R.W., Ariffin, A.K, An Investigation of Powder Compaction Processes, The International Journal of Powder Metallurgy, Vol. 30, No. 4, pp 385-398 (1994). 
[27] Jinka, A.G., Lewis, R.W., Gethin, D.T., Finite Element Simulation of Powder Compaction via the Flow Formulation, Proceedings: Advances in Powder Metallurgy and Particulate Materials, Vol. 1, pp 123-144 (1991).

[28] Gethin, D.T., Lewis, R.W., Tran, D.V., Jinka, A.G.K., Finite Element Simulation of Metal Powder Die Compaction, ibid, reference no. 17, pp 11.

[29] Green, R.J., A Plasticity Theory for Porous Solids, International Journal of Mech. Sci., Vol. 14, pp 215-224 (1972).

[30] Bandstra, J.P., Otto, W.L., Massa, T.R., Finite Element Simulation of Cold Die Compaction Leading to Sintered Part Dimension Control.

[31] Krauss, T.M., Petrus, G.J., Ferguson, B.L., Die Compaction Process Design Part 1: Knowledge Based Design, Proceedings: Advances in Powder Metallurgy and Particulate Materials, Vol. 1, pp 101-110 (1991).

[32] Trasorras, J., Krauss, T.M., Ferguson, B.L., Modeling of Powder Compaction using the Finite Element Method, Proceedings: Advances in Powder Metallurgy and Particulate Materials, Vol. 1, pp 85-104 (1989).

[33] Armstrong, S., Godby, V., Rachakonda, B.S., Cheng, S., McCabe, T.J., Finite Element Modeling of Cold Powder Compaction, Proceedings: Advances in Powder Metallurgy and Particulate Materials, Vol. 3, pp 165-173 (1993).

[34] Shima, S., Saleh, M.A.E., Development of Constitutive Equations for Granular Materials with Induced Anisotropy during Compaction Processes, Advances in Micromechanics of Granular Materials, Elsevier Science Publishers B.V. (1992).

[35] Nakagawa, T., Sato, M., Simulation of Powder Densification in Die Compaction Process, Proceedings: Advances in Powder Metallurgy and Particulate Materials, Vol. 2, pp 43-57 (1992).

[36] WANG De-guang, WU Yu-cheng, JIAO Ming-hua, XIE Ting, YU Jian-wei, Research of Favorable Conversion of Friction during Powder Compaction, Materials Science Forum, Vols. 575-578 (2008), pp 443-448.

[37] Marc 2008 R1, Vol. A, Theory and User Information, MSC.Software Corporation. [38] PM Design Manual, 1998, MPIF.

[39] MSC_Marc User's Guide, Version 2003, MSC.Software Corporation.

[40] MSC.Marc 2001, Volume E, Demonstration Problems, Part II, Chapter 3.25 pp 1-7. 